\title{
ENHANCING THE INFORMATION AVAILABILITY OF INDONESIA'S TOURISM DESTINATIONS THROUGH A TRAVEL APP
}

Yuwanti Rili Respatyanti

\begin{abstract}
A thesis
submitted to the Victoria University of Wellington in fulfilment of the requirements for the degree of

Master of Innovation and Commercialisation
\end{abstract}

Victoria University of Wellington

2019 


\section{Abstract}

Despite of Indonesia has many packages on offer to tourists, including cultural, culinary and natural attractions, UNWTO's (2018) research revealed that Indonesia is in the 9th position in terms of the number of international tourist arrivals compared to other Asia countries in 2017. Hence, the main objective of this project is to respond the lack of information availability of Indonesia's tourism destinations worldwide (Cholik, 2017; Petriana, 2017; Wijaya, 2017) by proposing a travel app called Extra. The utilization of an ICT tool has been preferred as it proved to be effective to support the dissemination of tourism products, services, and information (Buhalis \& Law, 2008; Hyde, 2008, Caraivan, 2017). In particular, Extra aims to give tourists a local experience while visiting Indonesia, as well as to boost more exposure of Indonesia's tourism destinations in the global market by providing tourism information, products and services derived from trusted locals.

Through using a mixed method research design, feedback from tourism stakeholders, tourists and the online questionnaire's respondents are collected and analyzed. Main findings that were emerged from this study suggested desired features of potential users to use Extra, which are local recommendations of local tours and activities, online/offline route planning, self-designed itinerary, and ratings/reviews from other travelers. From the tourism service providers' perspectives, Extra will be advantageous if it can provide more approachable contact to their customers, accommodate the lack of skill, time or resource to update tourism information or social media regularly, and encourage more efficient business operation by providing a single platform to manage all of tourism products and services. Due to the short nature of this study, limitations on the amount of research conducted have constrained the ability to examine certain subjects, such as the type of preferred communication channel to enable effective and more amicable interaction between tourist and tourism service providers, as well as the significance of a customer service feature in a travel app to encourage a better traveling experience. Following the data collection and analysis, a business case projection was created to propose the development and commercialization of Extra. It includes the recommendation of the business model design, market and product validation evaluation, as well as resource requirements of Extra development project. 
Reflecting on the research findings and business case recommendations, taking into an acknowledgement of the necessary future research that will be discussed, the initiation step of developing Extra will be started by seeking potential project partners such as Ministry of Tourism and angel investors, as well as consulting with legal advisor to process the necessary business permits to commence a travel app business in Indonesia. Later on, in a case of successful implementation of Extra, the lean startup methodology (Ries, 2011) will be applied consistently to allow continued adjustments in order to improve the app's service. This includes conducting further research on aspects that need further validation.

Without the implementation of Extra, it is difficult to identify the actual value propositions that are needed by both tourists and tourism stakeholders to make them use Extra or purchase it. Therefore, future research is required after the implementation of Extra in order to identify to what extent the app's values could entice its users to pay more for the service, and what features will be likely to be altered to improve Extra's perceived values to its users. 


\section{Acknowledgements}

Firstly, I would firstly like to thank Allah for his many blessings and making all of this possible.

Then, I would like to acknowledge both of my programme directors, Jenny Douche and Matt Stevens, who have introduced me to the world of innovation and provided me with encouragement and advice throughout the programme.

I also would like to extend my thankfulness to my supervisor, Dr Ina Reichenberger who has been incredibly helpful with her continuous guidance and patience that has motivated me to produce a quality report.

I thankfully acknowledge the funding received towards my study from the New Zealand Aid scholarship and the staff from Victoria International, Stefanie Fischer, who has been very helpful to provide me support and assistance throughout my study.

To the participants of this study, thank you for your time, feedback and support. I would have been unable to finalize this thesis without you all.

My next utmost appreciation is for my parents. To my mum, for her unconditional love and her extra support when I needed it most. To my late dad, who inspired me to take the extra mile to pursue higher education and enrich my knowledge.

To my husband Budi, thanks for always being by my side and encourage me through this challenging year. And for my dearest Alan, thanks for being such a good boy and making it easier for me to complete my study.

A special appreciation also goes to the members of my advisory boards and fellow students who provided me with valuable insights and sincere feedback throughout the Master of Innovation and Commercialization programme. 


\section{Table of Contents}

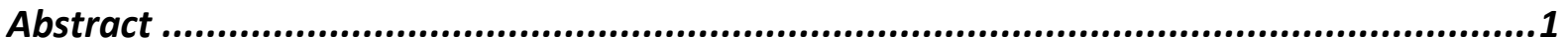

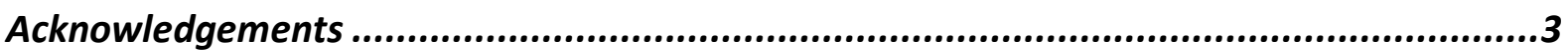

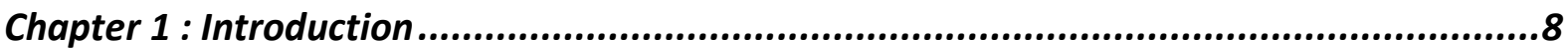

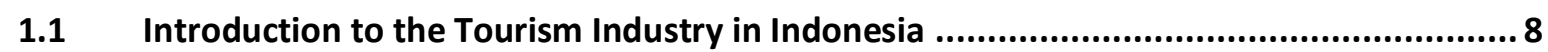

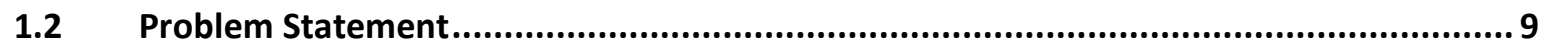

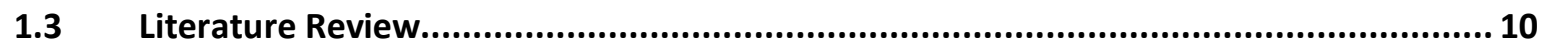

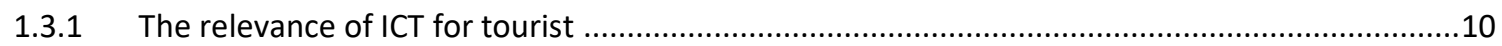

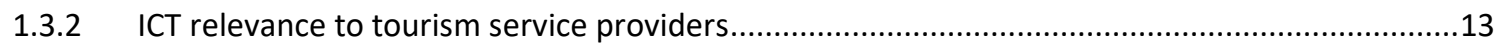

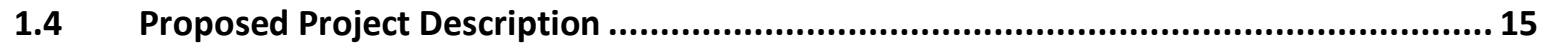

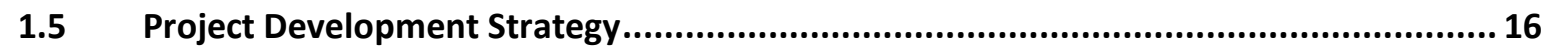

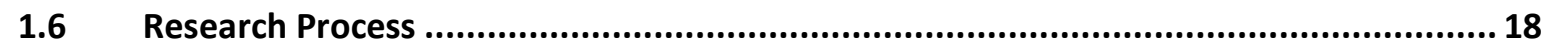

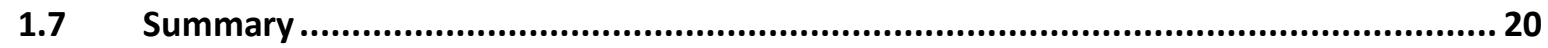

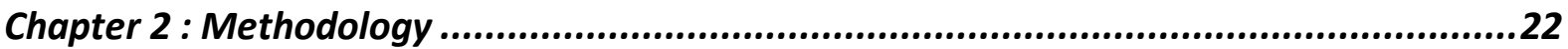

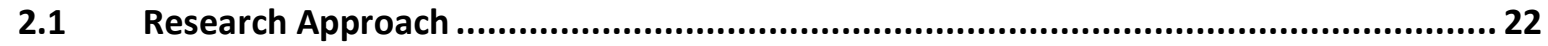

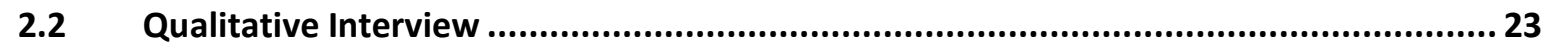

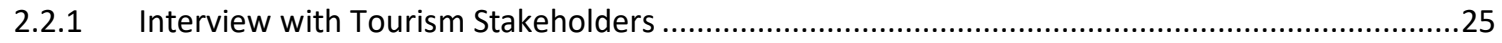

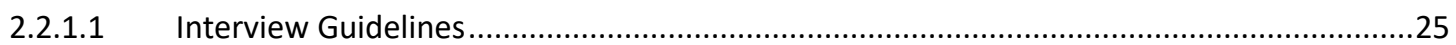

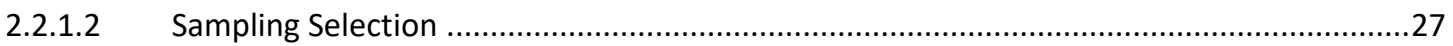

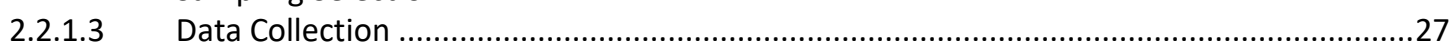

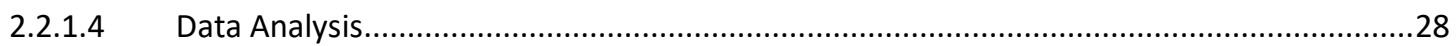

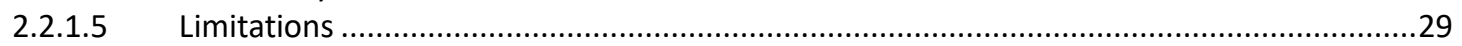

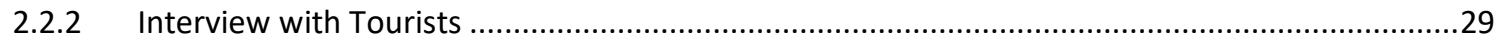

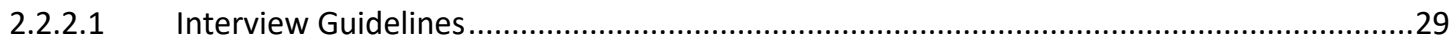

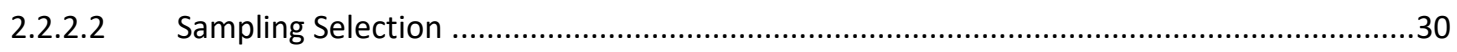

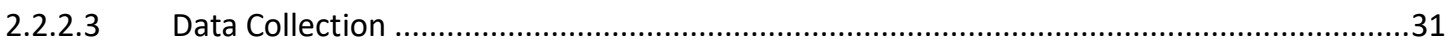

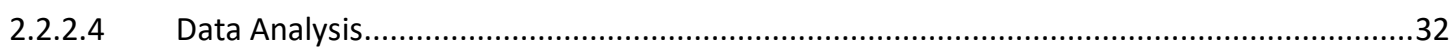

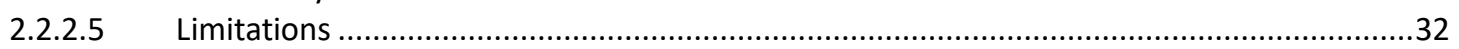

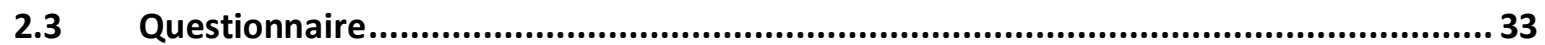

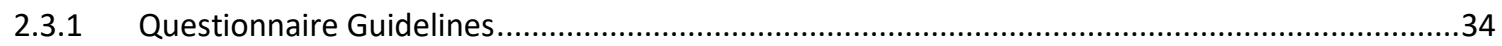

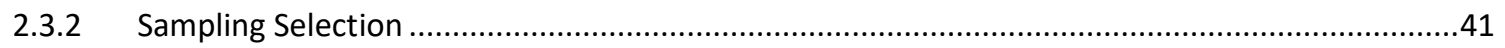

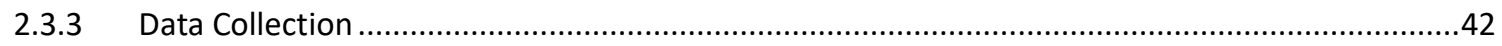

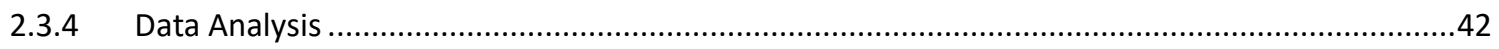

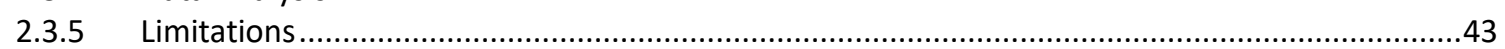

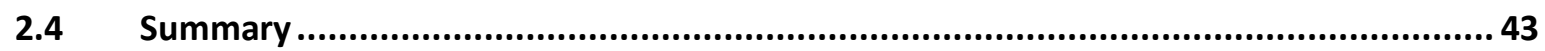

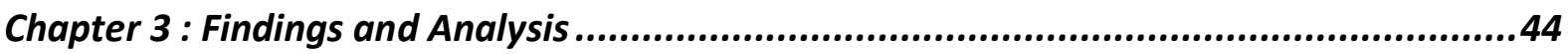

3.1 Findings and analysis - Interview with Tourism Stakeholders ....................................44

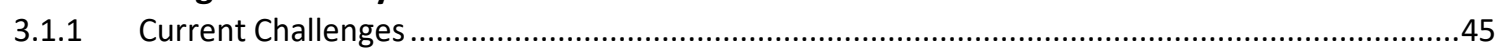

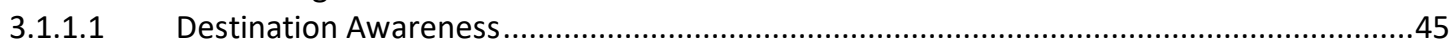

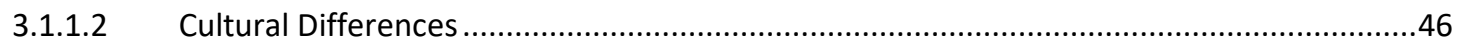

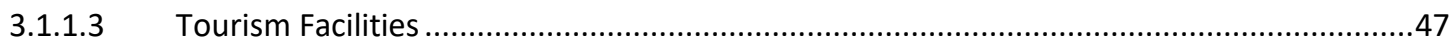

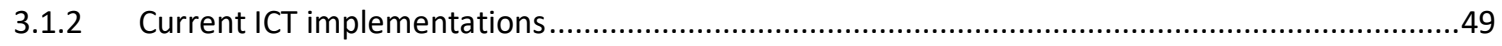

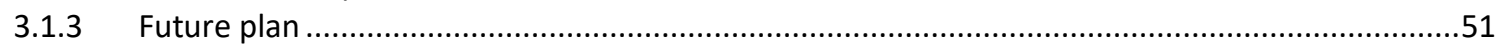

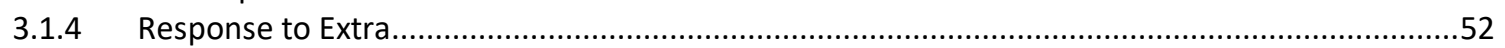

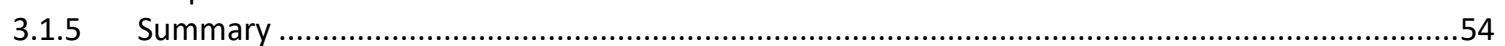




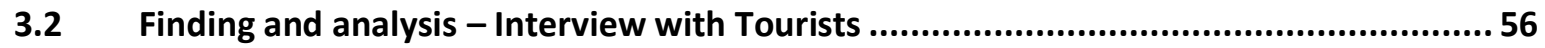

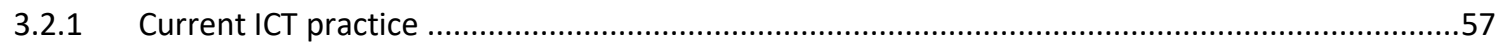

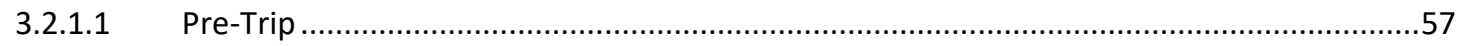

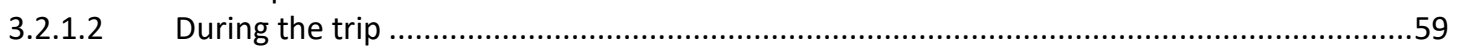

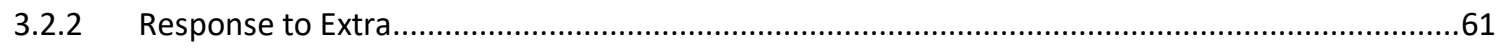

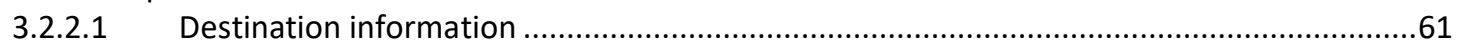

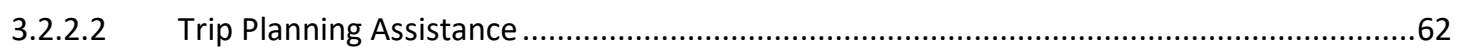

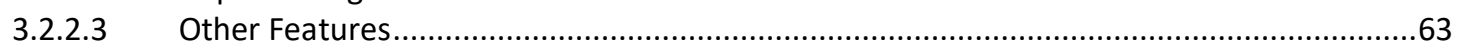

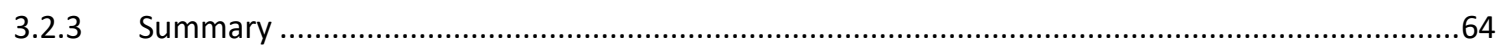

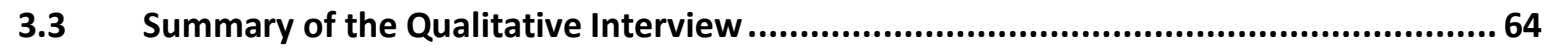

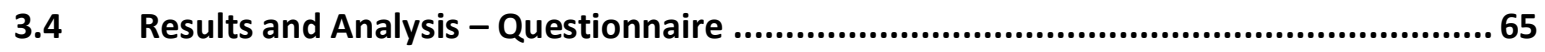

3.4.1 Demographic Information \& Travel Experience to Indonesia .....................................................67

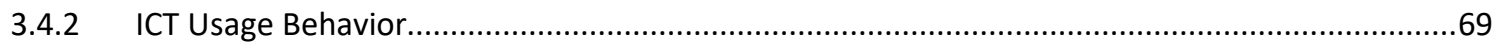

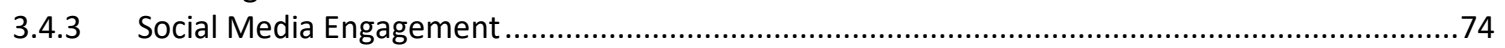

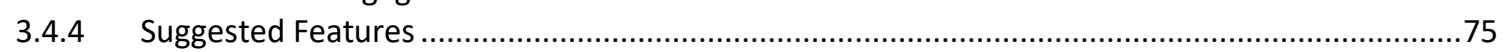

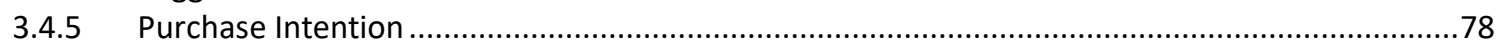

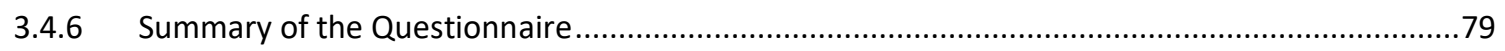

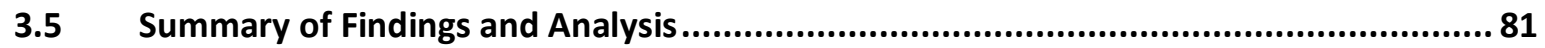

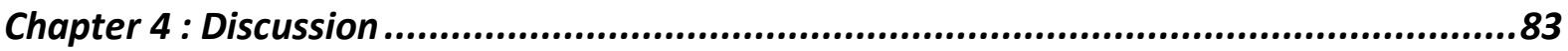

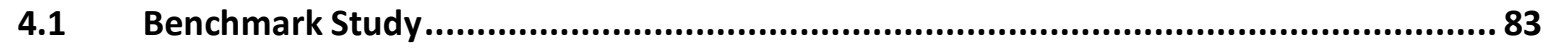

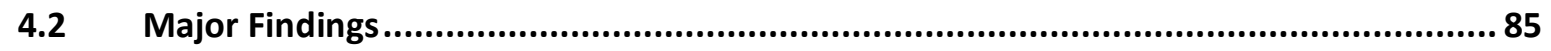

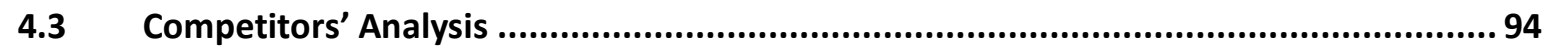

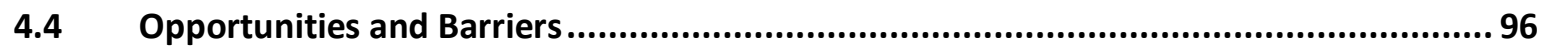

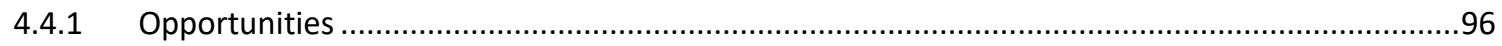

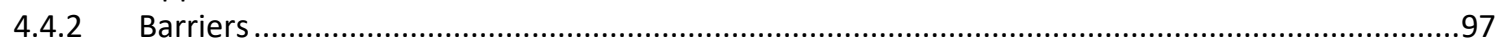

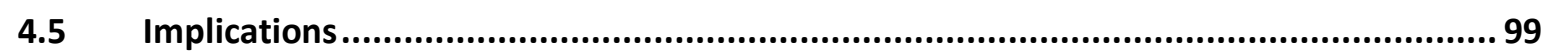

Chapter 5 : Recommendation (Business Case).................................................... 100

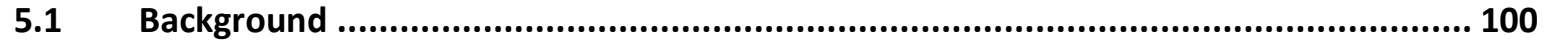

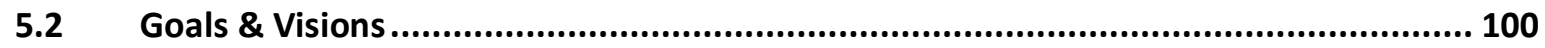

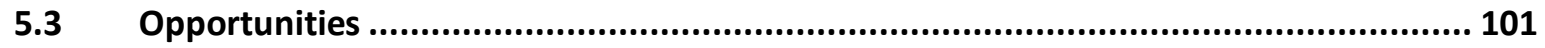

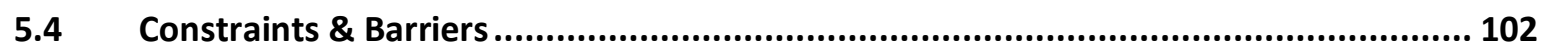

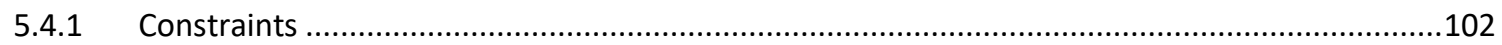

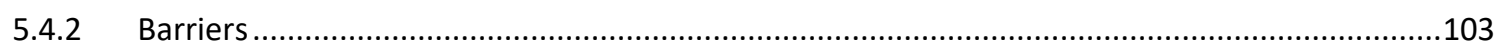

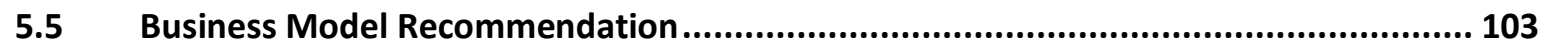

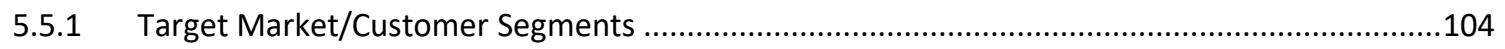

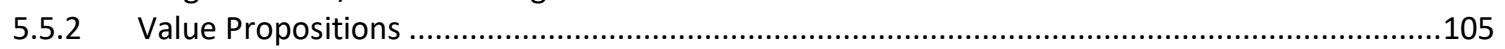

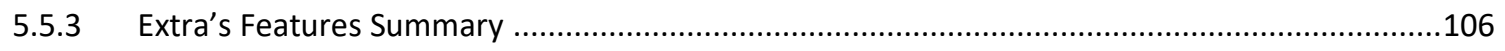

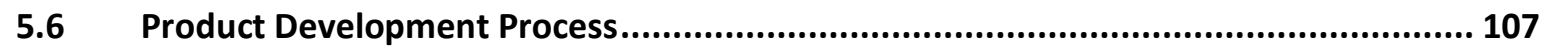

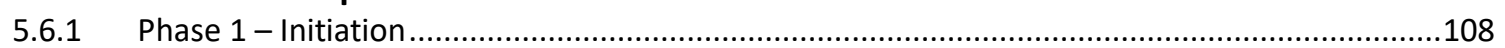

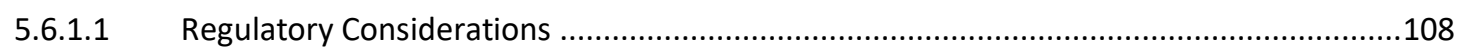

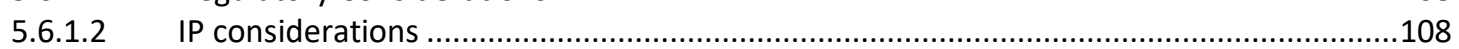

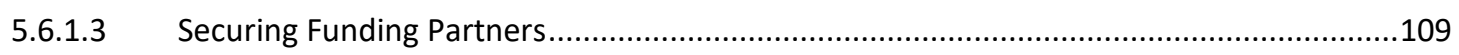

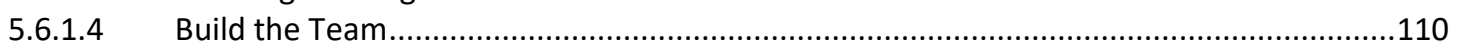

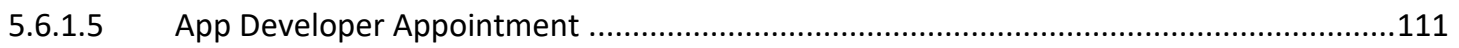

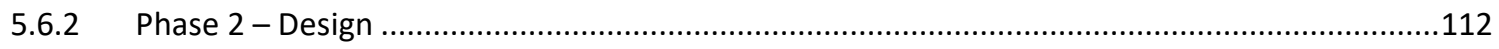

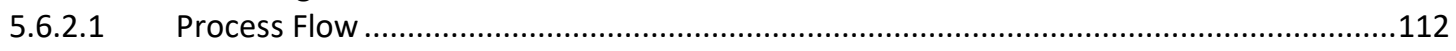

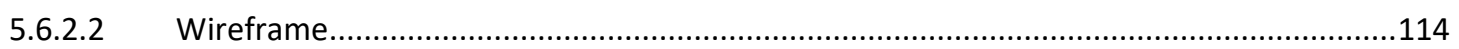




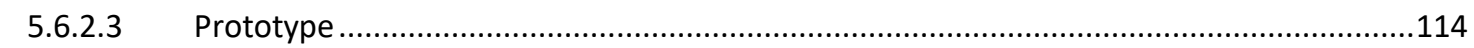

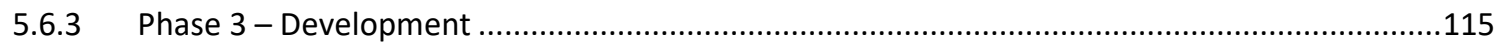

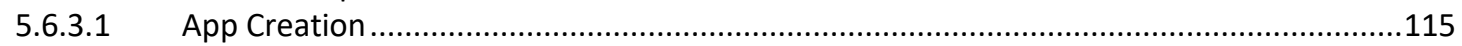

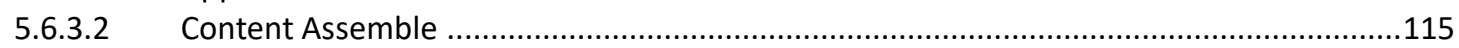

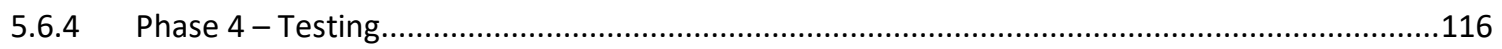

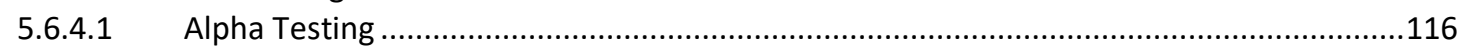

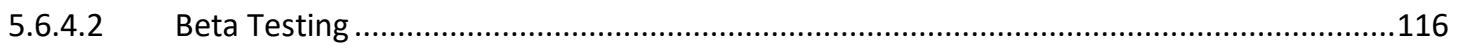

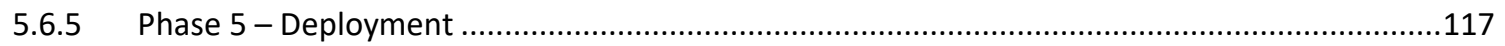

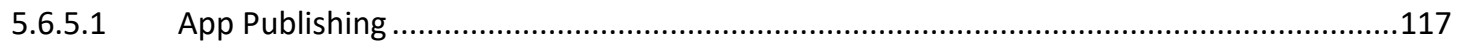

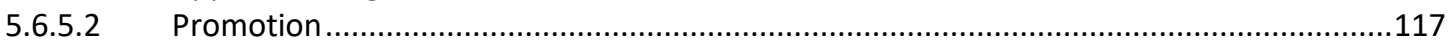

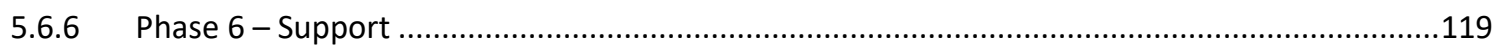

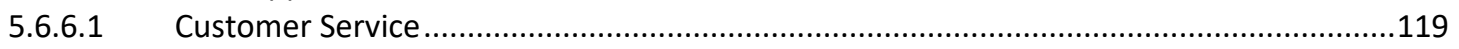

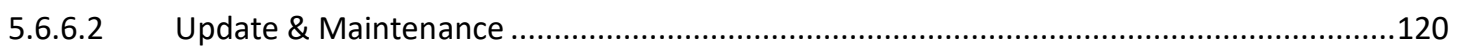

5.6.6.3 Partnership \& Content Update ............................................................................121

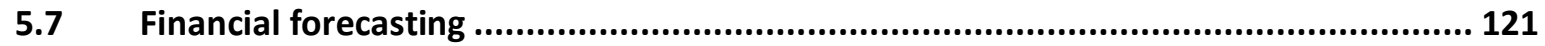

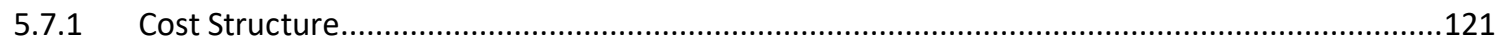

5.7.1.1 Technological Setup \& Running costs ...................................................................121

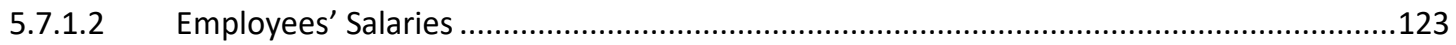

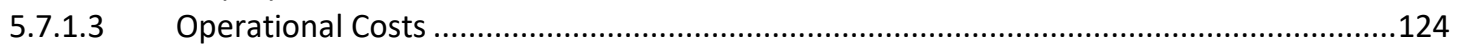

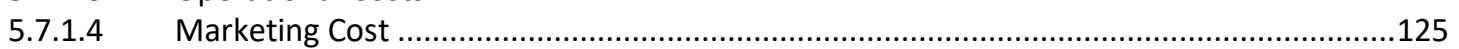

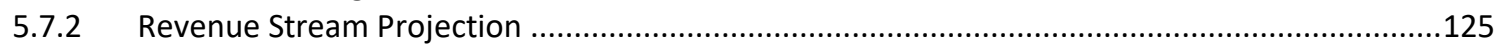

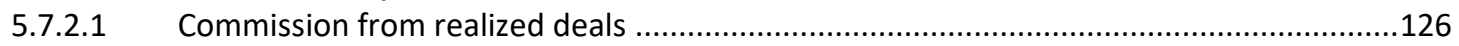

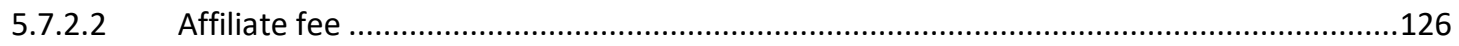

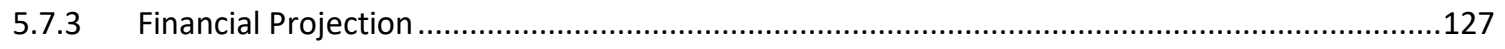

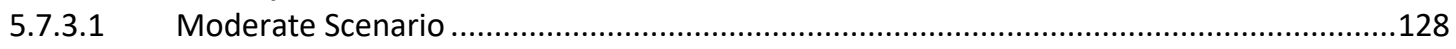

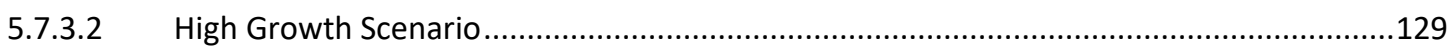

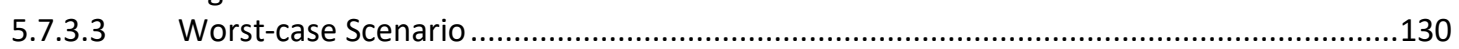

5.8 Timeline of All Activities........................................................................ 131

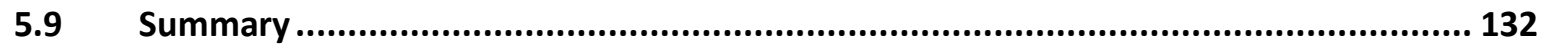

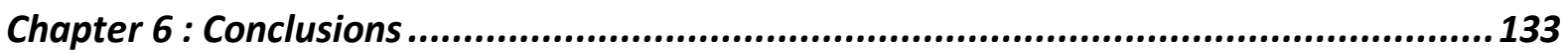

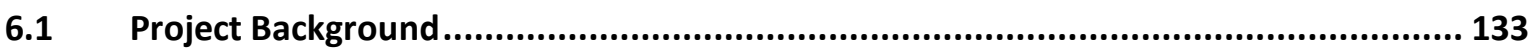

Key Outtakes and Implications ................................................................. 133

$6.3 \quad$ Limitations and Future Research ............................................................. 135

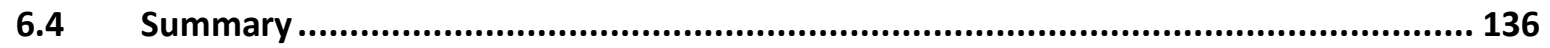

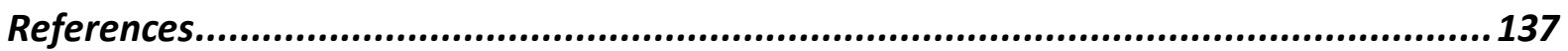

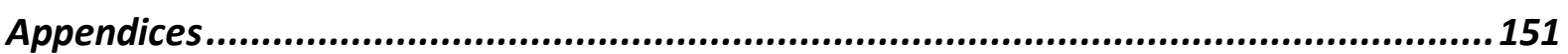

\section{List of Figures}

Figure 2.1 Exploratory Sequential Design (Watkins \& Gioia, 2015, p.33) .........................23

Figure 3.1 Table of Tourism Stakeholder Participants ...............................................44

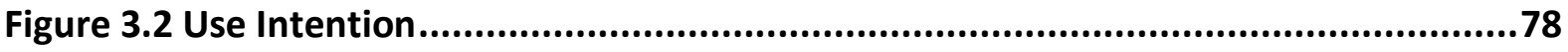

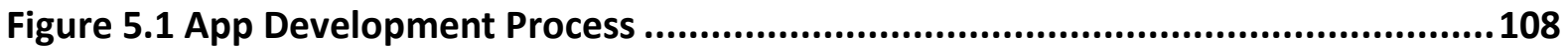

Figure 5.2 Process Flow of Extra .....................................................................113 


\section{List of Tables}

Table 1.1 Business Model Canvas of Extra ..............................................................17

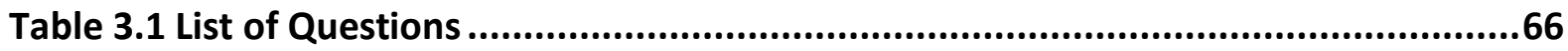

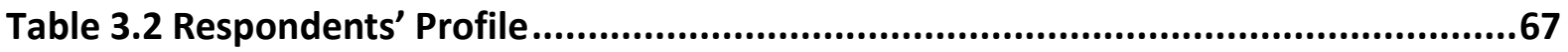

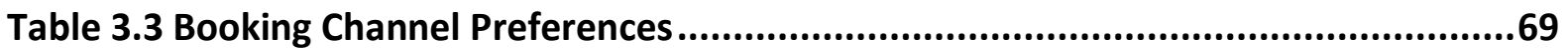

Table 3.4 Device Preferences ..............................................................................70

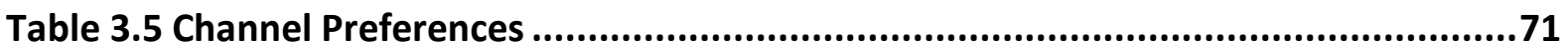

Table 3.6 Channel Preferences Based on Visit Frequencies .........................................72

Table 3.7 Channel Preference Level of Satisfaction ...................................................73

Table 3.8 Social Media Activities ...........................................................................74

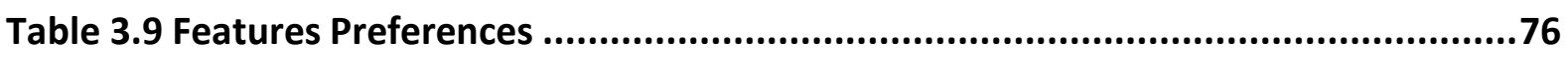

Table 3.10 Other Suggested Features ..........................................................................77

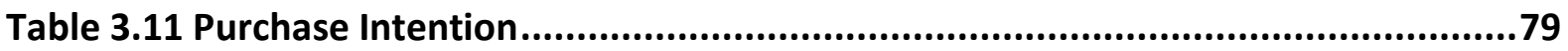

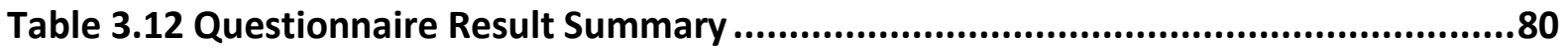

Table 3.13 Summary of Research Findings and Results ............................................82

Table 4.1 Initial Business Model Canvas of Extra.........................................................85

Table 4.2 Adjustment of the Business Model Canvas .................................................86

Table 5.1 Business Model Recommendation ...........................................................104

Table 5.2 Value Propositions and Validations ............................................................. 106

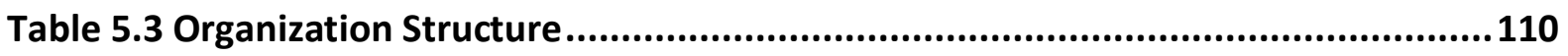

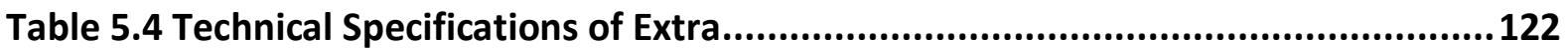

Table 5.5 Employee Salaries Estimation .................................................................... 123

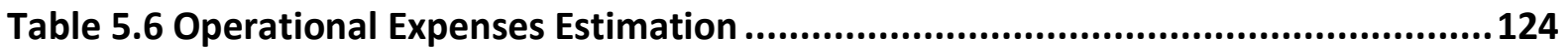

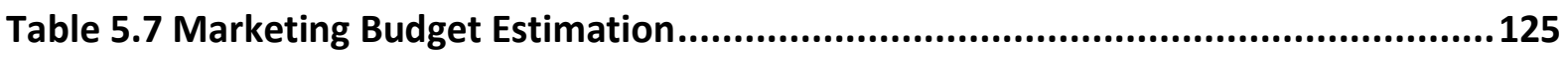

Table 5.8 Monthly Revenue Projection ............................................................... 127

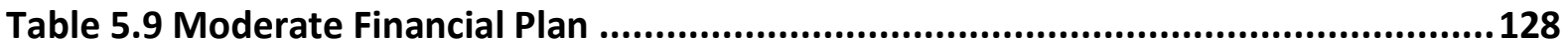

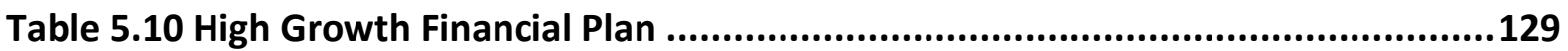

Table 5.11 Worst Case Financial Plan ................................................................ 130

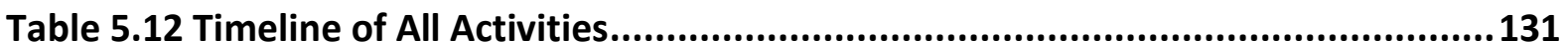




\section{Chapter 1 : Introduction}

\subsection{Introduction to the Tourism Industry in Indonesia}

The tourism industry is broadly recognized as a major factor for socio-economic development especially in developing countries (Sharpley \& Telfer, 2015). As for Indonesia, foreign exchange earnings from tourism totaled USD16.3 billion in 2016, rank Indonesia's tourism industry the twenty-second largest in the world according to the World Travel \& Tourism Council (Haan, 2018) and ranked 4th nationwide commodity after natural gas, coal, and oil palm (Indonesia Tourism Investment, 2018).

Indonesia's tourism attractions continue to grow with many packages on offer to tourists, including cultural, culinary and natural attractions. According to Wonderful Indonesia (2018), there are five highlights of cultural experience that can be explored in Indonesia: (1) natural, scenic landscape and wildlife; (2) culinary and wellness; (3) arts, culture and heritage; (4) recreation and leisure, and (5) adventure. Four cultural sites and four natural sites have been included in the UNESCO's world heritage sites, such as popular destinations like Borobudur Temple, Komodo National Park, and Ujung Kulon National Park. Furthermore, as a Muslim country based on most of the population, The Ministry of Tourism has branded some places as the most suitable vacation places for Muslims (Winarti, 2017), which makes Indonesia recently ranked the second world's halal tourism in the 2018 Global Muslim Travel Index (GMTI) (Rosana, 2018).

In 2015, the Ministry of Tourism set an ambitious goal of 20 million international visitors by 2020 (Lee, 2018). In 2017, Indonesia welcomed a total of 14.04 million foreign visitor arrivals, an increase in 21.9 percent year-on-year from 11.52 million foreign visitor arrivals in the previous year (Indonesia Tourism Investment, 2018). The data from Trading Economics (2018) shows that since March 2018, the average tourist arrival in Indonesia has climbed to around 1.3 million per month, increased $12.5 \%$ from the preceding month. The top three visitors are 
from China, Singapore, and Malaysia, which contributes $14 \%, 10 \%$ and $8.8 \%$ of the total foreign visitors respectively.

According to The Travel \& Tourism Competitiveness Report (World Economic Forum, 2017) Indonesia is ranked $42^{\text {nd }}$ out of 136 countries in terms of overall competitiveness factor. Though the tourist service infrastructure and environment sustainability are scored low (ranked $60^{\text {th }}$ and $131^{\text {st }}$ respectively), Indonesia has been succeeded to boost its natural resources in ranked $14^{\text {th }}$ with the support of price competitiveness (ranked $5^{\text {th }}$ ) and international openness (ranked $17^{\text {th }}$ ). It proves that Indonesia has a good product and a good price to attract international tourists. However, currently Indonesia is being in the $9^{\text {th }}$ position out of 15 Asia countries in terms of monthly tourist arrival number (Trading Economics, 2018).

With the motivation to accelerate the growth of tourist arrival, the reigned president of Indonesia, Joko Widodo, has launched the '10 new Balis' campaign to be a tourism destinations development priority in 2016 (Sinaga, 2017). According to Arief Yahya, the current Minister of Tourism, he will focus on three top priorities to support the program; digital tourism, accommodation, and accessibility (Travel Guide, 2017). He argues that those aspects are important to make Indonesia easy to access with its wide variety of destinations. Equipped with fiscal resources to improve infrastructure components such as airports upgrade, new transportation access, and new accommodation in tourism villages (Chan, 2017).

Thus, as aligned with Indonesia's government's goals to increase the number of tourist arrival by optimizing the digital tourism as part of their strategy, this research is undertaken to explore an opportunity to increase more awareness of Indonesia's unfamiliar destinations through a digital application.

\subsection{Problem Statement}

Based on a general comparison with other countries, Indonesia lags behind in terms of providing sufficient tourist information on the website and on-site (e.g. information boards, signages, brochures) (Hariguna \& Lai, 2015; Russel, 2016; Lubis, 2017). As Indonesia is an 
archipelago country with various topographies, the existence of tourism information is important because not every place is easily accessible for first time visitor (Indonesia Investments, 2016). Petriana (2017) argues that most tourists have strong desires towards Bali for affordable luxury and accessibility but struggle to find information about Indonesian destinations beyond Bali because many other destinations in Indonesia have not received the same level of endorsement. Wijaya (2017) also comments that Indonesia's tourism destinations are underrated due to the limited information of Indonesia tourism globally, resulted to many tourists having a low understanding of where Indonesia is located and what types of the destination they can explore in Indonesia. Further, tourists find difficulties to obtain on-site tourism information during their trip in Indonesia since many of local attractions' information and guidebooks are not available in English language (Asia Sentinel, 2017) and some of local guides are less skilled to provide information and communicate with tourists (Cholik, 2017).

It seems that lack of tourism information availability may prevent people to be aware of what Indonesia has to offer. Therefore, referring to the digital tourism strategy and considering the effectiveness of digital tools or apps to disseminate tourism information (Buhalis \& Law, 2008; Derrick Huang, Goo, Nam, \& Yoo, 2017; Wang \& Fesenmaier, 2013), this study will look deeper to the following research question:

\section{"How can a travel app contribute to the information availability of Indonesia's tourism destinations?"}

\subsection{Literature Review}

This section discusses the foundational theory to bring broad views and a depth understanding of the Information and Communication Technology (ICT) significance in the tourism industry both for tourist and tourism service providers with regard to explore further the research question of this study.

\subsubsection{The relevance of ICT for tourist}

The use of digital technology platform is essential in today's ICT era since many research 
suggested that the emerging of digital technology can support the enhancement of the service quality, contribute to higher guest/ traveler experience and have a positive effect on increasing the market share of the tourism service providers (Buhalis \& Law, 2008; Aramendia-Muneta, López, 2013). Tourist planning and information search behavior is changed by the emerging of ICT (Stamboulis \& Skayannis, 2003; Xiang, Magnini, \& Fesenmaier, 2015) as they can retrieve travel and destination information, make a plan for the trip and book their preferred trip itineraries (Hyde, 2008) effectively through reservation systems, online travel agencies, search engines, social networking, and destination management systems (Buhalis \& Law, 2008). Through various online travel channels, tourists have the option to design customized trip schedules based on the number of points of interest (POI), the total expense of the trip, the number of people involved in the trip (single or group traveler), and details for each visit (e.g. POI description, start and end time, cost, transport mode, etc.) (Sylejmani, Dorn, \& Musliu, 2017). Gursoy \& Umbreit (2004) also suggest that the use of ICT for trip planning and decision making is important as an external information source to complement internal information such as memory or past experience. Furthermore, with an internet access tourist can learn more about the destinations they have never visited before either from an ordinary approach such as searching posting recommendations on a tourist website or accessing a travel app with advanced digital content to enhance the visitor experience (Benyon, Quigley, O'Keefe, \& Riva, 2014). The latter method has been confirmed by Wright (2015) who suggests that ICT can provide almost 'real' destination imagery as part of the pre-travel experience by creating virtual reality (VR) technology in particular destination.

During the trip activity, most tourists make the most out of ICT by using tools such as digital guides, location maps, social media, augmented reality (AR) codes, or other mobile apps (Benyon et al., 2014). Some tourists desire to use the internet access from their smartphone to share GPS positioning via mobile apps, share video and engage in real-time video chat while they are traveling (Baym, 2009). Furthermore, advanced digital technologies can deliver more personalized experiences for the tourists, such as the use of smartphones for travel mobile apps, the use of high tech for high-touch experiences and the implementation of mobile tour guides for personalized routes and location-relevant information (Neuhofer, Buhalis, \& Ladkin, 2015). Travel mobile apps offer various handy tools for tourists such as weather 
information (Tussyadiah, Jung, \& tom Dieck, 2018), digital guide (Bohlin \& Brandt, 2014), or even a smart navigation with audio and touch feedback (Wei, Ren, \& O'Neill, 2014). Meanwhile, augmented reality technology has been applied to enhance outdoors walking experiences in heritage and natural sites such as national parks, historic building, castles and monuments (Curtin, 2017) and indoor touristic experiences such as museums, art galleries, and indoor theme parks by providing information through touch-screen displays, smartphones, and/or wearable devices (Tussyadiah et al., 2018).

After completing their trip, tourists make use of ICT to share their trip experience with others as it is important to raise positive self-identity (Baym, 2009), to give recommendation to other tourists as part of 'digital tourist ambassador' (Benyon et al., 2014), and to fulfill the need of fitting into a group of social media users (Kang \& Schuett, 2013). Tourists share their experiences online with family members, friends, and the general public via email messages, using Social network sites (SNSs) such as Facebook, Twitter, MySpace, Instagram (Fatanti \& Suyadnya, 2015) and by publishing travel blogs (Chandralal, Rindfleish, \& Valenzuela, 2014). One of the most appealing utilities of social media is that it enables users to easily create and post a variety of content in the forms of texts, photos, and video (Kang \& Schuett, 2013). While in blogs, people can write about their own destination perspectives and provide others with functional recommendations, such as good accommodation or essential attractions along with photos or films to give a better illustration about the places they have been (Petriana, 2017). Chandralal et al. (2014) also highlight that travel bloggers in a foreign destination often write blog pieces that showcase their "local experiences" when becoming impressed by the culture of local people, behavior, and food during their tours. For personal reminders of memorable travel experience, ICT's role for tourists is also quite useful to preserve travel photos by utilizing web-based service like Shutterfly and Blurb to create digital photo book and tell the story of recent adventures as opposed to traditional album (Keller, 2016) or upload photos, create and manage albums in Google+ (McNulty, 2012).

Although there are tourists who have the internet access but are not able to use it effectively because of a number of reasons such as lack of knowledge, trust, literacy, language skills, credit card availability and low bandwidth (Minghetti, Buhalis, 2010), current technology savvy tourists are more demanding and expect accurate, clear, and immediate information 
and will not accept slow response and invalid data (Bennett, 1993; Yeoman \& McMahonBeattie, 2006). Tourists have become more sophisticated and experienced (Mihalcescu, Sion \& Marginean, 2016) and the internet remains to be the most used tool of information for many tourists to enrich their travel experiences (Xiang, Magnini, \& Fesenmaier, 2015).

\subsubsection{ICT relevance to tourism service providers}

ICT's role in the tourism industry cannot be underestimated because it has vital contributions in supporting the operation of tourism services and management effectively and efficiently by providing trip planning and reservation system (Ray, et. al, 2011), destination awareness (Caraivan, 2017), as well as marketing and communication strategies (Buhalis \& Law, 2008). Due to the popularity of travel apps, most tourism providers such as hotels, airlines, and travel agencies have incorporated digital technologies as part of their distribution channel (Buhalis, 1998). Other research also revealed that an association of small suppliers that form a single platform containing various tourist services information on destinations (hotels, transport companies, tour activities) is more likely to be preferred than if they would do it individually (Berne, Garcia-Gonzalez Margarita, \& Mugica, 2012). Furthermore, travel agents are losing its market since tourists are more preferred to pursue their own preferences and itineraries (Buhalis, Law, 2008) by gathering information through blogs, interactive online platforms or travel apps to choose accommodation, transportation and tourism activities (Ma \& Scott, 2017).

Another benefit that can be flourished through the involvement of ICT is the empowerment of local communities in the tourism industry. Tosun (2000) suggested that the local communities are likely failing to compete over tourism due to their limited financial resources compared to a large capital business owner in a more popular and attractive tourist destination after considerable development or as a result of growing commercialized tourism. This is where the role of digital technology is important since it provides access to approach potential customers and overcome their challenge of being globally represented (Ray, et. al, 2011; Mihalcescu, Sion \& Marginean, 2016). Information technology can be used not only for operational purposes, but also for tactical and strategic management, as it allows tourism providers to communicate directly and more efficiently with prospective travelers (Ray, et. al, 
2011), as well as open new areas for players seeking to intermediate the relationship between tourism service providers and tourists (Digiorgio, 2016).

Furthermore, through ICT, the tourism service providers can provide a platform for experienced travelers to create tailor-made itineraries as part of tourism providers' innovation to aim competitiveness and performance improvement (Buhalis, 1998). However, sometimes the challenge to those who are interested in destination marketing through internet is a perceived gap between package or service promises and reality (Yeoman \& McMahon-Beattie, 2006), which Digiorgio (2016) also emphasizes to focus on promise delivery as if it is not well executed, the particular tourism destination will fail. To address such issue, ICT allows tourism service providers to focus on tourists experience as opposed to tourists acquisition as it will make the tourism industry more sustainable in the long run (Stamboulis, Skayannis, 2003) by providing responsive $24 / 7$ customer feedback, track profiles based on customer history (Wirtz, Schilke, \& Ullrich, 2010) and mobile loyalty rewards (Hasen, 2012), such as frequent flyer app (Boehmer, 2013) and hotel loyalty program (Wang, Xiang, \& Wang, 2016). An essential challenge for marketers in the travel and tourism industry is the growing popularity of the so-called 'eWOM', i.e., electronic word-of-mouth, in influencing consumers' attitudes, perceptions, intentions, as well as product preferences during the trip planning process (Xiang, Magnini, \& Fesenmaier, 2015). Although Pitoska (2013) argued that most of the tourism service providers are not used to have an electronic marketing channel, those who utilize the e-channel such as Facebook or electronic travel agencies (Booking.com) claim that their services have become more competitive.

Tourism destinations and SMEs in peripheral, low digital-access regions are even more lag behind their colleagues located in developed countries (Buhalis 1998, 2003). Not only their huge gap from their potential customers but they also still strive with access to skill, finance, and technologies that could allow them to promote their products and develop suitable tools for attracting prospective markets (Minghetti, Buhalis, 2010). Therefore, the association between ICT and sustained tourism is vital if the tourism industry is going to continue its growth and success (Ali \& Frew, 2014; Buhalis \& Law, 2008).

Numerous studies have identified the significance of ICT tools for tourism planning and activities, as well as their benefits for tourists and tourism service providers. Hence, 
throughout this study, these literature reviews will support the foundational theory to answer the research question on how a travel app can perform as a media to extend the information about Indonesia's local attractions, potential destinations, and tourism events to international tourists, as well as to support the tourism service providers' daily business activities.

\subsection{Proposed Project Description}

The main goal of this research is to create a sound business case for a commercialisable product that offers a solution to the identified problem. The proposed solution to address the lack of tourism information issue in Indonesia is to develop a travel web-based or mobile application (app) that provides products, services and information of Indonesia's tourism destinations with a focus on local experiences campaign to address the lack of local tourism information availability (Asia Sentinel, 2017; Cholik, 2017). This app will be called Extra, as an abbreviation from 'EXploring the TouRism in IndonesiA'. This proposed solution is chosen based on these potential opportunities; (a) local tourism endorsement, (b) follow the trend, (c) effective communication media, and (d) prospective customer base.

\section{a. Local Tourism Endorsement}

Through this app, tourists can discover authentic local places and activities through recommendation from trusted locals. Likewise, the app will enable tourism service providers from remote areas to promote untapped tourist destinations in a global context.

\section{b. Follow the Trend}

The need of a digital tool for traveling purpose such as Extra keeps growing since current technology savvy tourists are more sophisticated to retrieve fast and accurate travel information through online access (Yeoman \& McMahon-Beattie, 2006; Mihalcescu, Sion \& Marginean, 2016) and create their own itineraries (Buhalis, 1998). Through Extra, they will receive accurate tourism information from trusted locals and gain a flexibility to customize trip itineraries. 


\section{c. Effective Communication Media}

The digital technology is an effective tool to support tourism service providers' business operation as it allows them to communicate directly and more efficiently with prospective travelers (Ray, et. al, 2011). Hence, Extra aims to enhance the interaction between tourism service providers and tourists for trip planning and local recommendations.

\section{d. Prospective Customer Base}

The government's initiative to expand Indonesia's tourism attractions worldwide by promoting "Ten New Balis" (Chan, 2017) will attract more international visitors in the coming years. Accordingly, Indonesia is expected to welcome 20 million international tourist arrivals by 2020 (Lee, 2018). As such, it is estimated that those potential visitors will use Extra to explore Indonesia's tourist destinations and improve traveling experience.

On top of these opportunities, the proposed solution will support the existing Indonesia's official tourism website Wonderful Indonesia to provide tourism information. Research conducted by Yunus \& Tanuar (2018) on the said website reveals that although the web has provided complete information including maps, suggested activities and nearby hotels, there are still drawbacks in some respects such as some of the hotel reviews use the Indonesian language instead of English. Further, some menus are loaded with many layers, hence it is not easy to access the required information promptly.

\subsection{Project Development Strategy}

The project development strategy of Extra will adopt the lean start-up methodology, which define as a method to accelerate product development cycles through a combination of 'build-measure-learn' feedback loop (Ries, 2011). According to Blank (2013), the critical factor that distinct the lean start-up methodology from the conventional business wisdom is its flexibility to iterate the product design by continually listening to customers' needs in order to search for a scalable business model, or a minimum viable product (MVP) of Extra. The 
main characteristic of a minimum viable product is it has ample values to attract people to initially use or buy it and allows feedback from its early users to design future development of the product (Ries, 2011). Further, Blank (2013) emphasizes that this approach is considered as the most suitable product development approach for a new start-up in the sense of time and resources effectiveness with its agile development strategy. This includes applying customers' feedback to adjust assumptions, commencing the cycle over again, testing the updated product design, and continually creating further small adjustments/iterations (Blank, 2013). The first step of developing Extra is to design the business model that will give a better understanding of all elements that are involved in the product development process. A onepage 'business model canvas' is employed as it provides essential key components to visualize the business model with assumptions that can be adjusted easily after gaining research findings and results (Osterwalder \& Pigneur, 2010). The design of the business model canvas includes nine building blocks of key components as presented in Table 1.1.

\begin{tabular}{|c|c|c|c|c|c|}
\hline $\begin{array}{c}(1) \\
\text { KEY PARTNERS }\end{array}$ & $\begin{array}{c}\text { (2) } \\
\text { KEY ACTIVITIES }\end{array}$ & \multicolumn{2}{|c|}{$\begin{array}{c}\text { (3) } \\
\text { VALUE PROPOSITIONS }\end{array}$} & $\begin{array}{c}\text { (4) } \\
\text { CUSTOMER } \\
\text { RELATIONSHIPS }\end{array}$ & $\begin{array}{c}\text { (5) } \\
\text { CUSTOMER SEGMENTS }\end{array}$ \\
\hline \multirow[t]{3}{*}{$\begin{array}{l}\text { - Tourism service providers } \\
\text { - App developer } \\
\text { - Marketing partners } \\
\text { - Financial partners }\end{array}$} & $\begin{array}{l}\text { - Research for minimum } \\
\text { viable product } \\
\text { - App development and } \\
\text { testing } \\
\text { - App operational and } \\
\text { customer service monitoring } \\
\text { - App iteration project }\end{array}$ & \multirow{2}{*}{\multicolumn{2}{|c|}{$\begin{array}{l}\text { Users } \\
\text { - Easy way to find out } \\
\text { about local tours and } \\
\text { activities } \\
\text { - Provide channel to } \\
\text { connect with trusted } \\
\text { locals } \\
\text { - Provide other travelers' } \\
\text { reviews }\end{array}$}} & $\begin{array}{l}\text { - Call center } \\
\text { - Email } \\
\text { - Instant messaging } \\
\text { - Social media }\end{array}$ & \multirow{3}{*}{$\begin{array}{l}\text { Users } \\
\text { - First time visitors } \\
\text { - Those who want to } \\
\text { explore local experience } \\
\text { \& new culture } \\
\\
\text { Tourism service } \\
\text { providers } \\
\text { - Those who want to } \\
\text { reach out to more } \\
\text { people to increase sales } \\
\text { - Those who want to } \\
\text { promote local } \\
\text { attractions }\end{array}$} \\
\hline & $\begin{array}{c}\text { (6) } \\
\text { KEY RESOURCES }\end{array}$ & & & $\begin{array}{c}\text { (7) } \\
\text { CHANNELS }\end{array}$ & \\
\hline & $\begin{array}{l}\text { - Partnership with tourism } \\
\text { service providers } \\
\text { - Efficient app developer } \\
\text { - Technology } \\
\text { - Skilled staff }\end{array}$ & \multicolumn{2}{|c|}{$\begin{array}{l}\text { Tourism service providers } \\
\text { - Provide channel to get } \\
\text { promoted worldwide } \\
\text { - Flexibility to arrange tour } \\
\text { packages in a single } \\
\text { platform }\end{array}$} & $\begin{array}{l}\text { - Website } \\
\text { - Mobile app for } \\
\text { Android \& IOS }\end{array}$ & \\
\hline \multicolumn{3}{|c|}{$\begin{array}{l}\text { (8) } \\
\text { OST STRUCTURES }\end{array}$} & \multicolumn{3}{|c|}{$\begin{array}{c}\text { (9) } \\
\text { REVENUE STREAMS }\end{array}$} \\
\hline \multicolumn{3}{|c|}{$\begin{array}{l}\text { - Technological set up \& running costs } \\
\text { - Salaries to staff } \\
\text { - Operational costs } \\
\text { - Marketing cost }\end{array}$} & \multicolumn{3}{|c|}{$\begin{array}{l}\text { - Commision fee from every realized deal } \\
\text { - In-app purchase }\end{array}$} \\
\hline
\end{tabular}

\section{Table 1.1 Business Model Canvas of Extra}

The assumptions in value propositions ( 3 ) and customers segments (5) blocks are defined to address the lack of tourism information availability to explore local tours and activities (Asia Sentinel, 2017; Cholik, 2017) and endorse Indonesia's tourism destinations by emphasizing 
local experiences' reviews from other travelers (Chandralal et al., 2014). Likewise, Extra also offers benefits to tourism service providers as it provides a suitable tool to connect with prospective markets and promote local attractions (Minghetti, Buhalis, 2010), as well as to get endorsed globally (Tosun, 2000; Ray, et. al, 2011; Mihalcescu, Sion \& Marginean, 2016). Assumptions in other seven blocks are developed based on the discussion with the advisory board that consists of fellow students within the researcher's field of study. Due to the short nature of this study, the project scope of this study is to validate key assumptions in value propositions, customer relationships, customer segments, channels, and revenue streams (see Table 1.1). After concluding with finding and analysis of the data collection, any adjustments of this business model canvas will be reviewed in the discussion and business case chapter.

\subsection{Research Process}

The process of this research is grouped into three stages; (1) research preparation, (2) research practice and (3) research outcome.

\section{(1) Research Preparation}

The first process of this stage is problem identification and defining the solution of the problem. It has been recognized that Indonesia is lacking sufficient tourism information on the website and on-site while on the other hand the government has a goal to increase visitors by 20 million by the end of 2019. Since many scholars suggest that ICT is an effective tool for tourism awareness and promotion, the research question focusses on how a travel app can contribute to the information availability of Indonesia tourism destinations. In order to present justification why this research question has to be studied further and what methods that will be used to conduct the research, the next process is to construct the research proposal that outlines the work plan of the research, including objectives, timespan, background, and methodology of the research. Then, the following process is to apply the ethics approval to ensure that the research is conducted ethically and in accordance with the University's Human Ethics Policy. 


\section{(2) Research Practice}

After having the ethics approval, in order to have appropriate information for the research study, the next process is carrying out the data collection. This research implements the funnel approach with mixed methods research design as it presents more in-depth information and complete picture of product's perceived value for result analysis. The funnel approach - a technique used to narrow a broad view of topic information into more detailed key areas that are relevant with research objectives (Palinkas et al., 2015) - is undertaken in order to screen general ideas from various perspectives into more specific key areas/opportunities to answer the research problem. The mixed methods - which combines qualitative and quantitative research - is considered suitable for this research as the result can validate each other method (qualitative and quantitative method) and provide stronger evidence for the conclusion.

The first step was to conduct qualitative research. This entailed interviews with tourism stakeholders and tourists. The interviews with tourism stakeholders used snowball sampling method with semi-structured questions. The snowball sampling method, defined as a method of asking research participants to recruit other participants (Browne, 2005; Bryman, 2016), was carried out to explore particular characteristics of potential participants who have a sound expertise, skill, influence, and experience in running the tourism business in Indonesia. The semi-structured interview method is used as the prepared set of questions keeps the interview focus on how a travel app can support their business operation by providing information availability of Indonesia's tourism destinations, as well as offers an opportunity to explore particular themes or responses further with an open-ended interview. As for tourists, the interviews are using systematic random sampling method with semi-structured questions as well. The systematic random sampling method is a way of selecting participants with a random starting point and a fixed, recurring interval in the targeted population (O'Leary, 2017). It is considered as the most suitable data collection approach as it provides an unbiased representative sample and an equal chance of the target population of being selected. The interview is targeted to any international tourist who is visiting Indonesia during 
the data collection performance. The interviews take places in various locations in order to gain various feedback from the different type of tourist' travel interest regarding their experience of using ICT tools to obtain tourism information, as well as plan and book trip itineraries.

Before moving on to the next step, the result of the first step will be analyzed and interpreted in order to narrow general questions into more specific questions and tie some highlighted key areas that will be formulated in the next step. Then, the second step of this research is to conduct quantitative research with random sampling method. This method is defined as the basic sampling technique by selecting a group of respondents from a population (Frerichs, 2008) and it aims to increase the generalizability of the results from a wider audience. This step involves online surveys with a larger size of participants, targeted to every person who had visited Indonesia or had an international holiday trip experience. This survey will ask about their experience of using digital tools to obtain tourism information, plan and book trip itineraries, as well as their desired features for a future travel app.

\section{(3) Research Outcome}

This is the stage when all the data collection of the research is analyzed and interpreted for market validation and product development purpose. After completing the analysis and interpretation, in order to have a more comprehensive insight of the product analysis and validation, the next process is to consult with the related experts about the viability to commercialize the proposed product. The final process of this stage is to create the business case that consolidates the findings and recommendations of the research into one concise report designed for the project partner or investor audience, as well as recommendations for further research. Further, the summary of the findings is disseminated to the stakeholders as a feedback for their future business planning.

\subsection{Summary}

Aiming to solve the research problem by optimizing the digital tourism strategy, this study is looking an opportunity to support the information availability of Indonesia's tourism 
destinations through a digital application named Extra. Literature reviews suggest the importance of ICT tool to help tourists carrying out their travel activities and extend tourist's experiences (Buhalis \& Law, 2008; Aramendia-Muneta, López, 2013; Xiang, Magnini, \& Fesenmaier, 2015; Tussyadiah et al., 2018). At the same time, the ICT implementation also supports tourism service provider to promote and operate their business effectively (Buhalis \& Law, 2008; Ray, et. al, 2011; Mihalcescu, Sion \& Marginean, 2016). Hence, Extra attempts to address the research problem by providing a media to extend the information about Indonesia's local attractions, potential destinations, and tourism events from trusted locals to international tourists, as well as to support the tourism service providers' daily business activities.

This thesis is divided into six chapters. Chapter One, the introduction, outlines the background of the project, including problem statement, opportunities, and the relevant literature reviews to develop the project. The second chapter, methodology, provides the methodology used to collect and analyze the data. It will then proceed to Chapter 3, findings and analysis, which describes the findings in relation with the key assumptions and the results of any further data collection and analysis. Chapter 4, discussion, addresses how the findings of the research contribute to the initial assumptions, previous research and to the development of similar products within the industry. Chapter 5 presents the recommendations of the research, including the business case for further product development using the business canvas model, the literature review of technology development and manufacturing processes, and financial forecasting. The final chapter, Chapter 6 , includes the conclusions of the study and its implications. 


\section{Chapter 2 : Methodology}

\subsection{Research Approach}

This research aims to explore the opportunity of developing a commercialisable product that will solve the research problem, which is the lack of tourist information available on websites and on location regarding Indonesia's tourism destinations. Prior to the research practice, literature reviews were undertaken to have a thorough understanding of the research topic and support the foundational theory to address the research problem. Following the apparent opportunities emerged from literature reviews regarding the importance of ICT tools for tourism purpose, this study looks the prospect of solving the tourism information availability issue by means of a digital app. Hence, the next step is to gain an insight from tourism stakeholders and tourists in Indonesia regarding the ICT involvement and potentials for a better travel-related experience. It was important to understand the current conditions from their perspectives to ensure the research's validity and reliability.

The fundamental step in every research activity is to determine the best methodology that will be applied to collect and analyze the data. The nature of this research is to explore the most suitable features for a travel app that will be beneficial for both tourism stakeholders and tourists. Hence, it is necessary to gather broad descriptive information about participants' experiences and expectations and narrow the findings into more specific features with a significant level of validity. As such, applying the combination of qualitative and quantitative method, namely mixed research methods will suit this research's objective. A mixed method technique is considered the best approach for this research as it provides various combinations and connections of measurable statistical and descriptive/narrative research methods in which one data strand crosses with, enhances, and makes meaning for the other (Creswell \& Plano Clark, 2011). One of the most beneficial characteristics of performing mixed methods research is the possibility to identify aspects of a phenomenon more accurately by evaluating it from different vantage points using different methods and techniques (Morse, 2003). This approach relates to the research question of this study, which explores the opportunities to increase the tourism industry in Indonesia by developing a 
travel app. Multiple perspectives and methods will be necessary here to gain in depth understanding of these opportunities. In addition, Watkins \& Gioia (2015) suggest that the advantage of mixed methods research is that it can optimize the strengths of each other research method, where each single method falls short, the other one will help to fill the gap to increase the understanding of the phenomenon of the research subject.

This research is adopting an exploratory sequential design as outlined in Figure 2.1.

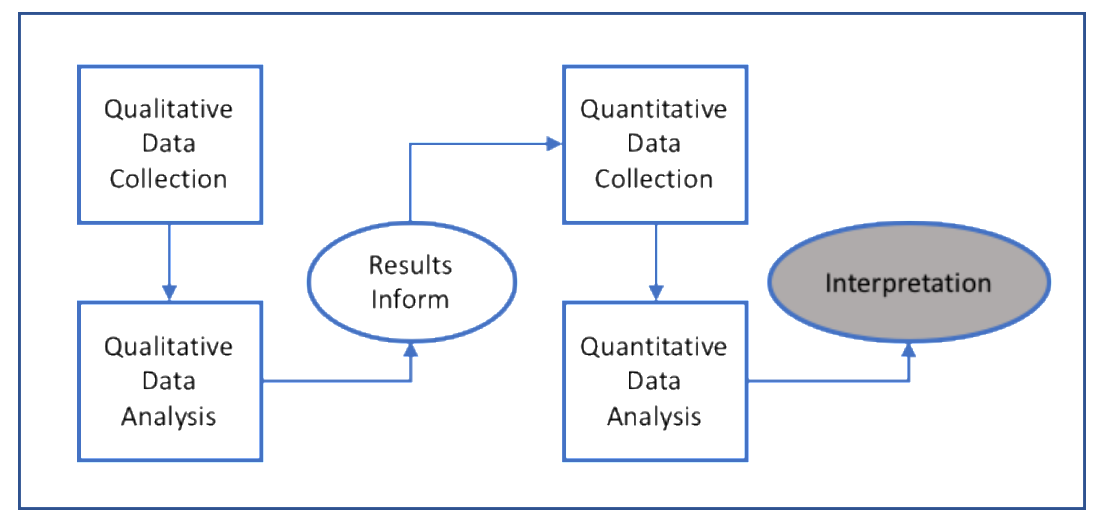

Figure 2.1 Exploratory Sequential Design (Watkins \& Gioia, 2015, p.33)

First, a qualitative research phase was conducted to gain in breadth and depth of understanding of the experiences of individuals and/or groups in the research topic (Crawford, 2009). After the results of the qualitative phase were analyzed, the quantitative research was developed to narrow the key areas of qualitative research findings. After the results of the quantitative phase were analyzed, the research interpretation will be made to support the research outcome and recommendation. In conclusion, by performing mixed method research with exploratory sequential design, it is expected that the result of this research is more comprehensive to develop a travel app that that will help tourism stakeholders increase their business by providing the most relevant desired features for tourists.

\subsection{Qualitative Interview}

The first step of doing a mixed method research with an exploratory sequential design is a qualitative interview. A qualitative interview is a structured conversation that contains a purpose (Brinkmann, 2013). DeMarrais (2004) describes that a research interview is a process 
which allows the researcher and the participant engage in a conversation focused on questions related to a research study. In more detail, interviewing for research purposes is a systematic activity that includes an introduction, asking effective questions, recording and evaluating interview data, and understanding the interaction between interviewer and respondent (Merriam \& Tisdell, 2016). In this research, the qualitative interview's purpose is to answer the following research question:

\section{"How can a travel app contribute to the information availability of tourism destinations in Indonesia?"}

The interviews were held with tourism stakeholders and tourists. The interviews with tourism stakeholders such as travel agents, local guides, and other tourism-related service providers were conducted due to their extensive experience in running the tourism business in Indonesia. Correspondingly, tourism stakeholders are the main contact to gain a better understanding of the current tourism phenomena such as challenges and opportunities of the tourism industry in Indonesia and how Extra can address them. In contrast, it was also important to gain feedback from tourists regarding their experiences of using travel apps to plan or during their trip and how Extra can add value on top of existing travel apps' services. It is apparent that both of tourist' and tourism stakeholders' feedback are essential to identify features that need to be developed in Extra so that it will be beneficial for them. These interviews utilized a semi-structured and open-ended style to allow a natural flow of the discussion and to encourage participants to convey their opinions without restrictions.

The interviews took place in Bali and Yogyakarta during W2-W3 July 2018. Previously, some potential locations were considered, but due to financial and time limitations, it was decided to choose at least two locations to gain various responses from various participants' demographics, perspectives, and interests. Bali was selected first since it is the most visited city in Indonesia (Trading Economics, 2018) and has wide-ranging attractions such as signature Balinese culture, nature, food, and extreme adventures. Further, Yogyakarta was also chosen since it is acted as the main hub to one of Seven Wonders of the World which attracts many tourists both local and foreign tourists, the Borobudur temple. 


\subsubsection{Interview with Tourism Stakeholders}

\subsubsection{Interview Guidelines}

The interview guidelines comprised five sub-questions to ensure that the gathered information would give the most relevant feedback to address the research question (see Appendix B). Referring to the assumptions in the business model canvas (see Table 1.1), the details of questions and the rationale for designing the interview sub-questions for tourism stakeholders are described as follows.

\section{Question 1 - What challenges exist in Indonesia's current tourism industry?}

The first sub-question aims to gain an initial insight about the participant's perspective regarding the occurrence perceived challenges of the tourism industry in Indonesia. It is important to identify whether they feel optimistic or pessimistic about the trend of tourism business in Indonesia, as it will give the first base of understanding of the current tourism industry situation and to give a general picture on how a travel app will be developed to improve the current tourism industry.

Question 2 - What are the challenges that occur in your organization related to tourism business operation?

The second question is highlighting the participant's experience of operating the business in their circle of organizations. It will give an illustration of the participants' challenges from inside and outside the organization and whether those are major or minor challenges, and whether the challenges are related to the tourism information availability. It is necessary to have this information in order to understand the correlation between the research question and the real situation of the research subject, as well as ensure that Extra will be beneficial for tourism service providers.

\section{Question 3 - How can a travel app or digital technology help you to cope with the challenges?}

The third question is designed to bridge the general question into more specific question that is relevant with the research objective. It is important to make sure that the interview will flow naturally so that participants stay comfortable to give as much as information about their 
experience in using the digital technology as part of their business routine, including how often do they use the digital technology to solve their problems, are there any challenges in using those tools, and how are the results so far? These key facts are essential as it provides insights whether the utilization of digital technology has helped them to solve their business challenges and in what aspect Extra could add value to address unsolved challenges.

\section{Question 4-How have you used the digital technology to support your business so far?}

The fourth question aims to query information about the participants' familiarity in using digital tools. It will reveal the fact whether they have used digital tools fluently, what kind of digital tools they have been using, and what plans do they have for future business improvement that relate to the utilization of the digital technology? There is also a chance that they might not have used any of digital tools. In this case, the follow-up questions are why does it happen and what challenges that prevent them from using the digital technology? This information is essential to determine the value propositions of Extra that will fill the market gap.

\section{Question 5 - What expectations do you have for a potential future travel app to make your business process easier?}

The last question aims to explore any value-added features that are expected by the participants to run their business more effectively. Then it is followed by the questions such as whether the wish list features are already available in existing travel apps. If the features are not available yet, will they purchase or use the future travel app that offers those features? This information is important to provide information about considerable features for the minimum viable product (MVP) that will fulfill the initial customers' needs and will be validated later on the quantitative research.

By implementing those five questions, it was expected that the interview would yield a relevant feedback to answer the research question on how Extra can contribute to the information availability of tourism destinations in Indonesia. 


\subsubsection{Sampling Selection}

The research participants sampling selection for tourism stakeholders applied a snowball sampling technique to target participants with particular expertise and characteristics that relevance to research questions, as they will provide a detailed exploration and understanding of the central themes (Browne, 2005; Bryman, 2016). Further, a snowball sampling is efficient to discover the appropriate population with the least time, money, and effort by using past ties and communication with prior research subjects in order to gain access to potential new subjects that have similar characteristics (Cohen \& Arieli, 2011). Initially, it was determined that the main criteria of the participants that would be relevant to include in the research study were individuals who had more than five years of experience in the tourism industry and possessed a principal position in tourism business/organization. It was assumed that five years of experience was sufficient to consider that the participant had a sound understanding of the current condition of the tourism industry in Indonesia. The snowball sampling method was held by actively seeking referrals of travel agents, hotel staffs and government representatives who were eligible with those criteria from the first identified respondent. The process of finding the right participants was started by contacting existing eligible tourism related colleagues. Then, it was followed by asking recommendations of their qualified colleagues to be the next research participants.

In total, the recruitment yielded 11 participants across two locations (Bali, $n=6$; Yogya, $n=5$ ) from individuals with a range of roles and expertise. All participants' identities will be replaced with a coding order to simplify the research analysis. The names and details of all participants is kept confidential to the researcher and supervisor.

\subsubsection{Data Collection}

Before conducting the research, the Victoria University of Wellington Human Ethics Committee granted ethical approval with approval number 0000026197 . Then, the next step was to set up a one-on-one meeting time with interview participants to conduct the interview. The interviews with tourism stakeholders were conducted on separate venues depending on participants' venue preferences. Specifically, interviews with hotel staffs were held at the hotels' premises such as lobby and café, while interview locations for other 
participants were determined by the participant's venue suggestion, such as hotel lobby and restaurant. All research began with all of the participants were asked to read the information sheet and sign the consent form (see Appendix A). Then, one-on-one interviews were held with firstly asking about the participant's name, position in the organization, and the number of years of work experience in the current position. Ten interviews were audio recorded and subject to be transcribed for the analysis process. The time length of each interview is varied between 30-60 minutes with a considerable pace of conversation. One of the interview was conducted through email correspondence since it was difficult to set up a one-on-one interview with this particular participant due to the participant's very tight business schedule.

The general observation from 11 interviews is that all of the participants were enthusiastic to convey their opinions and experiences since the nature of the interviews allows participants to provide a subject that may not have been considered and the researcher to clarify the feedback. Thus, each of interview flowed smoothly without any sign of hesitation. Most of the participants also indicated positive responses when it was introduced that the aim of the research is to prepare a business case for Extra that will support the awareness of the tourism industry in Indonesia by providing tourism information, products and services.

\subsubsection{Data Analysis}

The first step carried out for data analysis was to transcribe responses of interviews. After the transcription process, the data was reviewed to extract highlight sentences reflect back to the research and interview questions. The process of transforming raw data into more substantial information is important to pinpoint and focus in on what is meaningful towards the study (Charmaz, 2006). The next step was to categorize the sorted data based on four key themes that emerged from the data. These were current challenges, current ICT implementations, future plan, and response to a potential new travel app. Some multifaceted sentences were split into individual sentences to assure that each significant content in the sentences was placed into the appropriate theme. After grouping highlight sentences into each theme, the next phase was to re-read the data and create subthemes when necessary in order to organize the presentation of findings and simplify the process of data interpretation during analysis. As the interview was conducted with non-English native language and the non- 
English data lead to an English publication, the next step was to translate the final key sentences into the English language. The translation process was conducted after writing up findings analysis as van Nes et.al (2010) suggested to keeping the original language as long and as much as possible to prevent loss of context. The final step of this data analysis was to examine the language interpretations by referring back to the preliminary findings in the source language.

\subsubsection{Limitations}

Due to the short nature of this 12 -month course and the distant location of the participant sample, a follow-up face to face research interview in which participants may have been revisited was unable to be conducted. Likewise, as the participant sample includes only eleven tourism stakeholders from two areas, the sample may not be considered a fair representation of Indonesia tourism service providers.

Also, the qualitative nature of the research may draw a limitation aspect as the subjectivity issue may appear during the interview. Therefore, the researcher seeks to reduce this concern by designing neutral interview guidelines with no clue to the participant of what the researcher may want to hear, as well as being a passive recipient of external information without any intervention.

Further, the usage of non-English native language in interviews - that later on has been translated into the English language - may also contribute limitation in this research since meaning may get lost in the translation process. As such, this research attempts to minimize this concern by keeping read-through the origin of response and find the best possible English wordings.

\subsubsection{Interview with Tourists}

\subsubsection{Interview Guidelines}

With regard to respect the selected tourist' valuable time of enjoying the attractions, it was targeted to conclude the interview within 5 minutes. Therefore, the questions for tourists 
interviews were designed to be simpler and more straightforward than the sub-questions for tourism stakeholders. The details and rationale for designing the interview sub-questions for tourists are described as follows.

\section{Question 1 - How have you used the digital technology for travel related matters?}

The first question aims to give an initial insight about the tourists' familiarity with using digital tools. This sub-question will expose the facts whether they have used digital tools fluently, what kind of digital tools they have been using, what features do they like most, are there any challenges in using the tool and what efforts do they make so far to overcome the challenges? This information is important to understand tourists' most chosen travel apps and features as a product benchmark for future travel app.

\section{Question 2 - What expectations do you have for a future potential travel app in Indonesia?}

The second question is intended to explore any value-added features that are expected by tourists to help them doing their traveling activity more effectively. Further, this sub-question is also useful to explore facts such as whether the wish list features are already available in existing travel apps. And if the features are not available yet, will they purchase or use the future travel app that offers those features? This information is important to determine the minimum viable product (MVP) that will fulfill the initial customers' needs and will be validated later in the quantitative research.

\subsubsection{Sampling Selection}

The sampling selection for tourists employed a systematic random sampling technique, which targeted to every fifth person who was leaving the place of attractions. These various locations were approached to gain unbiased responses from different kind of tourists' interests. A systematic random sampling method was utilized as it offers a close approximation of each element in a population that has an equal chance of being selected for inclusion in a sample (O'Leary, 2017). Moreover, a systematic sampling method is more effective than a simple random sampling method which sometimes requires a complex calculation to determine the sample (Kemper, Stringfield \& Teddlie, 2003). This random sampling allowed participation from individual or group traveler. If there were a group of 
tourists such as couple, friends or family, the interviewer asked them one by one separately in order to gain various feedback. In total, 21 tourists were interviewed in Bali and 16 tourists were interviewed in Yogyakarta. All participants' identities are anonymous and will be replaced with a coding order to simplify the research analysis.

\subsubsection{Data Collection}

In order to gain various responses from various participants' demographics, perspectives, and interests, the interviews in Bali were held at Kuta beach, Ubud Monkey Forest, Ubud art gallery, Pandawa beach, and Uluwatu temple. Meanwhile, the interviews in Yogyakarta were held at Malioboro street, Prambanan temple, and the historical building of Bank Indonesia. Those places were chosen since they are representatives of cultural, natural, historical, and leisure attractions. The interviews took place at the exit access of the attractions as it was assumed that tourists had finished enjoying the attractions and already in their spare times at that particular spot. All research began with brief information about the research objective and participant rights in participation sheet (see Apendix A). Considering the dynamic of tourists' movement and the importance of gaining as many information in a short time frame, all of the participants' feedback were documented by note-taking with a predetermined outline of keywords such as who, where, what, when, and why. The expected answers that wil be derived from tourists with those keywords are demonstrated as below:

- Who: the origin and type of tourist, whether they are a single, couple, or group traveler.

- Where: the location of their stay and next destination of their trip in Indonesia.

- When: the length of stay in Indonesia

- What: sort of travel apps that they use for traveling purpose and expectations that they have in a potential new travel app.

- Why: the rationale of using current travel apps and having expectations in a potential new travel app.

The practice of note-taking with set of keywords was important to identify and recall any gaps in the participant's respond that were still needed to be addressed. Then, at the end of the 
interview, the participants was asked whether or not they wanted to participate in the followup online survey research. Further, in order to give a clear picture of the research purpose and proposed subject, there were some occasions where the researcher showed an example of some mobile travel apps that have been known generally and a broad scope of services such as Google Maps, Booking.com, and Trip Advisor. The average interview length time was between 5-15 minutes, since some tourists were excited to share more information, including their length of stays, favorite local attractions, upcoming destinations and travel experiences. Among all of the interview attempts that have been made, three attempts in separate venues were not successful to be proceeded further due to language and time constraints.

\subsubsection{Data Analysis}

The first step of the data analysis was to compile notes writing into the spreadsheet and organize the data based on participant's interview location, origin, type, and comments. Then, all of the comments were reviewed in order to select comments that were relevant to the research interviews. The next step was to attribute two themes based on key topics of the research and interview questions, namely current ICT practice and response to a potential travel app. Some complex comments were fragmented into more simple comments to ensure that each important element in the comments was assigned into the appropriate theme. After arranging highlight comments into each theme, the next phase was to re-read the data and create subthemes when necessary in order to set the presentation of findings into more structured order and make easier the process of data interpretation during analysis.

\subsubsection{Limitations}

Similar with the qualitative research of tourism stakeholders, a follow-up face to face research interview with participants was unable to be conducted due to the anonymity of the participant sample. Further, as the participant sample includes only 37 tourists with limited area of origins and places of interest, the sample may not be considered an unbiased representation of tourists from all around the world.

Due to the quick duration of the interview, a further limitation of this research was the lack of timing to give more explanation about the research objective and the proposed product in 
order to capture broader and objective responses from participant. This research attempted to counter this concern by presenting the brief of research purpose in the information sheet and by referring to some established travel apps to give a clear illustration about the proposed subject.

The third limitation that may be produced by this part of research was the dynamic activity of the participants that resulted to note-taking as opposed to audio recording to collect the respond. The concern of incomplete or misrepresent note taken was tried to be minimized by asking clarification for some unclear respond.

\subsection{Questionnaire}

Having concluded with the qualitative data collection and analysis, the second phase of this study was to conduct quantitative data collection as part of the mixed methods research design of this study. This quantitative phase was undertaken to corroborate qualitative key findings on how a travel app can contribute to the information availability of Indonesia's tourism destinations. It was necessary to follow-up the qualitative interview with the quantitative phase for validation purposes since the researcher was able to query fixed questions related to the qualitative findings across a larger sample through a quantitative data collection (Cotter, 2016), as well as to specify the value propositions of Extra. As such, the qualitative findings of tourism stakeholders' and tourists' interviews were employed to develop questions and identify variables that required validation in this quantitative phase. This included questions to reveal the most desirable form of Extra (i.e. website or mobile app), suggested features, and purchase intentions. The research instrument that was used for the quantitative data collection was a self-administered questionnaire - defined as a questionnaire that is designed to be fulfilled by a respondent without the involvement of the researchers (Lavrakas, 2008) - because it can collect a set of information from a sample of people with a wide range of probing question types (i.e. open-ended, single choice, multiple choices, and measurement scale) to generate some interpretation about the larger population (Kelley, et. al, 2003). The distribution method of the questionnaire was through an online channel since it can reach a large number of potential respondents and produce more data accuracy than a physical questionnaire (Gunter, Nicholas, Huntington, \& Williams, 
2002). It is also considered as an effective channel for communication between the researcher and participant, in regards to cost and time effectiveness (Brace, 2008; Patten, 2016). As will be discussed, 129 individuals ended up participating in this survey.

Brace (2008) emphasizes that an effective questionnaire should contain a language that is clear and easy to understand in order to make a smooth 'conversation' with respondents and help them to provide the needed information without any difficulty. Further, a piloting process such as carrying out a trial questionnaire to members of the target population before its final distribution is important to ensure that respondents will comprehend the questions and instructions of the questionnaire (Kelley, et. al, 2003).

\subsubsection{Questionnaire Guidelines}

This study employs the Qualtrics software to design and distribute the questionnaire. The first step in administering the questionnaire survey was to design key questions based on the research purpose, literature reviews and qualitative interview findings. Then, the questionnaire draft was reviewed by the advisory board team - which defined as a group of independent people who offer non-binding and unbiased strategic advice to the project owner (SME Business Owners/Directors, 2009) - that consisted of 3 colleague students from the researcher's field of study to assure that its content was concise and easy to understand. Valuable feedbacks that were received from the advisory board involved slight adjustment on the questions' phrasing in order to be more effective and clearer for every targeted respondent. After the reviewing process, the final draft of the online questionnaire was classified into four blocks of questions (see Appendix C). The first block of questions was about whether or not the respondent had visited Indonesia.

\begin{tabular}{|l|l|}
\hline Questions & Answer choices \\
\hline $\begin{array}{l}\text { Q1 Have you ever } \\
\text { visited Indonesia in the } \\
\text { past five years? }\end{array}$ & Yes \\
\end{tabular}

This information was needed to set a preliminary classification of the respondent. If they had visited Indonesia, their perceptions about traveling experience in Indonesia was important to assist the development of a travel app that will be relevant to Indonesia's tourism 
phenomenon. Nevertheless, if they had not visited Indonesia, their feedback on their last international holiday trip was important as well to enrich insights about how they use ICT for trip planning and activities to countries other than Indonesia, and what expectations they have on a future travel app that will give a better traveling experience.

The second block of questions - which was for the respondent who had visited Indonesia were outlined as below:

\begin{tabular}{|c|c|}
\hline Questions & Answer choices \\
\hline $\begin{array}{l}\text { Q2 How many times } \\
\text { have you visited } \\
\text { Indonesia in the past } \\
\text { five years? }\end{array}$ & $\begin{array}{l}\text { Once } \\
\text { Twice } \\
3 \text { times } \\
\text { More than } 3 \text { times }\end{array}$ \\
\hline $\begin{array}{l}\text { Q3 Which of these } \\
\text { channels did you use to } \\
\text { book your last trip to } \\
\text { visit Indonesia's } \\
\text { tourism attractions? } \\
\text { Please select all that } \\
\text { apply. }\end{array}$ & $\begin{array}{ll}\square & \text { Booking websites (e.g. Expedia, Skyscanner) } \\
\square & \text { Booking mobile apps (e.g. Airbnb, Agoda) } \\
\square & \text { Travel agent } \\
\square & \text { Hotel/flight direct channels (website/call center) } \\
\square & \text { Other (please specify) }\end{array}$ \\
\hline $\begin{array}{l}\text { Q4 During your last trip } \\
\text { to visit Indonesia's } \\
\text { tourism attractions, } \\
\text { what devices did you } \\
\text { use to obtain online } \\
\text { information about } \\
\text { places to visit and } \\
\text { things to do? Please } \\
\text { select all that apply. }\end{array}$ & $\begin{array}{l}\square \\
\text { A smartphone/internet on a mobile phone } \\
\text { A laptop } \\
\square \text { A tablet PC } \\
\square \text { A desktop at the hotel/internet cafe } \\
\square \text { I did not use any of these devices since I did not access any online information } \\
\square \text { Other (please specify) }\end{array}$ \\
\hline $\begin{array}{l}\text { Q5 Which of these } \\
\text { channels did you use } \\
\text { during your last trip to } \\
\text { visit Indonesia's } \\
\text { tourism attractions to } \\
\text { obtain information } \\
\text { about places to visit } \\
\text { and things to do? } \\
\text { Please select all that } \\
\text { apply. }\end{array}$ & $\begin{array}{l}\square \text { The official website of Indonesia tourism - Wonderful Indonesia } \\
\square \text { Travel community websites (TripAdvisor, Lonely Planet, etc) } \\
\square \text { Blog posts/reviews } \\
\square \text { Google search } \\
\square \text { Printed booklets/brochures provided by tour operators } \\
\square \text { Printed booklets/brochures at hotel's reception desk } \\
\square \text { Printed booklets/brochures at the tourism information center } \\
\square \text { Asking locals } \\
\square \text { Asking other travelers } \\
\square \text { Other (please specify) }\end{array}$ \\
\hline
\end{tabular}




\begin{tabular}{|c|c|c|c|c|c|c|}
\hline \multirow{11}{*}{$\begin{array}{l}\text { Q6 Thinking about your } \\
\text { last trip to visit } \\
\text { Indonesia's tourism } \\
\text { attractions overall, how } \\
\text { satisfied were you with } \\
\text { the availability of } \\
\text { information to help you } \\
\text { plan your trip? (only } \\
\text { displayed the selected } \\
\text { answers from Q5) }\end{array}$} & & $\begin{array}{c}\text { Extremely } \\
\text { satisfied }\end{array}$ & Satisfied & Neutral & Dissatisfied & $\begin{array}{l}\text { Extremely } \\
\text { dissatisfied }\end{array}$ \\
\hline & $\begin{array}{c}\text { The official website } \\
\text { of Indonesia } \\
\text { tourism - } \\
\text { Wonderful } \\
\text { Indonesia }\end{array}$ & 0 & 0 & 0 & 0 & 0 \\
\hline & $\begin{array}{c}\text { Travel community } \\
\text { websites } \\
\text { (TripAdvisor, } \\
\text { Lonely Planet, etc) }\end{array}$ & 0 & o & 0 & 0 & 0 \\
\hline & Blog posts/reviews & 0 & 0 & 0 & 0 & 0 \\
\hline & Google search & 0 & 0 & 0 & 0 & 0 \\
\hline & $\begin{array}{c}\text { Printed } \\
\text { booklets/brochures } \\
\text { provided by tour } \\
\text { operators }\end{array}$ & 0 & 0 & 0 & 0 & 0 \\
\hline & $\begin{array}{c}\text { Printed } \\
\text { booklets/brochures } \\
\text { at hotel's reception } \\
\text { desk }\end{array}$ & 0 & 0 & 0 & 0 & 0 \\
\hline & $\begin{array}{l}\text { Printed } \\
\text { booklets/brochures } \\
\text { at the tourism } \\
\text { information center }\end{array}$ & 0 & 0 & O & 0 & 0 \\
\hline & Asking locals & 0 & 0 & 0 & 0 & 0 \\
\hline & $\begin{array}{l}\text { Asking other } \\
\text { travelers }\end{array}$ & 0 & 0 & 0 & 0 & 0 \\
\hline & $\begin{array}{l}\text { Other (please } \\
\text { specify) }\end{array}$ & 0 & 0 & 0 & 0 & 0 \\
\hline
\end{tabular}

The first question for the respondent who had visited Indonesia - the Q2 question - was about how frequently they had visited Indonesia. It is necessary to have this information to measure their familiarity with the tourism situations in Indonesia that might tie to other variables of topics within the questionnaire. Then, Q3-Q4 questions focused on what devices and channels that were used by the respondent to gather travel information. This information was needed to identify the type of minimum viable product of Extra. For example, if the most used device and channel to gather travel information was a mobile phone and mobile app respectively, then the app will be designed solely as a mobile app. The following questions which was Q5 question - focused on details of channels that were used by the respondent to retrieve travel information. Then, Q6 question was asked using a 5-point Likert scale (from 
extremely satisfied to extremely dissatisfied) to identify the level of satisfaction of using those channels. The importance of gaining this data was to support the app's development benchmark analysis on the business case.

The third block of the questionnaire, contained questions for the respondent who had not visited Indonesia, were designed as below:

\begin{tabular}{|c|c|}
\hline Questions & Answer choices \\
\hline $\begin{array}{l}\text { Q7 Are you planning to } \\
\text { go to Indonesia anytime } \\
\text { soon? }\end{array}$ & $\begin{array}{l}\text { Yes, I am planning to go there and have booked all of my itineraries (1) } \\
\text { Yes, I am planning to go there but still do some research about Indonesia (2) } \\
\text { Probably, if I find interesting places or attractions in Indonesia (3) } \\
\text { No, I am not interested to go to Indonesia because (please specify) (4) }\end{array}$ \\
\hline $\begin{array}{l}\text { Q8 Which of these } \\
\text { channels did you use to } \\
\text { book your trip to } \\
\text { Indonesia? Please select } \\
\text { all that apply. } \\
\text { (only be displayed if } \\
\text { respondent chose (1) } \\
\text { from Q7) }\end{array}$ & $\begin{array}{l}\square \text { Booking websites (e.g. Expedia, Skyscanner) } \\
\square \text { Booking mobile apps (e.g. Airbnb, Agoda) } \\
\square \text { Travel agent } \\
\square \text { Hotel/flight direct channels (website/call center) } \\
\square \text { Other (please specify }\end{array}$ \\
\hline $\begin{array}{l}\text { Q9 Which of these } \\
\text { channels you usually } \\
\text { use to find information } \\
\text { about Indonesia? Please } \\
\text { select all that apply. } \\
\text { (only be displayed if } \\
\text { respondent chose (1) or } \\
\text { (2) from Q7) }\end{array}$ & $\begin{array}{l}\square \text { The official website of Indonesia tourism - Wonderful Indonesia } \\
\square \text { Travel community websites (TripAdvisor, Lonely Planet, etc) } \\
\square \text { Blog posts/reviews } \\
\square \text { Google search } \\
\square \text { Other (please specify) }\end{array}$ \\
\hline $\begin{array}{l}\text { Q10 During your last } \\
\text { international holiday } \\
\text { trip, what devices did } \\
\text { you use to obtain online } \\
\text { information about } \\
\text { places to visit and } \\
\text { things to do? Please } \\
\text { select all that apply. }\end{array}$ & $\begin{array}{l}\square \text { A smartphone/internet on a mobile phone } \\
\square \text { A laptop } \\
\square \text { A tablet PC } \\
\square \text { A desktop at the hotel/internet cafe } \\
\square \text { I did not use any of these devices since I did not access any online information } \\
\square \text { Other (please specify) }\end{array}$ \\
\hline $\begin{array}{l}\text { Q11 Which of these } \\
\text { channels did you use } \\
\text { during your last } \\
\text { international holiday } \\
\text { trip to obtain } \\
\text { information about } \\
\text { places to visit and } \\
\text { things to do? Please } \\
\text { select all that apply. }\end{array}$ & $\begin{array}{l}\square \text { The official tourism local website } \\
\square \text { Travel community websites (TripAdvisor, Lonely Planet, etc) } \\
\square \text { Blog posts/reviews } \\
\square \text { Google search } \\
\square \text { Printed booklets/brochures provided by tour operators } \\
\square \text { Printed booklets/brochures at hotel's reception desk } \\
\square \text { Printed booklets/brochures at the tourism information center } \\
\square \text { Asking locals } \\
\square \text { Asking other travelers } \\
\square \text { Other (please specify) }\end{array}$ \\
\hline
\end{tabular}




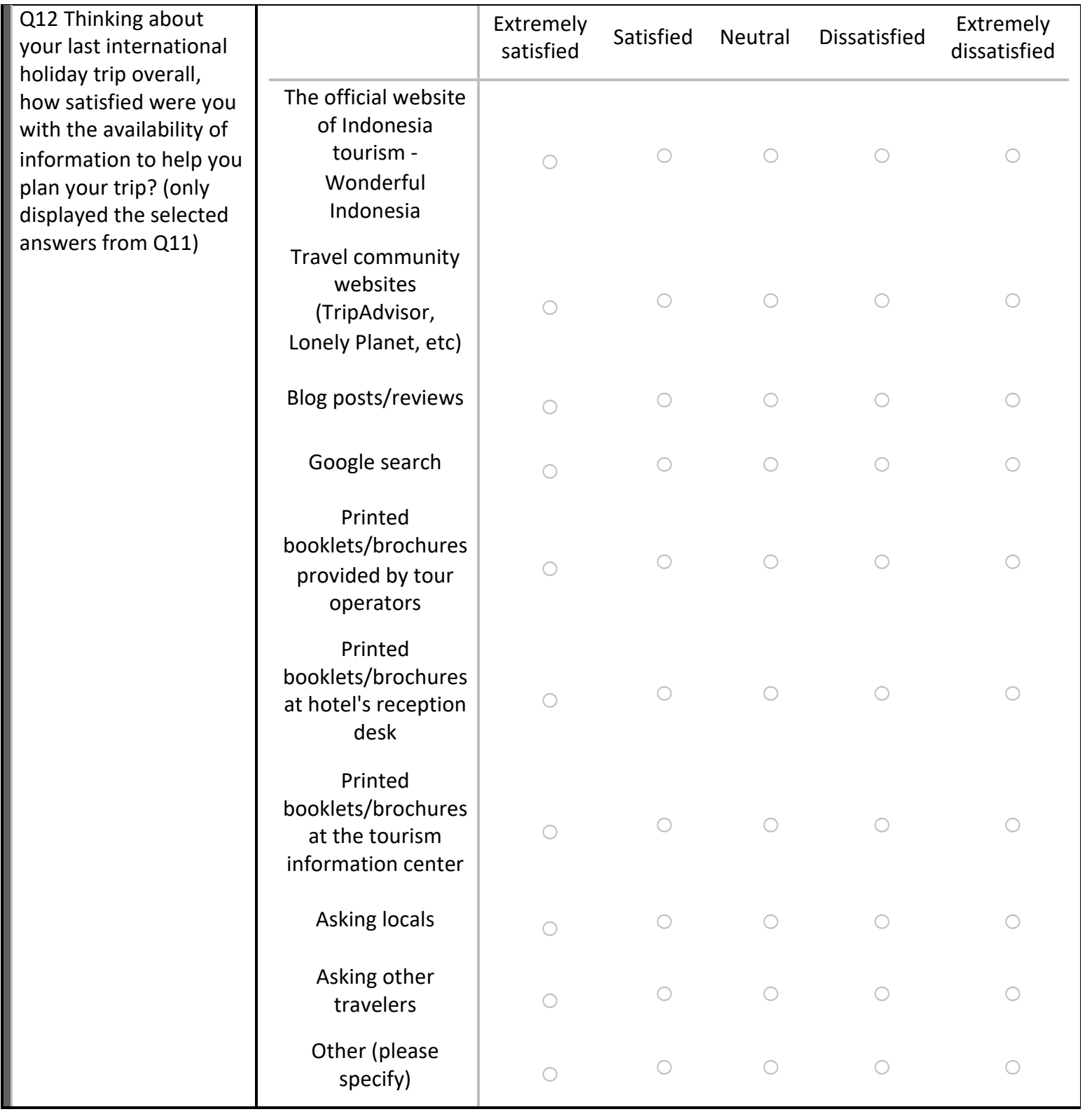

Within this block, the $\mathrm{Q} 7$ question aimed to gather information related to the respondent's interest to visit Indonesia, which would be valuable to add insight about features of the app that would attract potential tourists. Similar with questions to the respondent who had visited Indonesia, the Q8-Q10 questions aimed to supply the development of Extra by identifying which of the respondent's preferred methods to retrieve travel information on their last international holiday trip. It was followed by Q11-Q12 questions, which aimed to identify the respondent's resources of travel information and their level of satisfaction on their last international holiday trip. Again, this data was beneficial to gain an understanding regarding travel information resources preference for benchmark analysis of Extra. 
The fourth block of questions was about future app suggestions and demographic information.

\begin{tabular}{|c|c|}
\hline Questions & Answer choices \\
\hline $\begin{array}{l}\text { Q13 When you are } \\
\text { deciding which travel } \\
\text { application to use, what } \\
\text { features are most } \\
\text { important to you? } \\
\text { Please select a } \\
\text { maximum of } 5 \text { choices. }\end{array}$ & $\begin{array}{l}\square \text { Information on local attractions, accommodations, restaurants, events } \\
\square \text { Online/offline location map } \\
\square \text { Route planning } \\
\square \text { Self-designed tour package } \\
\square \text { Guests can discuss their inquiries with tour operators through online } \\
\text { messenger } \\
\square \text { Guests can book a personal guide during the trip } \\
\square \text { Loyalty reward program } \\
\square \text { 24/7 customer service support } \\
\square \text { Multilingual support } \\
\square \text { Post-trip guests rating \& review } \\
\square \text { Guests can reserve product or service with instant confirmation } \\
\square \text { Guests can book rental services such as car, motorbike, bicycle, pocket WiFi, } \\
\text { etc. } \\
\square \text { Interactive 3D experience of a real-world environment (Virtual Reality) } \\
\square \text { Show information on a captured object (Augmented Reality) } \\
\square \text { Other (please specify) }\end{array}$ \\
\hline $\begin{array}{l}\text { Q14 And what features } \\
\text { are least important to } \\
\text { you? Please select a } \\
\text { maximum of } 5 \text { choices. } \\
\text { (only displayed list of } \\
\text { choices that had not } \\
\text { been chosen from Q13) }\end{array}$ & $\begin{array}{l}\square \text { Information on local attractions, accommodations, restaurants, events } \\
\square \text { Online/offline location map } \\
\square \text { Route planning } \\
\square \text { Self-designed tour package } \\
\square \text { Guests can discuss their inquiries with tour operators through online } \\
\text { messenger } \\
\square \text { Guests can book a personal guide during the trip } \\
\square \text { Loyalty reward program } \\
\square \text { 24/7 customer service support } \\
\square \text { Multilingual support } \\
\square \text { Post-trip guests rating \& review } \\
\square \text { Guests can reserve product or service with instant confirmation } \\
\square \text { Guests can book rental services such as car, motorbike, bicycle, pocket WiFi, } \\
\text { etc } \\
\square \text { Interactive 3D experience of a real-world environment (Virtual Reality) } \\
\square \text { Show information on a captured object (Augmented Reality) } \\
\square \text { Other (please specify) }\end{array}$ \\
\hline $\begin{array}{l}\text { Q15 If a travel } \\
\text { application that covers } \\
\text { your most important } \\
\text { features and all you } \\
\text { need to know about } \\
\text { Indonesia were } \\
\text { available today, how } \\
\text { likely would you be to } \\
\text { use it? }\end{array}$ & $\begin{array}{ll}\text { Extremely likely } \\
\text { Very likely } \\
\text { Moderately likely } \\
\text { Slightly likely } \\
\text { Not likely at all }\end{array}$ \\
\hline
\end{tabular}




\begin{tabular}{|c|c|}
\hline $\begin{array}{l}\text { Q16 And what kind of } \\
\text { offer would you prefer } \\
\text { to use this app? }\end{array}$ & $\begin{array}{l}\text { Free (may contains advertising) (1) } \\
\text { Paid (no advertising, user can get all of the features) (2) } \\
\text { Free with in-app purchase for premium service (3) } \\
\text { Free with subscription option for premium service (4) }\end{array}$ \\
\hline $\begin{array}{l}\text { Q17 What price would } \\
\text { you be willing to pay for } \\
\text { this app? } \\
\text { (only be displayed if } \\
\text { respondent chose (2) } \\
\text { from Q16) }\end{array}$ & $\begin{array}{l}\text { Less than US } \$ 1 \\
\text { From US } \$ 1 \text { to US } \$ 3 \\
\text { From US } \$ 3 \text { to US } \$ 5 \\
\text { More than US } \$ 5 \text {, if I can receive these benefits (please specify) }\end{array}$ \\
\hline $\begin{array}{l}\text { Q18 What price would } \\
\text { you be willing to pay for } \\
\text { in-app purchase? } \\
\text { (only be displayed if } \\
\text { respondent chose (3) } \\
\text { from Q16) }\end{array}$ & $\begin{array}{l}\text { Less than US } \$ 1 \\
\text { From US } \$ 1 \text { to US } \$ 3 \\
\text { From US } \$ 3 \text { to US } \$ 5 \\
\text { More than US } \$ 5 \text {, if I can receive these benefits (please specify) }\end{array}$ \\
\hline $\begin{array}{l}\text { Q19 What price would } \\
\text { you be willing to pay for } \\
\text { the subscription? } \\
\text { (only be displayed if } \\
\text { respondent chose (4) } \\
\text { from Q16) }\end{array}$ & $\begin{array}{l}\text { Less than US } \$ 1 \text { per month } \\
\text { From US } \$ 1 \text { to US } \$ 3 \text { per month } \\
\text { From US } \$ 3 \text { to US } \$ 5 \text { per month } \\
\text { More than US } \$ 5 \text { per month, if I can receive these benefits (please specify) }\end{array}$ \\
\hline $\begin{array}{l}\text { Q20 During or after } \\
\text { your trip overall, did } \\
\text { you do any of the } \\
\text { following? Please select } \\
\text { all that apply. }\end{array}$ & $\begin{array}{l}\square \text { Upload trip photos to the internet, i.e. Instagram or Facebook } \\
\square \text { Upload trip videos to the internet, i.e. YouTube } \\
\text { Update your Facebook status about your trip } \\
\text { Tweet about your trip } \\
\text { Write blog about your trip } \\
\text { None of these }\end{array}$ \\
\hline $\begin{array}{l}\text { Q21 Based on your past } \\
\text { experience, what else } \\
\text { would you like to see in } \\
\text { an app that can } \\
\text { improve your traveling } \\
\text { experience? }\end{array}$ & \\
\hline $\begin{array}{l}\text { Q22 What is your } \\
\text { gender? }\end{array}$ & $\begin{array}{l}\text { Male } \\
\text { Female } \\
\text { Prefer not to answer } \\
\text { Other }\end{array}$ \\
\hline
\end{tabular}




\begin{tabular}{|c|c|}
\hline Q23 What is your age? & $\begin{array}{l}\text { Less than } 18 \text { years old } \\
18-24 \text { years old } \\
25 \text { - } 34 \text { years old } \\
35 \text { - } 44 \text { years old } \\
45 \text { years old and over }\end{array}$ \\
\hline $\begin{array}{l}\text { Q24 In which country } \\
\text { do you currently reside? }\end{array}$ & List of countries \\
\hline
\end{tabular}

In this block, Q13-Q14 questions focused on a travel app's features that were most important or least important to the respondent. Feature choices on these questions were developed based on qualitative interviews findings and literature review reference. The finding of this segment was vital as part of product validation assessment to design the minimum viable product of Extra. Then, Q15-Q19 questions aimed to gather information about the respondent's purchase intention. This information was essential to determine the most realistic revenue model of Extra. The Q20 question focused on the respondent's behavior after completed the trip with relevant to social media engagement. This question aimed to get a better understanding of how social media could be utilized for future endorsement purpose of Extra. The Q21 question was an open question that aimed to identify potential features that had not been revealed in the questionnaire yet in order to add insight of the future mobile app value prepositions. The last part of the questionnaire-Q22-Q24 questions - contained demographic questions that would be essential to pinpoint potential customers for Extra's market validation.

\subsubsection{Sampling Selection}

The online questionnaire applied random sampling method and the target of respondent was every person who had visited Indonesia or had an international holiday trip experience to other countries than Indonesia. This general characteristic of respondent was applied to gain feedback of ICT relevance to traveling experience to various tourism destinations. A random sampling technique - which defined as the basic sampling technique by selecting a group of respondents from a population (Frerichs, 2008) - was employed to increase the generalizability of the results from a larger population. Based on time and cost considerations, the random sampling method is the most effective technique to generate information on a sample of an unknown population (Bryman, 2016) such as potential tourists to Indonesia. 


\subsubsection{Data Collection}

The online survey was held during 23 October - 19 November 2018 by using Qualtrics online survey software. The distribution of the online survey link was via email and social media. The target of respondents were Facebook travel pages' communities ${ }^{1}$, international students' communities, and previous qualitative research tourist participants (from 37 participants of tourist interview, 20 of them were willing to be invited for the follow-up online survey). These various groups of potential respondents were invited to fill out the survey in order to gather broad travel experience information from diverse backgrounds and characteristics. Further, it was expected that distributing the online survey to different types of respondents may have a bigger chance to represent the entire target population. At the beginning of the survey, an information sheet about the survey objectives was provided in order to give a clear illustration about the research objective, details of why the respondent was selected, what sort of information that was sought from the survey, and how the respondent's information would be treated in this research (see Appendix C). The survey took around five minutes to complete and all feedback was confidential and anonymous. During the survey period, there were three times of survey reminder emails that were sent from the Qualtrics system to respondents who had been invited through email to fill out the survey but had not completed it yet. Likewise, the survey invitation via Facebook was posted twice in order the to optimize the response rate. At the end of the survey period, 129 respondents completed the questionnaire.

\subsubsection{Data Analysis}

The first step of analysis of the questionnaire was to retrieve all of the responses from Qualtrics system at the data and analysis section. Then, the responses were filtered and all of incomplete responses were removed from the core data. Next, the cross tabulation and reporting functions in the Qualtrics system were employed to sort respondents' answers that are ranging from single choice, multiple choices, to Likert scales - into tables and charts. The following step was to assign each table into key topics in the finding and analysis section. As for respondents' text answers in the open-ended question regarding other suggested

\footnotetext{
${ }^{1}$ such as Intrepid Travel, Solo Travel Society, Travel Dudes, We Love to Travel, Travel Mindset, and World Nomads
} 
features for Extra, the first step to analyze these was by exporting the text data into CSV file and open it in Excel spread sheet. Then, the data was sorted based on key themes that emerged from respondents' answer.

\subsubsection{Limitations}

Due to the time limitation of the survey distribution, the sample size may have a potential bias to represent the general feedback in the entire population. However, this limitation was attempted to be reduced by distributing the online survey link to the various groups of respondents.

A further limitation of this research was to identify an adequate proportion of sample size due to an unknown population of Indonesia's potential tourists. This research tried to lessen this limitation by optimizing the number of complete responses during the survey timeframe. This included sending weekly reminder emails to respondents who had not started to complete the survey yet and posting the survey link in several social media on a regular basis.

\subsection{Summary}

In order to comprehend the breadth and depth of the required information regarding the relevance of a travel app to support the information availability of the tourism industry in Indonesia, this study employs an exploratory mixed methods research design. This research approach consists of three phases of data collection, namely the interview with tourism stakeholders, interview with tourists, and online questionnaire. The qualitative interview was carried out to gain a better understanding of the current tourism phenomenon such as challenges and opportunities of the tourism industry in Indonesia. Then, the online questionnaire was conducted to validate the findings of the qualitative interview across a larger sample in order to specify the value propositions of Extra. Overall, while 11 tourism stakeholders and 37 tourists were participated in the qualitative interview, the online questionnaire yielded 129 respondents. The following chapter will present the findings and analysis of this research. 


\section{Chapter 3 : Findings and Analysis}

This chapter presents the findings and results of the data collection and the interpretation of how they relate to the research question, including challenges that are revealed during the interviews and key areas that will be explored further.

\subsection{Findings and analysis - Interview with Tourism Stakeholders}

The interviews with tourism stakeholders were held with a semi-structured guideline that were comprised of these following 5 questions:

1. What challenges exist in Indonesia's current tourism industry?

2. What are the challenges that occur in your organization related to tourism business operations?

3. How can a travel app or digital technology help you to cope with the challenges?

4. How have you used the digital technology to support your business so far?

5. What expectations do you have for a potential future travel app to make your business process easier?

With regards to keeping the confidentiality of participants' identities, each of the participants is labeled with pseudonym as in Figure 3.1.

\section{Bali}

\section{Yogyakarta}

Travel Agents: Mr A, Mr B, Mr C

(3)

Tour Guide: Mr D

Hotel Staff (Director of Sales \&Marketing): Mr E

Hotel Staff (General Manager): Mr F
Government Staffs: Ms G, Mr H

(2)

Hotel Staffs (Digital Content Marketing Manager): Mr I, Ms J

(2)

Hotel Owner: Ms K

Figure 3.1 Table of Tourism Stakeholder Participants 
The next sections discuss and analyze the four themes or key topics that were drawn from the interview results as presented earlier on the data analysis section.

\subsubsection{Current Challenges}

This theme describes participants' perspectives regarding the occurrence of challenges facing the tourism industry in Indonesia. The findings and analysis of tourism stakeholders' current challenges are divided into three sub-sections, namely destination awareness, cultural difference, and tourism facilities.

\subsubsection{Destination Awareness}

Previous research (Cholik, 2017; Petriana, 2017) revealed that there was lack of sufficient information regarding Indonesia's tourism destinations, causing many foreign people to not be aware of the various interesting attractions Indonesia has to offer. In contrast, most of the participants' first responses indicated that the emergence of Indonesia's tourism industry is moving in a positive direction and they feel optimistic that this trend will keep growing in the future as opposed to being negative and skeptic when they had been asked about the challenges towards the tourism industry in Indonesia. Still, through a deeper exploration during the interview, some of the participants indicated that there were some areas that needed awareness improvement.

One of the government representatives highlighted that currently Indonesia has achieved good performance in terms of growing the numbers of international tourist arrivals.

"The development of Indonesian tourism is very good ... it is confirmed by the statistics showing that now Indonesia is one of the most visited countries in the world, as well as winning various prestigious tourism awards from various parties." - $\mathrm{Mr} \mathrm{H}$, Government Staff 
A tour guide in Bali pointed out that the key to success for developing the tourism industry in Bali was the solid collaboration between the government and local communities to maintain and improve the tourism facilities and infrastructures.

"It's about filling the gap and understanding each other about strengths and weaknesses of the facilities, places of tourists, information, transportation, and keep maintaining the synergy between the community and the government." - $\mathrm{Mr} D$, Tour Guide

The participants' broad perspectives lead to an initial finding that Indonesia's tourism development is in the right direction. However, when it was explored deeper on whether any prevailing challenges that they perceived in spite of some constructive improvements in some areas as represented above, it was also confirmed that the current condition was required to be improved further to support the government goal.

"In order to accomplish Yogyakarta region as the New Bali, our challenge is to increase the promotion of Joglosemar ${ }^{2}$ destinations where Borobudur and Prambanan temple are located to attract more tourists from the ASEAN Region, ASIA and Europe." - Mr $H$, Government Staff

\subsubsection{Cultural Differences}

Two of the participants explicitly stated that some challenges still occur concerning the sociological factors such as cultural difference and language barrier.

"Actually, Indonesia has a lot of good natural resources, however the problem is the cultural difference. Some local people still cannot welcome international visitors with more open clothing styles." - Mr F, Hotel Staff

Being a predominantly Muslim country, the local rules such as local traditions, customs, laws and religions are still remaining a concern of some people in some areas in Indonesia. Hence,

\footnotetext{
${ }^{2}$ Abbreviation of Jogjakarta - Solo - Semarang
} 
tourists should be well informed about these circumstances to ensure that they will respect locals at all times.

"Surely, the ability to speak English is very important. In Bali, most people can speak English, but not everyone in other parts of Indonesia have this skill." - Mr E, Hotel Staff

The lack of language skill is also a challenge that has to be tackled. It was emphasized that the English language is the first communication language that local people must gain in order to give information or recommendations about local attractions or things to do to international tourists during their trips. However, it takes process as well as motivation to get people to not only understand but also be confident to speak English. As soon as they have realized that they can earn income from the tourism business, it will be easier to persuade locals' willingness to learn the English language. In the meantime, the presence of an alternative media to help tourists to get the information they need in certain destinations such as a travel app seems feasible to minimize this issue.

Related to the language issue, the staff from the tourism office similarly mentioned that currently the main problem of the Yogyakarta tourism office's web promotion is that the website is presented only in the Indonesian language, thus she noticed that it would be difficult to promote Yogyakarta's attractions to international tourists.

"I had submitted a proposal for the web development funding annually in the last three years, but it kept disapproved by the central government, well I think it's just not part of their priorities yet." - Ms G, Government Staff

\subsubsection{Tourism Facilities}

Some responses concerning the current challenges were related to tourism facilities. Two participants mentioned that tourism facilities in some of the destinations in Yogyakarta were not well maintained, thus it can potentially be a hurdle to attract visitors. Moreover, it was implicitly revealed that the lack of tourism information such as destination signs was perceived as an issue that has to be rectified as well. 
"The main challenge is the shortage of the tourism facilities, Yogyakarta has many destinations to offer, but accesses to get there are sometimes difficult, there are no signages, the roads are poor, and toilets are not maintained or clean." - Ms J, Hotel Staff

Another tourism facility issue that was cited by five participants was related to the airport and airline availability to serve international tourists. Two participants in Bali agreed that the government should be aware that some destinations in Indonesia still have no direct airline access though those places offer uniqueness that can be highly desired by international tourists.

"No matter how massive the publications of some destinations are, it means nothing if it is not supported by the airline access." - Mr E, Hotel Staff

"If other regions have developed the tourism destinations but are not improving the airlines access or the number of frequent flights, it will hold back the overall development of the tourism industry at those areas." - Mr A, Travel Agent

Another three participants from Yogyakarta consistently stated that Yogyakarta's international airport is no longer convenient for tourists since it is too small, too crowded and over capacity. However, they also mentioned that the government is already in progress of building a bigger international airport and it is expected to be operational in 2021 .

To sum up, there were three major current challenges that had been identified by tourism stakeholders i.e. destination awareness, cultural differences and tourism facilities issues. In particular, one of the major challenges that will be addressed by this research is the destination awareness challenge. The possibility to minimize this challenge is obtained by creating a sound business case for Extra that is intended not only to increase the awareness of Indonesia's tourism destinations, but also to bring benefit for tourism stakeholders' business operations. 


\subsubsection{Current ICT implementations}

This theme represents the utilization of ICT as part of participants' daily business activities and the level of familiarity of using the ICT tools. This theme is essential to give an illustration whether Extra will be appropriate for them based on participants' current practice. More than half of participants have optimized the ICT utilization to manage hotel promotion, destination information, and travel package offering by website, collaborating with booking online services, or social media. For example, one of the travel agents had been promoting his tour packages through his own website for more than 10 years. He expressed that he also endorsed some preferred hotels as part of his tour packages on his website.

"I run my business with the help of the internet. In tourism industry, the internet is very useful as long as we know how to utilize it." - Mr B, Travel Agent

Hotel staffs in Yogyakarta were also showing high familiarity in using the ICT for tourist information service, such as destination guides, places of recommendation, and itinerary suggestions.

"On the desktop version, we provide a Google map, so people can estimate the distance between one place to another. Our website also features information about local attractions such as temple, historical sites, and handicraft." - Mr I, Hotel Staff

"We have our own website as part of our contribution to the tourism industry in Yogyakarta, it contains 3 days itineraries, 4 days itineraries, what destinations must be visited involving adventure, nature, event, or activities." - Ms J, Hotel Staff

It was revealed that the role of influencer such as bloggers and journalists are significant to endorse new tourism destinations, including the surrounding accommodations, services and facilities. Moreover, bloggers, YouTubers and Instagrammers already have their own solid followers or fan bases, therefore it would be easy to gain more exposure on Indonesia's tourism destinations through their social media accounts. 
"We are collaborating with bloggers, we have a monthly target to invite four bloggers or influencers from domestic or global to stay in our hotel and endorse our hotels' services and facilities. Now influencers are the most effective promotion tool." - Ms J, Hotel Staff

Meanwhile, few participants still find it more convenient to manage their business with less ICT interference. The reason was because there was no resource or skill to manage the web, or they felt that they had received enough income from the current business stream.

"I only use the email account from the website, that's it, because no one can manage the website." - Mr A, Travel Agent

"My customers mostly come from group tour. I hardly use the app, I have put my hotel in a hotel listing app, but there is only $20 \%$ of customers come from there." Ms K, Hotel Owner

One of the travel agents conveyed the challenge that he had thought he really wanted to optimize his tour and package promotion through online channel. He specifically pointed out that there was a lack of resources to manage his website since he run the business independently. Therefore, sometimes it needed a huge effort to serve on-site guests and handle online website at the same time.

"The constraint is the web maintenance because I handle it myself. When I have to do field guide activity with guests, it is rather difficult to update the latest info or respond quickly to any inquiry in my web." - MrC, Travel Agent

All in all, almost all of the participants exposed sound familiarity in using the ICT tools. It showed that they most likely will be confident to take up a new ICT tool if they believe that it will add values for their business sustainability. Therefore, there is a relation between current business practice and the research objective, which is offering a travel app as an alternative tool to support the support the tourism stakeholders' business purposes. 


\subsubsection{Future plan}

This theme focusses on thoughts and ideas for participants' future business plan. This theme is important to forecast how Extra can support their future business plan. Most of the participants expressed that they will keep using current tools for destinations package information and/or partnering with existing vendors such as Booking.com, Agoda, Traveloka, and Tiket.com. The latter two are local online airline ticketing and hotel booking services. They thought that existing apps are already ample to serve their needs, yet they also embrace any opportunity that enables them to operate their business more effectively. One of the travel agents planned to increase the percentage of online customers by upgrading his website.

"I am planning to update my website with more detailed info, innovations in the tour packages, including new destinations and additional benefit such as free airport transfer." - Mr C, Travel Agent

Meanwhile, one of the hotel staffs emphasized the importance of building customer loyalty. Therefore, he planned to develop the hotel's website by offering loyalty program in order to takeover customers from other online app channels and lock repeat customers. It was also confirmed by another participant who cited that an advanced feature in the hotel's website will give the hotel a chance to be more popular with tourists.

"This hotel's website will be equipped with 360-degree photos, so people won't only see static photos ... the 360-degree photos feature will raise the hotel's booking opportunity." - Mr I, Hotel Staff

However, there was a participant who claimed that although he was fully aware that the use of ICT can boost his business further, he didn't plan to promote his business through the internet in the near future due to financial restrictions to hire resources that will manage the website and social media. 
"The promotion will be successful if we can assure that someone is there to manage and maintain the social media for 24 hours." - Mr A, Travel Agent

All of the participants were confident about their future plans. However, there were relatively low expectations about features or services that they need most and give a better result for their business operation until they had been asked about ideas for a potential new travel app that they wish they should have.

\subsubsection{Response to Extra}

This theme highlights some opportunities that aroused from participants' responses with regards to the development of a potential new travel app. Some positive and innovative feedback were delivered by the participants indicating their grasp and experience in tourism business. These responses are valuable as a fundamental source of information to design a minimum viable product such as a travel app that not only offers a new feature but is also needed by the tourism providers. The main element that was implicitly exposed from the interviews for Extra was a feature that can encourage sound social interactions between tourists and tourism service providers.

"I will emphasize on social media since it is more personal and can directly answer all customers' needs." - Mr A, Travel Agent

"The role of social media is very important for us to communicate with customers, not just through Facebook and Instagram, but also through other channels." - Ms J, Hotel Staff

"Good reviews from check out guests is important to be maintained. It shows that we can serve our guests well, so other people will be confident to use our service based on previous guests' recommendation." - Mr B, Travel Agent

The above statements suggested that no matter how complete the information or promotion on the website or travel app, it will be inadequate unless there is a 'human touch' in it. A 
personal touch with potential or repeat customers is important to build customer trust and loyalty, as well as to facilitate the tourism service providers to be more approachable and offer a more personalized service.

Further, all of the travel agents confirmed that they needed a sort of tool that can make their business easier to manage. Operating as an independent travel agent, most of them need a digital tool that can facilitate them to update travel packages information or services more effectively.

"A lot of tour guides are currently cooperating with hotels to offer tour packages. So, it would be great if there is a travel app that enables tour guides to stand alone offering tour packages with pricing information and customer review." - Mr B, Travel Agent

"A travel app is very much needed for me or other tourism players, since we can also contribute in Extra. It's the place where we can promote our product and service." Mr C, Travel Agent

Likewise, most of the hotel staffs agreed that they are in the era of competition with other hotels, other booking channels, or other place of destinations. Therefore, it is important to win the competition by emphasizing their innovative facilities or services. The presence of a potential travel app can certainly accommodate this requirement. For the staffs of independent hotels, there is a flexibility to create their own contents and features.

"Apps that can integrate many products. I have a villa, but I don't have any package tour. I need a travel app in which I can access package tours information instantly without contacting many travel agents one by one to find the most suited tour packages for my customers." - MrF, General Manager

"Sometimes a travel app only provides general information such as hotels' locations, stars, and prices. If people want to know more about what kind of activities they can do in a certain area, the app should be ready to handle this and have comprehensive information." - Mr I, Hotel Staff 
As for a chain hotel, the hotel staff expressed that it was not feasible to insert local content in the official hotel's website since all of the website content was managed by the headquarter. Therefore, it is necessary to have an alternative tool to communicate new local attractions as well as local events.

"A travel app that can show people what to do or provide complete guidance when they come to Yogyakarta, right now we don't have that kind of media." - Ms J, Hotel Staff

A response from the government representative was also confirming the needed of a travel app that can facilitate tourists' bookings and inquiries on a single platform. It was hinted that collaboration with third-party tourism providers were required to provide a tourist friendly app that enables a simple process for customized package reservations and transactions.

"A website or app that allows people to choose where they want to go, what transportation they will use, where to stay, and finally they can make a payment as well, so it offers all-in package, maybe the government can't manage it directly, but we can collaborate with the tourism promotion agency." - Ms G, Government Staff

All in all, the responses from different participants regarding their desired features for Extra are summarized as below:

- Platform for interaction between tourism service providers and tourists

- Tour packages offering with pricing information and customer review

- Complete information about local attractions, accommodations and facilities

- Destination guides

\subsubsection{Summary}

The interview with 11 tourism stakeholders produced valuable feedback such as challenges in the tourism industry, current ICT implementations and future plans related to tourism business activities, as well as opportunities for a potential new travel app. By far, the findings 
of this research complement the previous study about the significant role of ICT to support tourism stakeholders' trip planning and reservation arrangement (Ray, et. al, 2011), as well as products and services promotion (Buhalis \& Law, 2008; Caraivan, 2017). Most of the participants' responses confirmed the connection between current challenges and the research gap, which is the importance of information availability to increase the awareness of the tourism destinations in Indonesia. Some feedbacks emphasize the need of a supporting tool to provide $24 / 7$ customer support, direct communication with prospective tourists (Digiorgio, 2016), and global acknowledgment (Ray, et. al, 2011; Mihalcescu, Sion \& Marginean, 2016).

Therefore, the findings of this study seem to validate the objective of this research, which is exploring an opportunity of a potential new travel app that can perform as a media to extend the information about local attractions, potential destinations, and tourism events to international tourists, as well as to support the tourism service providers' daily business activities. Below are the several value propositions of a potential new travel app that can be explored in light of tourism stakeholders' feedback:

- Provides more approachable contact between tourism service providers and tourists.

- Accommodates the lack of skill, time or resource to provide updated tourism information or manage social media regularly.

- Encourages more efficient business operation since all of the products and services information will be managed in a single platform.

Still, there is a little evidence that indicates the importance of loyalty rewards (Hasen, 2012; Wang, Xiang, \& Wang, 2016), and customer history profiling (Wirtz, Schilke, \& Ullrich, 2010) to increase customer loyalty and capture new business prospects. This aspect may not be revealed due to the limited time of the interview or its low implication in the tourism business in Indonesia.

This key area will be explored further along with value proposition opportunities in the subsequent quantitative data collection, namely the online questionnaire. The quantitative research is needed to validate the key areas of qualitative research findings, as well as to form the business case for the minimum viable product of the potential travel app. 


\subsection{Finding and analysis - Interview with Tourists}

The interviews with tourists were held with a semi-structured guideline that comprises these following 2 questions:

1. How have you used the digital technology for travel related matters?

2. What expectations do you have for a potential new travel app in Indonesia?

There were 37 participated tourists in this research, varied from different origins and place of interests. The types of tourists are also diverse such as singles, couples, group of friends and families. All of the participants were considered as anonymous and the detail of the number of participants along with places of the interview is presented in Table 3.2 below.

\begin{tabular}{|l|c|c|}
\hline \multicolumn{1}{|c|}{ Description } & Total & $\%$ \\
\hline Interview Location & & \\
\hline Bali & 21 & 57 \\
\hline - Beach & 5 & 14 \\
\hline - Monkey Forest & 6 & 16 \\
\hline - Shopping Street & 3 & 8 \\
\hline - Art Gallery & 4 & 11 \\
\hline - Temple & 3 & 8 \\
\hline Yogyakarta & 16 & 43 \\
\hline - Temple & 4 & 11 \\
\hline - Royal Palace & 4 & 11 \\
\hline - Beach & 3 & 8 \\
\hline - Shopping Street & 5 & 14 \\
\hline Type of Visitor & & \\
\hline Single & 7 & 19 \\
\hline Couple & 15 & 41 \\
\hline Group of Friends & 12 & 32 \\
\hline Family & 3 & 8 \\
\hline Area of Origin & & \\
\hline Europe & 29 & 78 \\
\hline Australia & 5 & 14 \\
\hline Africa & 2 & 5 \\
\hline USA & 1 & 3 \\
\hline
\end{tabular}

Table 3.2 Tourist Participants Figures 
It was considered to conclude the tourist interview after the $37^{\text {th }}$ participant since the responses had reached the saturation point, meaning that the interviewer had received similar responses in several attempts of interviews (Guest, Bunce, \& Johnson, 2006).

The next sections discuss and analyze the 2 themes or key topics that were derived from the interview results as previously described in the data analysis section.

\subsubsection{Current ICT practice}

Almost all of the participants demonstrated good familiarity in using ICT with regard to their traveling activities. Moreover, some established travel apps have been consistently revealed as part of participants' essential tools. The findings and analysis of current ICT implementations for tourists are divided into two sub-sections, namely pre-trip and during the trip.

\subsubsection{Pre-Trip}

In general, most of the participants have used the ICT related components for their pretraveling purposes such as to book hotel, airline, and travel packages. Further, the majority of responses confirmed that the most favorite online travel agencies for hotel and airline booking are Booking.com ${ }^{3}$ and Skyscanner ${ }^{4}$ respectively. There are also some significant responses regarding booking accommodation through AirBnb ${ }^{5}$.

"I always use Booking.com. It's so simple because I already have the account, so no need to fill guest details anymore for every booking." - Male, Australia

"Recently, I find accommodation that fits my budget and expectation through AirBnB."

- Female, France

\footnotetext{
3 a website for lodging reservations.

${ }_{4}$ a travel fare aggregator website.

${ }^{5}$ an online marketplace and hospitality service for accommodation and tourism experience reservations.
} 
The motivation of using online booking services to book accommodation in advance was because they wanted to feel confident with the accommodation availability and get sufficient information about the accommodation's price and facilities prior to their arrivals. A tourist in Bali expressed that he would be traveling around Bali for two weeks and had made several hotel reservations through online booking channels before his arrival. Prior to the hotel booking, he checked out the hotel options that were located near the intended location or attraction to get a value comparison.

"I use the hotel search based on the location of places that I need to visit according to my itineraries, so I don't stay in the same hotel most of the time." - Male, Italy

Other aspects that tourists benefited from ICT tools before their trip were related to travel itineraries arrangement and reviews information. Mostly, they arranged their itineraries based on tourism information and destinations reviews from some established travel platforms such as Trip Advisor and Lonely Planet.

"So far, I trust reviews from TripAdvisor, I think the reviews are honest and fair, so I won't go to hotels or places that have bad reviews." - Female, Czech Republic

"I always get information from Lonely Planet about cool places to visit, unique food to try, tips about things to do or things that you should not do in certain countries." Male, UK

A family from France expressed that they booked their trip to Bali from a French travel agent website called Voyage Prive since they were more comfortable to use a website that spoke their language.

"We booked a travel package for this trip from Voyage Prive. It's just because we are afraid to have misleading information if we use English websites." - Female, France

Another channel such as an independent travel blog was perceived to be useful as well to give them ideas on how to plan their trips. The use of travel blogger reviews as a media to gather 
information about tourism destinations was implemented by one of the tourists that was planning to have 6 weeks traveling around Indonesia.

"I look for the information about Indonesia's tourist attractions from my Spanish friend's travel blog." - Female, Spain

\subsubsection{During the trip}

The use of ICT for on-site trip assistance has been identified as well during the interview with tourist participants. There were numerous ways in which tourists employed the internet access while they were doing their trips, such as to search local attractions information, explore the new touristic location, guide the trip with location map apps, and book services such as online taxi or food delivery.

In general, tourists want to be kept updated with the latest online information about local destinations and events during their trips. They need to assure that they do not miss any interesting places or events while they are still in the location.

"While I am here, I want to explore everything. I found information about tonight's leather puppet show from a local website, so my plan for tonight is to go there and watch it." - Female, Argentina

Further, some spontaneous tourists were keen to regularly checked local tourism website to get information about updated local events and alternative things to do since they didn't have any planned itineraries.

"Sometimes I get the information about new places or upcoming events from local people or other tourists, then I search the information myself through an online website." - Male, Netherlands 
Some of the participants used navigation apps such as Waze ${ }^{6}$ and Google Maps ${ }^{7}$ regularly to get direction to their intended locations. The utilization of journey planning apps such as Rome $2 \mathrm{Rio}^{8}$ was also revealed by a few of participants to gain information about travel options i.e. planes, train, bus, car driving, or a combination of modes.

"Waze and Google Maps are very useful to show me the direction of places that I want to go to." - Male, Germany

"It's always easy to get all of the information I need from apps. I have Rome2Rio app and I use it all the time for travel option reference." - Male, UK

Further, the use of ICT was expanded in every angle of participants' activities include online transportation booking, tour package booking, and food delivery. It is interesting to discover that some of the participants had already known a local app called GoJek ${ }^{9}$. This app, although intended for locals, had been employed by participants as well due to its comprehensive services such as Go Car (transportation service), Go Food (food delivery) and Go Send (parcel delivery).

"When I want to taste local food but don't know where the outlet location is, I simply order Go Food." - Female, Australia

"I use Go Car to get anywhere in this city. You see, I am using it now. I have put the order and now I am waiting for the driver to pick me up." - Female, Senegal

It is obvious that-digital technology has been playing an important role to support the tourism activities in a more effective and simpler way. Further, the need of ICT for tourists has been increased gradually from basic needs such as to search information and book traveling amenities to more advanced requirements such as to give on the spot destination guidance

\footnotetext{
${ }^{6}$ a GPS navigation software app.

${ }^{7}$ a web mapping service developed by Google.

${ }^{8}$ an online multimodal transport search engine.

${ }^{9}$ a local app that specializes in ride-hailing and logistics.
} 
and recommendation. In order to accommodate these needs, many of the prominent travel apps have been constantly applied by tourists before and during their trips. However, as indicated by most of the participants, there is also an opportunity to create features on a travel app that they wish they would use for a better travel experience.

\subsubsection{Response to Extra}

Most of the participants responded positively with the idea of creating a new potential travel app that would suit their needs. Due to the various features that were implied by the participants, this section is divided into three sub-sections, which are destination information, trip planning assistance, and other features.

\subsubsection{Destination information}

The most significant feature that was desired by more than half of the participants is a userfriendly destination guidance. A first-time visitor tends to have no idea on what kind of activities they should do in a certain destination. The first effort that they make before traveling is to find complete information about recommended accommodations and things to do by searching in travel-related websites, blogger reviews or ask questions in travel communities' mobile platforms such as TripAdvisor and Lonely Planet. It is important to have sufficient information beforehand in order to obtain a better understanding of places that they want to visit. Therefore, some of the participants mentioned that they needed a travel app that will help them to get comprehensive information about things to do and destination information such as nearby attractions, hotels, cafes or restaurants. In addition, the feature that was required by a couple of tourists was the ability to keep retrieving the information in case they don't have an internet plan, a WiFi access or they are traveling in a remote area that does not has an internet network coverage.

"I need a digital map to show the city's attraction, it's because Google map doesn't always give a complete direction." - Female, Switzerland

"Just a simple local app featuring attraction and things to do." - Female, Senegal 
"Showing distance and information on how to get there just like an Uber app, so I can choose what kind of transportation I am going to use by looking at the travel time and the price." Male - Australia

\subsubsection{Trip Planning Assistance}

The next thing to do after collecting trip information is to plan a travel itinerary. Most of the participants had performed their trips individually based on a travel itinerary that they created earlier. However, there are also some cases that tourists such as a group of friends and families still feel uncomfortable to travel by themselves in an unfamiliar country, although they had collected travel information through online research. The presence of local guide is considered important to get more exploration of destinations, attractions, and activities to do. In addition, one of the participants believed that she could get more information by booking 1-day tour package at her first arrival. Then she asked directly to the tour guide about the next interesting places to visit in order to create her own traveling itinerary for the following day. The potential travel app is relevant with this kind of need since it can be designed to showcase local tour guides, include with their highlight tour packages, prices, customer reviews, as well as access to communicate directly with potential tourists for customized travel itinerary arrangements.

"When it's your first time to visit a country for holiday, the first thing you are looking for is an app that provides trip planning or tour package." - Female, Switzerland

"[A travel app that] offers tour package information for a segmented market like for single, family, couple, with several budget options." - Female, France

A tourist that booked an arranged guided tour hinted that a favorable travel app was not only chosen by its availability to offer complete tourism information and best deals but supposed to be trustful as well to build loyalty from its user.

"A user-friendly apps that provide detail and transparent information about itineraries and its pricing, and there is absolutely no hidden cost." - Male, Netherlands 


\subsubsection{Other Features}

This section presents other desired features that were expressed less frequently compared to the above two features. A distinctive wish list feature was stated by a tourist who already spent two weeks in Bali and planned to stay for another two weeks. He conveyed that at the moment there was no app that provided a motorbike rental option. Traveling in a congested city like Bali triggers some tourists to use an alternative transport mode such as a motorbike or bicycle.

"Practically, I go anywhere by motorbike. But I can't find apps that offer motorbike rental. Some locals offer me different price ranges. It would be good if there's an app that offers motorbike rental, or probably offer a cheaper deal if it's booked in advance." - Male, Austria

There was also a wish list feature related to calculation assistance of shared expenses. One of the participants conveyed that she usually paid her expense for accommodation, meal and transportation collectively with her friends. At the end of the trip, sometimes it needs an extra effort to distribute the cost share of every member in the group.

"I used to travel with friends and we usually stay in different hotels. So I need an app that can record group expenses, especially for accommodation expense, and at the end of the trip it can give an exact figure on how much money that we owe to each other." - Female, France

Most of the participants also considered the importance of price comparison. For example, different booking channels can offer different prices for the same hotel or flight. Currently, there are several travel apps that have provided a price comparison feature such as Trivago and Skyscanner. Still, there are tourists that did not recognize that this feature is already available on some established travel apps and they wish that they could have it. As such, Extra could be considered to address this demand as well if it is confirmed by the next validation process (quantitative research) and feasible business case. 


\subsubsection{Summary}

The wide range of travel websites and apps that have been used by tourist participants as part of their traveling routines illustrate the importance of ICT in the tourism industry. As such, the findings of this research show a significant connection with the literature study in terms of the role of ICT in enhancing travel experience (Buhalis, Law, 2008; Muneta, et.al., 2013) by providing destination information and trip planning assistance (Hyde, 2008; Caraivan, 2017). Similar with Benyon's (2014) study, an adequate ICT practice was demonstrated by tourist participants to inquire information such as destination guidance, location map, and trip planning. In addition, the internet has enabled tourists to obtain competitive prices, updated information, as well as access to communicate with tourism service providers and make transactions. Further, as indicated by several participants, there are potential new features that can be developed in a new travel app for a better traveling experience, such as off-line destination information, customized tour assistance, and additional booking services such as motorbike and pocket WiFi rental.

However, as suggested by current literatures, there are also advanced features for trip assistance such as augmented reality technology (Curtin, 2017) and smart navigation with audio and tactile feedback (Wei, Reni, \& Neill, 2014) that were not exposed during the interview as required features. Again, this condition might occur as a result of the quick duration of interviews. Therefore, both of revealed and unrevealed desired features will be explored further through quantitative research or online questionnaire.

\subsection{Summary of the Qualitative Interview}

The qualitative interview with tourism service providers and tourists has brought valuable findings for the depth of this study. The findings of current ICT implementation and practice illustrate the sound digital capability that has been possessed by most of the participants as well as the significant role of ICT to support participants' travel-related activities. In response to a question about what expectations do the participants have for a potential new travel app, there is a noticeable correlation between the tourism stakeholders' and tourists' required features. The most desired features of both parties are related to destination 
information and customized travel package assistance. Further, as also stated in the previous discussion, these findings will be used for the development of the quantitative research. The identified key points will be specified in the online questionnaire in order to have more narrowed findings as part of the validation stage in the process of creating a potential new travel app. Below is the summary of features that are desired by tourism stakeholders only, tourists only, both of tourism stakeholders and tourists, and features that are considered important from the literature study but unidentified during the data collection.

\begin{tabular}{|c|c|c|c|}
\hline \multirow{2}{*}{ Suggested Features } & \multirow{2}{*}{ Literature } & \multicolumn{2}{|c|}{ Qualitative Findings } \\
\hline & & $\begin{array}{c}\text { Tourism } \\
\text { Stakeholders } \\
\end{array}$ & Tourists \\
\hline $\begin{array}{l}\text { Destination information (local attractions, } \\
\text { accommodations and facilities) }\end{array}$ & $\mathbf{v}$ & $\mathbf{v}$ & $\mathbf{v}$ \\
\hline $\begin{array}{l}\text { Destination guide (location map, route } \\
\text { planning) }\end{array}$ & $\mathbf{v}$ & $\mathbf{v}$ & $\mathbf{v}$ \\
\hline $\begin{array}{l}\text { Platform for interaction between tourism } \\
\text { service providers and tourists }\end{array}$ & $\mathbf{v}$ & $\mathbf{v}$ & $\mathbf{v}$ \\
\hline $\begin{array}{l}\text { Customized tour packages with pricing } \\
\text { information }\end{array}$ & $\mathbf{v}$ & $\mathbf{v}$ & $\mathbf{v}$ \\
\hline Loyalty reward & $\mathbf{v}$ & $\mathbf{v}$ & \\
\hline Multi language & & $v$ & $v$ \\
\hline 24/7 customer support & $\mathbf{v}$ & $\mathbf{v}$ & $\mathbf{v}$ \\
\hline Customer reviews & $\mathbf{v}$ & $\mathbf{v}$ & $\mathbf{v}$ \\
\hline Instant booking & $\mathbf{v}$ & & $\mathbf{v}$ \\
\hline Blog reviews & $v$ & $\mathbf{v}$ & $v$ \\
\hline $\begin{array}{l}\text { Trip essentials rental information (motorbike, } \\
\text { bicycle, pocket WiFi) }\end{array}$ & & & $\mathbf{v}$ \\
\hline Cost share calculation & & & $\mathbf{v}$ \\
\hline Augmented reality (AR) & $\mathbf{v}$ & & \\
\hline Virtual reality (VR) & $\mathbf{v}$ & & \\
\hline
\end{tabular}

Table 3.3 Features Summary

\subsection{Results and Analysis - Questionnaire}

As part of the mixed methods research design of this study, the online questionnaire was carried out after the qualitative interview in order to validate the findings of the qualitative interview for the development of a minimum viable product of Extra. It was necessary to conduct this quantitative phase to specify the critical success factors of Extra according to a larger sample of the targeted population. The topics of questions focused on devices and channels that were used to gather travel information, features preference, purchase 
intention, social media engagement, and demographic information. The questionnaire comprised questions as illustrated in table 3.1 below:

\begin{tabular}{|c|c|}
\hline \multicolumn{2}{|c|}{ Have you ever visited Indonesia in the past five years? } \\
\hline Yes & No \\
\hline $\begin{array}{l}\text { How many times have you visited Indonesia in the past } \\
\text { five years? }\end{array}$ & Are you planning to go to Indonesia anytime soon? \\
\hline $\begin{array}{l}\text { Which of these channels did you use to book your last trip } \\
\text { to visit Indonesia's tourism attractions? }\end{array}$ & $\begin{array}{l}\text { Which of these channels did you use to book your trip } \\
\text { to Indonesia? }\end{array}$ \\
\hline $\begin{array}{l}\text { During your last trip to visit Indonesia's tourism } \\
\text { attractions, what devices did you use to obtain online } \\
\text { information about places to visit and things to do? }\end{array}$ & $\begin{array}{l}\text { Which of these channels you usually use to find } \\
\text { information about Indonesia? }\end{array}$ \\
\hline $\begin{array}{c}\text { Which of these channels did you use during your last trip } \\
\text { to visit Indonesia's tourism attractions to obtain } \\
\text { information about places to visit and things to do? }\end{array}$ & $\begin{array}{l}\text { During your last international holiday trip, what devices } \\
\text { did you use to obtain online information about places to } \\
\text { visit and things to do? }\end{array}$ \\
\hline $\begin{array}{l}\text { Thinking about your last trip to visit Indonesia's tourism } \\
\text { attractions overall, how satisfied were you with the } \\
\text { availability of information to help you plan your trip? }\end{array}$ & $\begin{array}{l}\text { Which of these channels did you use during your last } \\
\text { international holiday trip to obtain information about } \\
\text { places to visit and things to do? }\end{array}$ \\
\hline & $\begin{array}{l}\text { Thinking about your last international holiday trip } \\
\text { overall, how satisfied were you with the availability of } \\
\text { information to help you plan your trip? }\end{array}$ \\
\hline \multicolumn{2}{|c|}{ Questions for all respondents } \\
\hline \multicolumn{2}{|c|}{ When you are deciding which travel application to use, what features are most important to you? } \\
\hline \multicolumn{2}{|c|}{ And what features are least important to you? } \\
\hline \multicolumn{2}{|c|}{$\begin{array}{l}\text { If a travel application that covers your most important features and all you need to know about Indonesia were } \\
\qquad \text { available today, how likely would you be to use it? }\end{array}$} \\
\hline \multicolumn{2}{|c|}{ And what kind of offer would you prefer to use this app? } \\
\hline \multicolumn{2}{|c|}{ What price would you be willing to pay for this app? } \\
\hline \multicolumn{2}{|c|}{ During or after your trip overall, did you do any of the following? } \\
\hline \multicolumn{2}{|c|}{$\begin{array}{c}\text { Based on your past experience, what else would you like to see in an app that can improve your traveling } \\
\text { experience? }\end{array}$} \\
\hline \multicolumn{2}{|c|}{ What is your gender? } \\
\hline \multicolumn{2}{|c|}{ What is your age? } \\
\hline In which country do y & ou currently reside? \\
\hline
\end{tabular}

Table 3.1 List of Questions

The next sections discuss and analyze variables that were emerged from the online questionnaire result. 


\subsubsection{Demographic Information \& Travel Experience to Indonesia}

The profile of respondents who were managed to complete the questionnaire is outlined at Table 3.2 below.

\begin{tabular}{|c|c|c|}
\hline Total respondents & $\mathrm{N}=129$ & $100 \%$ \\
\hline \multirow{2}{*}{ Gender } & Male (55) & $43 \%$ \\
\hline & Female (73) & $57 \%$ \\
\hline & & \\
\hline \multirow{4}{*}{ Age Group } & $18-24(25)$ & $19 \%$ \\
\hline & $25-34(56)$ & $43 \%$ \\
\hline & $35-44(38)$ & $29 \%$ \\
\hline & 45 and over (10) & $8 \%$ \\
\hline & & \\
\hline \multirow{6}{*}{ Country of Residence } & Target market countries (74) & $57 \%$ \\
\hline & Asia (12) & $9 \%$ \\
\hline & Europe (9) & $7 \%$ \\
\hline & America (6) & $5 \%$ \\
\hline & Africa (3) & $2 \%$ \\
\hline & The Pacifics \& New Zealand (25) & $20 \%$ \\
\hline & & \\
\hline \multirow{2}{*}{ Have visited Indonesia } & Yes (77) & $60 \%$ \\
\hline & No $(52)$ & $40 \%$ \\
\hline
\end{tabular}

Table 3.2 Respondents' Profile

There were 129 respondents from the wider sample of email invitation and social media. From all of these respondents, the percentage of female respondents (57\%) was higher than male respondents (43\%). The age distribution of respondents was concentrated in a range of $25-34$ age band (43\%), followed by $35-44$ age band (29\%) and $18-24$ age band (19\%). Since social media had been utilized to distribute the survey link, it is obvious that young respondents, which classified between $18-34$ years old, were the majority of the sample (62\%). Then, in order to simplify the analysis for the country of residence, the decision was made to categorize the country of residence into 6 groups based on target market countries and regions as follows:

1. Target market countries: Indonesia's Ministry of Tourism has targeted particular countries to be the market of their tourism campaign ("Wonderful Indonesia Campaign - Visual + Movement," 2015). These countries are Singapore, Malaysia, Australia, China, Japan, South Korea, Taiwan, the Philippines, the United States, the United Kingdom, France, India, Germany, the Netherlands, the Middle East countries and Russia. 
2. Asia: all Asian countries except China, Japan, South Korea, Taiwan, and the Middle East countries which are included in the target market countries.

3. Europe: all European countries except the United Kingdom, France, Germany, Russia, and the Netherlands which are included in the target market countries.

4. America: excluding the United States of America, which is included in the target market countries.

5. Africa

6. The Pacifics and New Zealand

The result of the questionnaire shows that more than half of the respondents were from target market countries (57\%), followed by respondents from Pacific countries and New Zealand (20\%). The proportion of respondents from Asian countries (9\%) and European countries (7\%) was almost similar, and the smallest percentage of respondents was from Africa (2\%). Initially, the purpose of including the country of residence question was to pinpoint the potential countries to market Extra. With the largest percentage of respondents was from target market countries, it is confirmed that the target market of Extra will reflect to target market countries of the government's tourism campaign. However, it is surprising that the second largest proportion was from the Pacific countries and New Zealand instead of Asian countries which are closer to Indonesia. It is suspected that this anomaly occurred since the questionnaire was distributed to international students' communities in New Zealand as well. Further, since not all countries were represented in the survey, the sample size of respondents might not be sufficient as the representative of the whole potential tourists of Indonesia.

Among respondents who had not visited Indonesia, most of them were from target countries (48\%), followed by the Pacific countries and New Zealand (15\%). Most of the respondents who had not visited Indonesia felt that they were keen to visit Indonesia if they found interesting places or attractions (65\%). In addition, there were $25 \%$ of respondents who showed their affirmation to visit Indonesia and were in process of searching for further information about Indonesia. These respondents represented potential visitors of Indonesia that may lead to potential users of Extra. Still, there were five respondents from the Pacific countries and New Zealand who had no intentions to visit Indonesia and commented that 
traveling to Indonesia was costly. This finding is linked with the research problem, which is lack of available information regarding Indonesia's tourism destinations. It is assumed that this perception might arise because of their brief observation on the high-priced of return airline cost from their country of origin to Indonesia. However, if they could view it as a whole trip package, including inexpensive accommodation, meal, and transportation on location, they might consider visiting Indonesia in the near future.

\subsubsection{ICT Usage Behavior}

Table 3.3 illustrated channels that were used to book respondents' itineraries of their last trip to Indonesia.

\begin{tabular}{|l|r|r|}
\hline \multicolumn{1}{|c|}{$\mathbf{N}=\mathbf{7 7}$} & \multicolumn{1}{c|}{ Count } & \% of cases \\
\hline Booking mobile apps (e.g. Airbnb, Agoda) & 53 & $69 \%$ \\
\hline Booking websites (e.g. Expedia, Skyscanner) & 40 & $52 \%$ \\
\hline Hotel/flight direct channels (website/call center) & 22 & $29 \%$ \\
\hline Travel agent & 12 & $16 \%$ \\
\hline Other (please specify) & 3 & $4 \%$ \\
\hline Total responses & 130 & $\mathbf{1 6 9 \%}$ \\
\hline
\end{tabular}

Table 3.3 Booking Channel Preferences

From 77 respondents who had visited Indonesia, the questionnaire result showed that the most utilized channel was booking mobile apps, that was mentioned by 53 respondents (69\%). Then, the second most preferred booking channel was booking websites (52\%). It is followed by booking directly to hotel/flight direct channels (29\%). The least preferred method was by employing travel agent services (9\%). It is apparent that utilizing offline channel such as travel agent was least desired at the moment due to the rapid growth of ICT, which is aligned with literature reviews that tourist planning behavior is changed by the emerging of ICT (Stamboulis, Skayannis, 2003; Xiang, Magnini, Fesenmaier, 2015). Further, this result confirms that the minimum viable product of this research is a travel app since it is more preferred than a travel website. In order to have a validation on the most preferred device that was used by respondents to obtain travel information, table 3.4 represents the 
proportion of preferred devices to obtain online information during the trip of respondents who had visited Indonesia or not.

\begin{tabular}{|c|c|c|c|c|}
\hline \multirow[t]{2}{*}{ Device preference } & \multicolumn{2}{|c|}{$\begin{array}{l}\text { Respondents who had } \\
\text { visited Indonesia } \\
(\mathrm{N}=77)\end{array}$} & \multicolumn{2}{|c|}{$\begin{array}{l}\text { Respondents who had } \\
\text { not visited Indonesia } \\
\text { (referred to last } \\
\text { international holiday } \\
\text { trip) }(\mathrm{N}=52)\end{array}$} \\
\hline & Count & $\%$ of cases & Count & $\%$ of cases \\
\hline A smartphone/internet on a mobile phone & 72 & $94 \%$ & 44 & $85 \%$ \\
\hline A laptop & 34 & $44 \%$ & 33 & $63 \%$ \\
\hline A tablet $P C$ & 15 & $19 \%$ & 13 & $25 \%$ \\
\hline A desktop at the hotel/internet cafe & 5 & $6 \%$ & 2 & $4 \%$ \\
\hline None of the above & 1 & $1 \%$ & 0 & $0 \%$ \\
\hline Other (please specify) & 1 & $1 \%$ & 1 & $2 \%$ \\
\hline Total responses & 128 & $166 \%$ & 93 & $179 \%$ \\
\hline
\end{tabular}

Table 3.4 Device Preferences

With regard to respondents who had not visited Indonesia, their responses referred to their last international holiday trip. The result that emerged from both types of respondents shows that a smartphone is the most preferred device to obtain online information. The fact that mobile phone was the most preferred device to access travel information during the trip is relevant with Urry (2001) study who suggested that tourists are keen to utilize mobile devices during their dynamic movement from one place to another. In particular, the number of respondents who selected a smartphone for those who had visited Indonesia was larger (94\%) than respondents who had not visited Indonesia (85\%). It suggests that almost all of respondents with travel experiences to Indonesia used a smartphone compared to respondents who traveled to other countries. Therefore, this result emphasizes that Extra will be designed solely as a mobile app as it is more relevant to Indonesia's visitors.

In order to have more insight regarding respondents' most desired information channel for the benchmark analysis of Extra, Table 3.5 portrays the percentage of chosen channels that were used by respondents to obtain travel information during the trip to Indonesia or the last international holiday trip. 


\begin{tabular}{|c|c|c|c|c|}
\hline \multirow[t]{2}{*}{ Channel preference } & \multicolumn{2}{|c|}{$\begin{array}{l}\text { Respondents who had } \\
\text { visited Indonesia } \\
(\mathrm{N}=77)\end{array}$} & \multicolumn{2}{|c|}{$\begin{array}{l}\text { Respondents who had } \\
\text { not visited Indonesia } \\
\text { (referred to last } \\
\text { international holiday } \\
\text { trip) ( } N=52 \text { ) }\end{array}$} \\
\hline & Count & $\%$ of cases & Count & $\%$ of cases \\
\hline Google search & 60 & $78 \%$ & 44 & $85 \%$ \\
\hline $\begin{array}{l}\text { Travel community websites (TripAdvisor, Lonely } \\
\text { Planet, etc) }\end{array}$ & 52 & $68 \%$ & 28 & $54 \%$ \\
\hline Asking locals & 36 & $47 \%$ & 10 & $19 \%$ \\
\hline Asking other travelers & 35 & $45 \%$ & 19 & $37 \%$ \\
\hline The official tourism local websites & 32 & $42 \%$ & 18 & $35 \%$ \\
\hline Blog posts/reviews & 31 & $40 \%$ & 12 & $23 \%$ \\
\hline Printed booklets/brochures at hotel's reception desk & 18 & $23 \%$ & 11 & $21 \%$ \\
\hline $\begin{array}{l}\text { Printed booklets/brochures at the tourism } \\
\text { information center }\end{array}$ & 10 & $13 \%$ & 7 & $13 \%$ \\
\hline $\begin{array}{l}\text { Printed booklets/brochures provided by tour } \\
\text { operators }\end{array}$ & 7 & $9 \%$ & 11 & $21 \%$ \\
\hline Other (please specify) & 4 & $5 \%$ & 1 & $2 \%$ \\
\hline TOTAL & 285 & $370 \%$ & 161 & $310 \%$ \\
\hline Average number of choices per respondent & 4 & & 3 & \\
\hline
\end{tabular}

Table 3.5 Channel Preferences

The result shows that each respondent who had visited Indonesia selected 4 channels on average, while each respondent who had not visited Indonesia chose 3 channels on average. It indicates that respondents used multiple sources to gather travel information and online channels were more desired than offline channels such as printed booklets/brochures. In more detail, the result signifies a similar profile from both types of respondents that the Google search was the most preferred channel to obtain travel information (78\% and 85\%), followed by travel communities' websites such as Lonely Planet and Trip Advisor (68\% and 54\%). Specifically, the proportion of utilizing travel communities' websites for respondents who had travel experiences to Indonesia was larger (68\%) than respondents who had no experiences of visiting Indonesia. It suggests that information channels such as online communities are relevant to Indonesia's tourism awareness context. Further, the result also displays that almost half of respondents who had visited Indonesia preferred asking locals to gain travel information (47\%), which is quite contrast with respondents who had not visited Indonesia (19\%). Therefore, this result corroborates the initial purpose of Extra, which is to provide tourism service and information through interaction between tourists and hosts. 
In order to examine further the behavior of choosing information channels based on respondents' visit frequencies, Table 3.6 presents a confirming result that the first and second most preferred information channels across all visit frequencies were the Google search and travel communities' websites.

\begin{tabular}{|c|c|c|c|c|}
\hline Channel preference $(\mathrm{N}=77)$ & $\begin{array}{l}\text { Once } \\
(N=29)\end{array}$ & $\begin{array}{l}\text { Twice } \\
(\mathrm{N}=\mathbf{2 8})\end{array}$ & $\begin{array}{l}3 \text { times } \\
(\mathrm{N}=11)\end{array}$ & $\begin{array}{l}\text { More than } 3 \\
\text { times }(\mathrm{N}=9)\end{array}$ \\
\hline Google search & $86 \%$ & $68 \%$ & $82 \%$ & $78 \%$ \\
\hline $\begin{array}{l}\text { Travel community websites (TripAdvisor, } \\
\text { Lonely Planet, etc) }\end{array}$ & $66 \%$ & $64 \%$ & $73 \%$ & $78 \%$ \\
\hline Asking other travelers & $55 \%$ & $36 \%$ & $27 \%$ & $67 \%$ \\
\hline Asking locals & $48 \%$ & $46 \%$ & $45 \%$ & $44 \%$ \\
\hline $\begin{array}{l}\text { The official website of Indonesia tourism - } \\
\text { Wonderful Indonesia }\end{array}$ & $38 \%$ & $43 \%$ & $55 \%$ & $33 \%$ \\
\hline Blog posts/reviews & $28 \%$ & $43 \%$ & $45 \%$ & $67 \%$ \\
\hline $\begin{array}{l}\text { Printed booklets/brochures at hotel's } \\
\text { reception desk }\end{array}$ & $17 \%$ & $25 \%$ & $45 \%$ & $11 \%$ \\
\hline $\begin{array}{l}\text { Printed booklets/brochures provided by tour } \\
\text { operators }\end{array}$ & $10 \%$ & $4 \%$ & $27 \%$ & $0 \%$ \\
\hline $\begin{array}{l}\text { Printed booklets/brochures at the tourism } \\
\text { information center }\end{array}$ & 7\% & 7\% & $36 \%$ & $22 \%$ \\
\hline Other (please specify) & $7 \%$ & $7 \%$ & $0 \%$ & $0 \%$ \\
\hline
\end{tabular}

Table 3.6 Channel Preferences Based on Visit Frequencies

There is also an interesting fact that asking locals were selected by almost half of respondents across all visit frequencies, implying that local recommendations were essential for them to plan their trip. Moreover, regardless of their frequent visit experience, around two-third of respondents who had visited Indonesia more than three times considered asking other travelers and blog posts/reviews would enrich their travel insights. This result indicates the demand of respondents to connect with other people to find inspirations or ideas to make trip decisions. On the case of the official website of Indonesia tourism - Wonderful Indonesia, this channel was less preferred by respondent who had visited Indonesia once (38\%) than respondents who had visited Indonesia three times (55\%). It implies that first time visitors might not be aware with this website to retrieve travel information. Therefore, Extra will be able to support the Wonderful Indonesia website to promote Indonesia's tourist destinations. 
Since there were multiple channels used by respondents to gather travel information, this research intends the explore which channels that gave respondents the most satisfaction level. Identifying the most satisfying channels of travel information is essential as a reference for the development of the potential travel app. In order to identify the level of satisfaction, the 5-point Likert scale was implemented in the questionnaire with its scale attributes, namely extremely satisfied (5), satisfied (4), neutral (3), dissatisfied (2), and extremely dissatisfied (1).

\begin{tabular}{|c|c|c|c|c|}
\hline \multirow[t]{2}{*}{ Channel preference $(\mathrm{N}=129)$} & \multicolumn{2}{|c|}{$\begin{array}{l}\text { Respondents who had } \\
\text { visited Indonesia } \\
\qquad(\mathrm{N}=77)\end{array}$} & \multicolumn{2}{|c|}{$\begin{array}{l}\text { Respondents who had not } \\
\text { visited Indonesia (referred } \\
\text { to last international } \\
\text { holiday trip) ( } N=52 \text { ) }\end{array}$} \\
\hline & Count & Mean & Count & Mean \\
\hline The official tourism local website & 32 & 4.31 & 18 & 4.0 \\
\hline $\begin{array}{l}\text { Travel community websites (TripAdvisor, Lonely } \\
\text { Planet, etc) }\end{array}$ & 51 & 4.06 & 28 & 4.0 \\
\hline Blog posts/reviews & 31 & 3.94 & 12 & 4.0 \\
\hline Google search & 57 & 4.00 & 44 & 4.0 \\
\hline Printed booklets/brochures provided by tour operators & 7 & 3.71 & 11 & 4.3 \\
\hline Printed booklets/brochures at hotel's reception desk & 18 & 3.89 & 11 & 3.7 \\
\hline $\begin{array}{l}\text { Printed booklets/brochures at the tourism } \\
\text { information center }\end{array}$ & 9 & 4.00 & 7 & 3.9 \\
\hline Asking locals & 36 & 4.14 & 10 & 4.1 \\
\hline Asking other travelers & 35 & 4.31 & 19 & 3.7 \\
\hline Other (please specify) & 4 & 4.50 & 0 & 0 \\
\hline
\end{tabular}

Table 3.7 Channel Preference Level of Satisfaction

As shown in Table 3.7, respondents who had visited Indonesia rated the official tourism local website - Wonderful Indonesia - and asking other travelers as the most satisfying travel information channels (4.31). Regarding the Wonderful Indonesia website, this result is not aligned with the previous study that suggested that it is not easy to access the required information directly at the website although it provides complete travel information (Yunus \& Tanuar, 2018). However, since the number of respondents who selected Wonderful Indonesia website was less than half of the total respondents who had visited Indonesia, this occurrence needs to be validated in a further research. The next most satisfying channels were asking locals (4.14) and travel community websites (4.06). The satisfaction level of 
information channels for respondents who had not visited Indonesia was almost similar. It implies that asking locals (4.1), official local tourism websites (4.0), travel community websites (4.0), blog posts/reviews (4.0), and Google search (4.0) as the most satisfying channels to gather travel information. In overall, this result confirms that the majority of respondents considered satisfied with channels that they used to gain travel information. Also, the result suggests that it was essential for respondents to make trip itineraries by gathering local travel content through browsing official tourism local websites, asking locals and learning from other travelers' experiences. Therefore, this result is relevant with one of the value proportions of Extra, which is to establish an interaction between tourism service providers and tourists for trip planning and local recommendations.

\subsubsection{Social Media Engagement}

In pursuance of having a better understanding of how social media could be utilized for future endorsement purpose of the app with regard to the literature reviews (Benyon, et.al., 2014; Chandralal, Rindfleish, \& Valenzuela, 2014) and stakeholders' feedback (see Ch. 3.1.4), Table 3.8 below describes the social media activities of respondents during and/or after their trip.

\begin{tabular}{|l|r|r|}
\hline \multicolumn{1}{|c|}{ Social media activities (N=129) } & Count & $\begin{array}{r}\text { \% of } \\
\text { cases }\end{array}$ \\
\hline Upload trip photos & 112 & $87 \%$ \\
\hline Update status about the trip on Facebook & 75 & $58 \%$ \\
\hline Upload trip videos & 36 & $28 \%$ \\
\hline Tweet about the trip & 29 & $22 \%$ \\
\hline Write blog about the trip & 17 & $13 \%$ \\
\hline None & 12 & $9 \%$ \\
\hline \multicolumn{1}{|c|}{ TOTAL } & 281 & $\mathbf{2 1 8 \%}$ \\
\hline
\end{tabular}

Table 3.8 Social Media Activities

Uploading trip photos to social media were the most popular activities among respondents during and/or after the trip (87\%), followed by posting status about their trip (58\%), upload trip videos (28\%), and tweet about the trip (22\%). There were also a small proportion of some respondents who write a blog about the trip (13\%). Out of 129 respondents, only 12 
respondents, or $9 \%$, who did not engage to social media during and/or after the trip. This data showed that the majority of respondents were enthusiastic to share travel experience through social media. This finding may lead to the opportunity to explore social media as part of the marketing strategy of Extra, including approaching bloggers and YouTubers as influencers.

\subsubsection{Suggested Features}

This section discusses the questionnaire result regarding respondents' most preferred features from a list of features emerged from qualitative interviews findings and literature review reference. Table 3.9 illustrates the rank of features that were considered by respondents as the most important features in a travel app. In the survey, respondents could choose up to five features in a random order. 


\begin{tabular}{|c|c|c|c|c|}
\hline No & Features preference $(\mathrm{N}=129)$ & Count & $\begin{array}{c}\% \text { of } \\
\text { responses }\end{array}$ & $\begin{array}{l}\% \text { of } \\
\text { cases }\end{array}$ \\
\hline 1 & $\begin{array}{l}\text { Show information of local } \\
\text { attractions, accommodations, } \\
\text { restaurants, events }\end{array}$ & 119 & $21 \%$ & $92 \%$ \\
\hline 2 & Online/offline location map & 93 & $17 \%$ & $72 \%$ \\
\hline 3 & Route Planning & 57 & $10 \%$ & $44 \%$ \\
\hline 4 & Self-designed tour package & 45 & $8 \%$ & $35 \%$ \\
\hline 5 & Post-trip guests rating \& review & 43 & $8 \%$ & $33 \%$ \\
\hline 6 & Loyalty reward program & 36 & $4 \%$ & $28 \%$ \\
\hline 7 & $\begin{array}{l}\text { Guests can book a personal guide } \\
\text { during the trip }\end{array}$ & 35 & $4 \%$ & $27 \%$ \\
\hline 8 & $\begin{array}{l}\text { Guests can book rental services } \\
\text { such as car, motorbike, bicycle, } \\
\text { pocket WiFi, etc }\end{array}$ & 34 & $6 \%$ & $26 \%$ \\
\hline 9 & $\begin{array}{l}\text { Guests can reserve product or } \\
\text { service with instant confirmation }\end{array}$ & 22 & $3 \%$ & $17 \%$ \\
\hline 10 & $\begin{array}{l}\text { Guests can discuss their inquiries } \\
\text { with tour operators through online } \\
\text { messenger }\end{array}$ & 21 & $4 \%$ & $16 \%$ \\
\hline 11 & Multilingual support & 21 & $6 \%$ & $16 \%$ \\
\hline 12 & 24/7 customer service support & 14 & $6 \%$ & $11 \%$ \\
\hline 13 & $\begin{array}{l}\text { Interactive 3D experience of a real- } \\
\text { world environment (Virtual Reality) }\end{array}$ & 8 & $1 \%$ & $6 \%$ \\
\hline 14 & $\begin{array}{l}\text { Show information on a captured } \\
\text { object (Augmented Reality) }\end{array}$ & 8 & $1 \%$ & $6 \%$ \\
\hline 15 & Other (please specify) & 2 & $0 \%$ & $2 \%$ \\
\hline & TOTAL & 558 & $100 \%$ & $433 \%$ \\
\hline
\end{tabular}

Table 3.9 Features Preferences

At the top five positions, the first most important feature was information about local attractions, accommodations, restaurants, and events that were mentioned by 129 respondents (92\%). Then, it is followed by online/offline location map (72\%), route planning (44\%), self-designed tour package (35\%), and post-trip guests' ratings and reviews (33\%). These top five features confirmed the findings of the qualitative interview, in which tourism stakeholders emphasized that they need a platform to promote their tourism products and services in the global context; and some tourists indicated the importance of location map, route planning, and customized trip itineraries features in a travel app. Ratings and reviews from previous travelers were considered vital as well by both tourism stakeholders and 
tourists in order to build customer loyalty and make trip decision respectively. Therefore, these top five features will be considered as the minimum viable product of Extra. It is also confirmed that augmented reality (AR) and virtual reality (VR) smart navigation features which were not revealed as desired features during the qualitative interview with tourists were the least important features for respondents as well. This phenomenon might occur because AR and VR are less utilized by other travel apps at the moment due to their complex hardware and technology (Goldman, 2018).

In an open question about what else they would like to see in a travel app, there were more viewpoints from respondents regarding features that they desired apart from a list of features that were presented in the questionnaire.

\begin{tabular}{|l|c|}
\hline \multicolumn{1}{|c|}{ Other suggested features } & Count \\
\hline Local recommendation & 19 \\
\hline A single platform tourism information & 14 \\
\hline $\begin{array}{l}\text { Other (weather forecast, call home, game \& } \\
\text { quizes) }\end{array}$ & 7 \\
\hline Event calendar & 5 \\
\hline Compelling images of attractions & 3 \\
\hline Convenient payment method & 2 \\
\hline
\end{tabular}

Table 3.10 Other Suggested Features

As shown at Table 3.10, the most recommended additional feature, suggested by 19 respondents was a local recommendation of food, culture, a road less traveled, route tips, and do's and don'ts at certain places. 14 respondents recommended that a travel app should contain complete and updated travel information of flight, accommodation, and attraction including their prices, so they only need to access a single app to arrange all of their trip itineraries. This result emphasizes the need for a travel app that features recommendation from locals and comprehensive travel information to provide a better traveling experience. It is also aligned with one of the identified opportunities that Extra could target, which is to endorse untapped local tourist destinations, including their products and services (see Ch. 1.4.a). Also, it validates the assumption in the business model canvas customer segments, which is visitors who want to explore local experience and learn new culture. However, one of the respondents suggested that the app is not exclusively created for Indonesia's tourist attractions, but for other countries as well since an exclusive app will only waste the mobile 
phone's memory space. At the moment, Extra aims to focus on providing information of Indonesia's tourism destinations as part of solving the research problem. However, this recommendation is valuable for the further development of Extra.

\subsubsection{Purchase Intention}

As respondents had identified the most important features in a travel app, they had been asked whether they were intended to use the app if those features were available in the potential travel app, including how likely they would pay for its service.

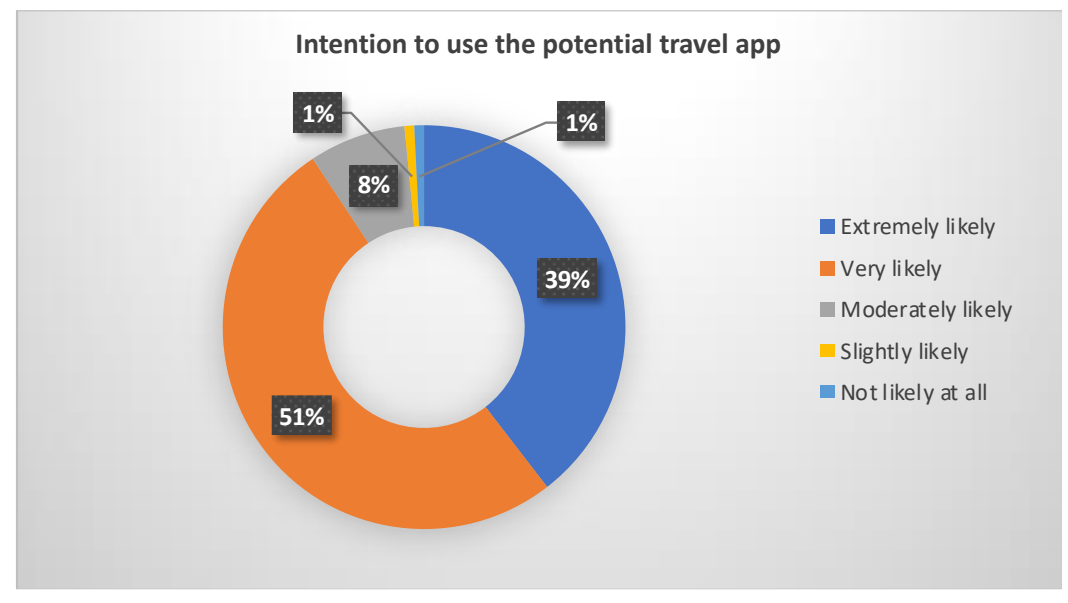

Figure 3.2 Use Intention

As portrayed in Figure 3.2, the total proportion of respondents who were extremely likely (51\%) and very likely (39\%) to use the app is $90 \%$. Therefore, it indicates that generally, respondents will use the potential travel app if they gain value from it. However, as illustrated in Table 3.11, when they had been asked about how likely they would pay for the app's service, almost all of the respondents mentioned that they desired to be able to use the app for free (76\%). The second most preferred app offer was free with in-app purchase (14\%), and the least preferred app offer was a paid only scheme (3\%). 


\begin{tabular}{|c|c|c|c|c|c|}
\hline App offer & $\begin{array}{l}\text { TOTAL } \\
(\mathrm{N}=129)\end{array}$ & $\begin{array}{c}\text { Less than } \\
\text { US\$1 } \\
(\mathrm{N}=7)\end{array}$ & $\begin{array}{c}\text { From US\$1 } \\
\text { to US\$3 } \\
(\mathrm{N}=19)\end{array}$ & $\begin{array}{c}\text { From US\$3 to } \\
\text { US\$5 }(N=3)\end{array}$ & $\begin{array}{c}\text { More than } \\
\text { US\$5 } \\
(\mathrm{N}=2)\end{array}$ \\
\hline & Column \% & Column \% & Column \% & Column \% & Column \% \\
\hline Free (may contains advertising) & $76 \%$ & 0 & 0 & 0 & 0 \\
\hline Paid options & $24 \%$ & $23 \%$ & $61 \%$ & $10 \%$ & $6 \%$ \\
\hline $\begin{array}{l}\text { Paid only (no advertising, user can get all of the } \\
\text { features) }\end{array}$ & $3 \%$ & $25 \%$ & $50 \%$ & $25 \%$ & $0 \%$ \\
\hline Free with in-app purchase for premium service & $14 \%$ & $22 \%$ & $67 \%$ & $6 \%$ & $6 \%$ \\
\hline $\begin{array}{l}\text { Free with monthly subscription option for premium } \\
\text { service }\end{array}$ & 7\% & $22 \%$ & $56 \%$ & $11 \%$ & $11 \%$ \\
\hline
\end{tabular}

Table 3.11 Purchase Intention

From 31 respondents who chose paid scheme (or $24 \%$ of the total respondents), the result shows that the majority of respondents who chose paid scheme enjoyed paying the app charge that ranges from US\$ 1 to US\$ 3 (61\%). Then, it is followed by less than US\$1 app charge $(23 \%)$ and US\$3 to US\$ 5 charge band (10\%). There were two respondents who were keen to pay more than US\$5 for in app-purchase if they could receive exclusive deals such as hotels and attractions' discounts, loyalty reward, and premium access to specific places. This result gives an illustration that the most realistic business model for Extra is the free scheme. This result is also relevant to the fact that most of the existing travel apps such as Expedia, Booking.com, and Tripadvisor are available to be downloaded for free. The analysis of how existing travel apps receive income with free scheme business model - which aims to have a better insight to create a profit and loss forecast of the app - will be portrayed further in the business case section. Moreover, this result implies that there is an opportunity to leverage the business model of the app into in-app purchase scheme at the next development of the potential travel app with further assessment on features and users' requirements.

\subsubsection{Summary of the Questionnaire}

The online questionnaire of this research - that aimed to validate the findings of the qualitative interview - yielded 129 respondents with a range of genders, ages, and country of origins. With questions that focused on devices and channels that were used to gather travel information, features suggestion, purchase intention, and social media engagement, the result of the online questionnaire was essential for the development of the minimum viable product of Extra to answer the research problem. Likewise, this result is corroborated by the 
literature review that tourists prefer online channels over offline channels to book and plan travel itineraries effectively (Hyde, 2008; Caraivan, 2017) and collect information through blogs, interactive online platforms or travel apps to choose accommodation, transportation and tourism activities (Ma, Scott, 2017).

The summary of the online questionnaire results is outlined in Table 3.12.

\begin{tabular}{|c|c|}
\hline Key preferences & Results \\
\hline Device & A mobile phone (90\%) \\
\hline Booking channels & $\begin{array}{l}\text { - Booking mobile apps (e.g. Airbnb, Agoda) (69\%) } \\
\text { - Booking websites (e.g. Expedia, Skyscanner) (52\%) }\end{array}$ \\
\hline Information sources & $\begin{array}{l}\text { - Google search }(80 \%) \\
\text { - Travel communities websites }(62 \%)\end{array}$ \\
\hline Top 5 important features & $\begin{array}{l}\text { - Show information of local attractions, } \\
\text { accommodations, restaurants, events (92\%) } \\
\text { - Online/offline location map (72\%) } \\
\text { - Route planning (44\%) } \\
\text { - Self-designed tour package (35\%) } \\
\text { - Post-trip guests rating \& review (32\%) }\end{array}$ \\
\hline Usage intention & Extremely likely (51\%) and very likely (39\%) \\
\hline Offer schemes & $\begin{array}{l}\text { - Free }(76 \%) \\
\text { - Free with an in-app purchase (US } \$ 1 \text { - US } \$ 3)(14 \%)\end{array}$ \\
\hline Activities on social media & $\begin{array}{l}\text { - Upload trip photos to the internet, i.e. Instagram or } \\
\text { Facebook (87\%) } \\
\text { - Update Facebook status about the trip (58\%) }\end{array}$ \\
\hline
\end{tabular}

Table 3.12 Questionnaire Result Summary

The result of the online questionnaire regarding respondents' most desired features is aligned with the finding of the qualitative interview where tourists suggested features such as off-line destination information and customized tour assistance. Some other features that were revealed during the survey also showed a connection with the literature review, such as weather information (Tussyadiah, Jung, \& tom Dieck, 2018) and local recommendation (Chandralal et al., 2014). It is also confirmed that features such as augmented reality (AR) and virtual reality (VR) that were not revealed during the qualitative interview were least important for questionnaire respondents as well. Overall, the result of the online questionnaire emphasizes the need of a potential travel app to increase the awareness of Indonesia's tourism destinations. 


\subsection{Summary of Findings and Analysis}

The purpose of the findings and analysis chapter is to find correlation between the results of data collection and the research question that focusses on how a travel app can contribute to the information availability of Indonesia's tourism destinations. Through using an exploratory mixed methods research design, the findings of this study confirm that Extra could benefit the tourism industry in Indonesia by providing features that are desired by both tourism stakeholders and tourists. The first phase of the data collection - which is qualitative interviews with tourism stakeholders and tourists - were held to gain a better understanding of the current tourism phenomena such as challenges and opportunities of the tourism industry in Indonesia, as well as their expectations of the potential travel app. Then, the findings of the qualitative interviews were employed to design the next phase, namely the online questionnaire. This second phase of the study was intended to validate qualitative key findings across a larger sample on how a travel app can support the information availability of Indonesia's tourism destinations. This study yielded 11 tourism stakeholders, 37 tourists for the qualitative interview; and 129 respondents for the online questionnaire.

Table 3.13 presents features summary based on findings and results of this study as recommendations for the development of Extra, with emphasize on local recommendations and destination guide features as they are the most preferred features by the questionnaire respondents. 


\begin{tabular}{|c|c|c|c|c|}
\hline \multirow{2}{*}{ Suggested Features } & \multirow{2}{*}{ Literature } & \multicolumn{2}{|c|}{ Qualitative Findings } & \multirow{2}{*}{$\begin{array}{c}\text { Questionnaire } \\
\text { Results (Top } 5 \\
\text { Features) }\end{array}$} \\
\hline & & $\begin{array}{c}\text { Tourism } \\
\text { Stakeholders }\end{array}$ & Tourists & \\
\hline $\begin{array}{l}\text { Destination information (local attractions, } \\
\text { accommodations and facilities) }\end{array}$ & $\mathbf{v}$ & $\mathbf{v}$ & $\mathbf{v}$ & $\mathbf{v}$ \\
\hline $\begin{array}{l}\text { Destination guide (location map, route } \\
\text { planning) }\end{array}$ & $\mathbf{v}$ & $\mathbf{v}$ & $\mathbf{v}$ & $\mathbf{v}$ \\
\hline $\begin{array}{l}\text { Platform for interaction between tourism } \\
\text { service providers and tourists }\end{array}$ & $\mathbf{v}$ & $\mathbf{v}$ & $\mathbf{v}$ & \\
\hline $\begin{array}{l}\text { Customized tour packages with pricing } \\
\text { information }\end{array}$ & $\mathbf{v}$ & $\mathbf{v}$ & $\mathbf{v}$ & $\mathbf{v}$ \\
\hline Loyalty reward & $\mathbf{v}$ & $\mathbf{v}$ & & \\
\hline Multi language & & $\mathbf{v}$ & $\mathbf{v}$ & \\
\hline $24 / 7$ customer support & $\mathbf{v}$ & $\mathbf{v}$ & $\mathbf{v}$ & \\
\hline Customer reviews & $\mathbf{v}$ & $\mathbf{v}$ & $\mathbf{v}$ & $\mathbf{v}$ \\
\hline Instant booking & $\mathbf{v}$ & & $\mathbf{v}$ & \\
\hline Blog reviews & $\mathbf{v}$ & $\mathbf{v}$ & $\mathbf{v}$ & $\mathbf{v}$ \\
\hline $\begin{array}{l}\text { Trip essentials rental information (motorbike, } \\
\text { bicycle, pocket WiFi) }\end{array}$ & & & $\mathbf{v}$ & \\
\hline Cost share calculation & & & $\mathbf{v}$ & \\
\hline Augmented reality (AR) & $\mathbf{v}$ & & & \\
\hline Virtual reality (VR) & $\mathbf{v}$ & & & \\
\hline
\end{tabular}

Table 3.13 Summary of Research Findings and Results

The qualitative findings produced various features that were desired by both tourism stakeholders and tourists in Extra. Then, a validation process through the online questionnaire reveals that the most desirable feature in the potential travel app is a complete information on local attractions, accommodations, restaurants, and events. Then, the other four features that were chosen by the majority of the questionnaire's respondents are local recommendations, offline/online map and route planning, self-designed tour package, and reviews from previous travelers. The findings and results of this study also expose that $A R$ and VR features were least preferred by both the qualitative interview's participants and the questionnaires respondents. 


\section{Chapter 4 : Discussion}

The purpose of the discussion chapter is to discuss the major findings and what implications these have for the development project of Extra. This includes an evidence-based reflection of the project, the opportunities and barriers, and how these will be addressed.

\subsection{Benchmark Study}

This section discusses comparisons to previous research within the travel industry in order to have a holistic picture of the apps' development project. This benchmark study is vital to identify gaps of existing travel apps that can be filled by the potential travel app as value propositions to potential users and partners.

Comprehensive previous research regarding the ICT relevance for tourists and tourism stakeholders has been presented earlier in the literature review section within this thesis report. Also, there are with corresponding the findings and results of this study, such as the need to create self-designed itineraries (Buhalis, 1998), communicate directly with prospective travelers (Ray, et. al, 2011), gather travel information through blogs, interactive online platforms or travel apps (Ma, Scott, 2017), and share their experiences with family members, friends, and the general public via social media (Fatanti \& Suyadnya, 2015).

It is clear that numerous academic literature reviews have brought broad views and a depth understanding of the ICT significance in the tourism industry to inform the foundational theory of this study. At the moment, due to the progression of this exploratory travel app project, this study will look further to previous research with industry perspectives that focusing on travel apps' features and their relevance to travel apps' users to complement the academic literature and research findings of this study. Previous research with this classification is important to have a better grasp of the current trend of travel apps and their positioning in the market. To start with, Xiang and Wang (2012) investigated types of information services provided by mobile apps to support travel activities and found out that mobile tour guide apps that offer 'single city destination guide' - such as "a wide range of classified information about that city such as attractions, transportation, restaurants, and shows" (p.5) - are the leading category in terms of number of apps, and several of them are paid apps with prices range from US\$0.99 to US\$5.99. Nonetheless, they also discovered that 
users of paid apps are easier to be displeased if the apps did not work well, which include untimely response on customer' inquiries or fixed bugs. This key evidence is crucial to be considered if the potential travel app would like to change its free scheme to the paid business model.

A study conducted by Cristescu (2016) indicated that TripAdvisor is the most preferred travel app to improve tourist experience with its worldwide scope, customer-driven values, and objective reviews about hotels, restaurants, tourist destinations, and activities. This phenomenon is confirmed by the findings of this study, where travel communities' websites - including TripAdvisor - were the second most preferred channel to obtain travel information. It was also revealed in one of Cristescu (2016) findings that Instagram - although it is not an exclusively travel app - has been used by many tourists to store "precious moments of their travels and sharing these moments with their relatives, friends and followers" (p.30). This phenomenon is aligned with the findings in this report regarding the most popular social media activities during and/or after the trip.

According to recent research by Google, $57 \%$ of tourists want service providers that enable them to have more personalized experiences when accessing travel information, whether by matching their preferences or past travel activities. Further, if a travel app could offer this service, one-third of respondents from Google's research would be likely to pay more (Loo, 2017). Oliver Heckmann, Google's VP of engineering for travel and shopping, also emphasized the expectation of travelers who want to have information that is tailored with their past interests of location, time, and event whenever they search for a nearby hotel or restaurant (Influence Society, 2018). This circumstance is aligned with the findings of this study, where the self-designed tour package was revealed as one of the most preferred features in the potential travel app.

Another research that has been done by Criteo (Lucey, 2018) revealed that up to $80 \%$ of lastminute bookings are made on mobile devices due to its flexibility to offer same-day price deal during the trip. Out of that $80 \%, 46 \%$ of respondents made the booking through mobile apps and $54 \%$ through mobile websites. However, their data also indicated that mobile apps' conversion rate - which defined as the percentage of users who make actual purchases 
(Nielsen, 2013) - is five times higher than mobile websites. This key indication validates the intention of developing the potential travel app as a mobile app exclusively.

\subsection{Major Findings}

The main purpose of this research is to develop a sound business case for a commercialisable product that offers a solution to the lack of available information regarding Indonesia's tourism destinations. Further, the intention of this research is to support the information availability of Indonesia's tourism destinations through a travel app. In the business model canvas, initial assumptions were mapped with regards to Extra's development plan (see Table 4.1).

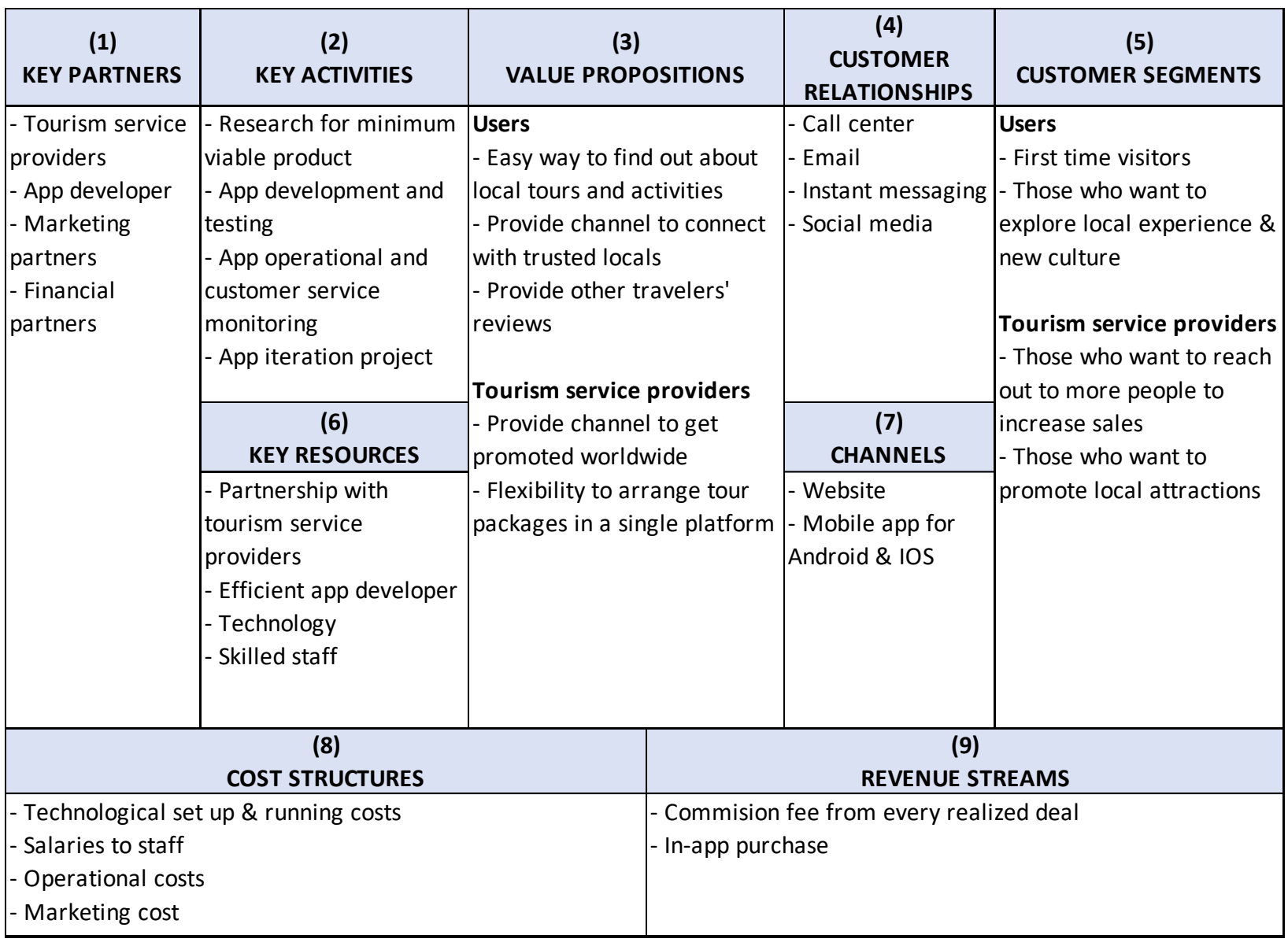

Table 4.1 Initial Business Model Canvas of Extra

The scope of this research is to validate key assumptions in value propositions, customer relationships, customer segments, channels, and revenue streams blocks. As presented 
earlier in the findings and analysis chapters, assumptions in those five blocks were mostly validated by the research conducted, though there were limitations that potentially reduced a broader exploration of this research. Table 4.2 illustrates the modification of the business model after being aligned with the major findings of this study.

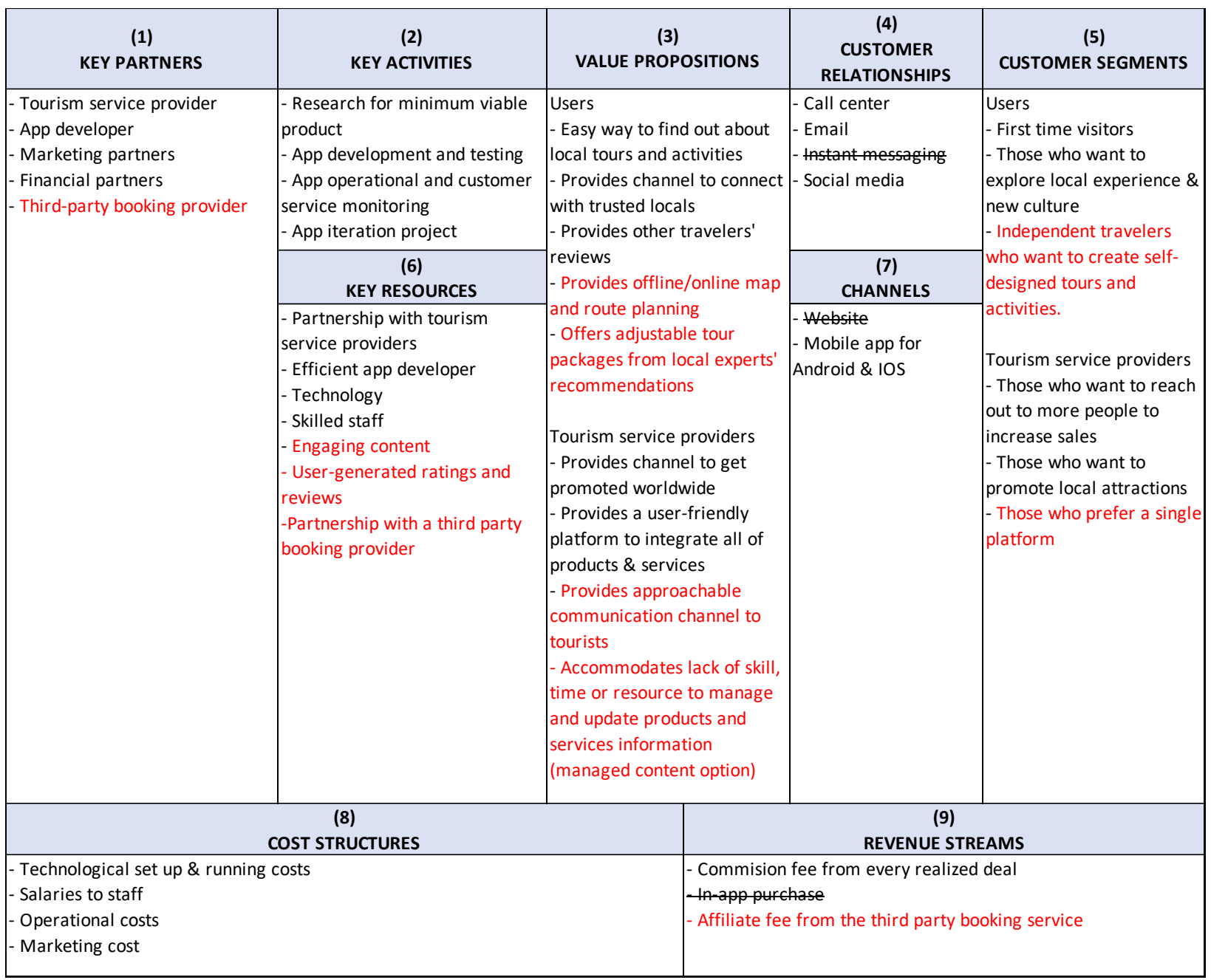

Table 4.2 Adjustment of the Business Model Canvas

The following is the discussion of each block that relates to the updated business model canvas. Adjustments of the initial business model are made in customer relationships, channels and revenue streams blocks, where assumptions in strikethrough texts are removed and new components that are written in red texts are added in light of the research's major findings. 


\section{(1) Key Partners}

The tourism service providers participants from the qualitative interview - that were varied from travel agents, government representatives, to hotel staffs - were keen to have a travel tool to support their business operations more efficiently. Moreover, one of the government staff emphasized the importance to commence a partnership with a third party to offer all-in local tour packages (see Ch. 3.1.4). Likewise, the app developer, marketing partners, and financial partners are still considered as key partners as well, since they are the core elements that will enable the realization of Extra. Additionally, since most of the respondents preferred to have complete information about local attractions including their accommodation and facilities, it is deemed to have a third-party booking service as one of the key partners subsequently. This key partner is essential in the sense of resource effectiveness since they already have a solid database of accommodation and transportation services such as Booking.com. Extra will accommodate customers that desire to book combination products and services from Extra and the third-party booking service by direct them to the third-party booking site after they have completed Extra's booking transaction.

\section{(2) Key Activities}

The four phases of key activities related to the app creation process are still relevant to be kept as they are since it can be considered that those phases are still realistic to be attained referring to the lean start-up methodology (Blank, 2013). At this point, a research has been conducted to identify the minimum viable product of the app. Further, after an agreement with the project partner/s is finalized, the design and development process of Extra will be started accordingly, followed by the testing process to ensure its service's stability. Soon after the performance test is verified, Extra will be launched, and its service will be regularly monitored. At this stage, it is important to listen the customers' responds regarding the performance and service of Extra and make necessary adjustments on aspects that need improvements. Then, as part of the lean startup methodology, this iteration process can be repeated again to optimize Extra's value based on its customers' perspectives (see Ch. 1.5).

\section{(3) Value Propositions}

In this block, it was assumed that users would use Extra as it provides information about local tours and activities that include reviews from previous travelers and channel to connect with 
trusted locals. The result of this study shows that the feature 'information on local attractions, accommodations, restaurants, and events' was chosen by $92 \%$ respondents and about onethird of respondents preferred the feature 'post-trip guests' ratings \& reviews' as the most important feature in a travel app. It means that the results are well aligned with the assumption and it is expected that users would use Extra because it provides information about local tours and activities and reviews from previous travelers. Local recommendations about things to do, where to eat, where to stay and efficient routes to reach certain destinations (off the beaten track, a road less traveled) were the most suggested feature by the questionnaire respondents in the open question regarding what additional element they would like to see in a travel app. It indicates that they would like to connect with trusted locals to gain that information, which fits reasonably with the assumption as well. Further, $72 \%$ of the questionnaire respondents and some of the interview participants expected that they could have a travel app that supports offline maps during their trip, so they can access all the information regarding trip itineraries, route planning, and maps when there is no WiFi or mobile data connection. This distinctive feature is considered to be added in the value propositions as well. Another interesting fact is that $35 \%$ of the questionnaire respondents wished to have the ability to create their own trip itineraries in a travel app. It is emphasized by some comments in the questionnaire's open question section that the app should be "informative and intuitive", and a comment from the interview's tourist participant that the app should "offer tour packages information for a segmented market like for single, family, couple, with several budget options". This feedback relates to the current phenomenon that typically tour packages offered by travel agents contain fixed destinations, schedules, and activities. Therefore, Extra could gain a competitive advantage by featuring tour packages offered by trusted independent local guides or travel agents that can be modified based on users' preference. For example, Extra's user can put their initial travel planning such as the arrival and departure date, type of visitors (single, family, etc.), destinations of interest (city, tourist attraction), and preferred activities (hiking, snorkeling, shopping, etc). After this information is submitted, Extra will curate its database from tourism service providers' offers and accommodation booking services. Then, Extra will suggest the most well-matched tour packages, including accommodation, on-site transportation, destinations, and activities. Then, Extra's user can accept the offer instantly or modify the offer based on other recommended options available. 
To conclude, two additional features are added in the user section of the value propositions block and there is no change of the initial assumptions since all of them are well aligned with the major findings of the study.

Meanwhile, for tourism service providers, it was assumed that Extra will be desirable if it could offer a channel to get promoted worldwide and manage all of the products and services in a single platform. Some of the respondents highlighted the need for a travel app that can promote their products and services in the global context. This includes providing tourist information in the English version to complement their established Indonesian language tourism promotion websites. Some of the participants emphasized the desire to have a platform that can integrate all of their products and services information by stating that the potential travel app should be able to provide "tour information instantly without contacting many travel agents one by one to find the most suited tour packages for my customers" (Mr F, General Manager) and "information about what to do or provide complete guidance" (Ms J, Hotel Staff). Therefore, the findings of the qualitative interviews with tourism stakeholders indicate a sound alignment with the initial assumptions.

Additionally, there are two essential utilities identified from the qualitative interview findings that can enhance the value propositions of Extra. The first additional value proposition is Extra will provide an approachable communication channel between tourism service providers and their potential customers/tourists. This value was highlighted by one of the interview participants by citing that alternative channels other than social media are important to communicate with customers directly. The second additional value proposition is to accommodate lack of skill, time or resource to keep updating products and services information. This value proposition is considered to be desired by tourism service providers since it was revealed during the interview that some of the participants do not have the capability to manage the app by themselves due to the lack of time, skill and experience. Therefore, once they become Extra's business partner, there will be an option whether or not their account will be managed by the app's content manager. 
In conclusion, two additional features were subsequently added in the tourism service providers section of the value propositions block and there is no modification of the initial assumptions since all of them are validated through the findings of the study.

\section{(4) Customer Relationships}

It was assumed that channels that will be utilized by Extra to connect with its users are call center, email, instant messaging and social media. Since the call center and email are the main customer service channels that will be applied in Extra, this research examines the significance of instant messaging and social media as alternative channels to incorporate the call center and email channels.

The results of this research indicate a low percentage (16\%) of respondents who preferred an instant messenger feature to discuss their trip inquiries directly with tourism service providers, while this feature was revealed during the qualitative interview with tourism stakeholders and tourists. Meanwhile, the findings of this research signify that $91 \%$ of respondents are engaged with social media.

Therefore, the results of this study support social media and reject instant messaging as the alternative customer relationship channel to incorporate call center and email. Nonetheless, considering the importance of a communication channel that is easy to use and provides straightforward interaction to complement a phone and email channel, further research will be needed to examine to what extent the channel to connect with tourism service providers is desirable with a different tool other than instant messaging i.e. video chat, live chat, etc.

\section{(5) Customer Segments}

The assumptions of targeted users are first-time visitors, those who want to explore local experiences, and those who want to learn new cultures. It is discovered from the questionnaire result that only $38 \%$ of respondents who had visited Indonesia once had utilized the official website of Indonesia tourism, namely Wonderful Indonesia, as a source to gather traveling ideas to Indonesia. This implies that Extra will be able to provide an alternative channel to promote Indonesia's tourist destinations to first-time visitors. 
Then, the majority of respondents also chose the feature 'information on local attractions, accommodations, restaurants, and events'. Therefore, the findings of this study corroborate the assumptions that people who want to explore local experiences and learn new cultures will be the targeted customers of Extra. Moreover, since $35 \%$ of the questionnaire respondents preferred a travel app that allows them to create their own trip itineraries, another additional customer segment was added, namely independent travelers who want to create self-designed tours and activities.

As for tourism service providers, the target market of Extra will be those who want to reach out to more people to increase sales and those who want to promote local attractions. During the qualitative interview, some tourism stakeholders' participants viewed that they needed a platform to promote their products and services in a broader scope. Further, the government representative highlighted the difficulty of promoting local tourist destinations worldwide due to the language limitation. Therefore, these findings indicate a strong relationship with assumptions in the customer segments block.

Further, Extra will not be limiting only to tourism service providers as its content partners. Local enthusiasts who want to promote local attractions by offering unique experiences or guide service to show around the city can also be the partner of the app.

In regard to the demand of participants of having a platform to manage all of their products and services, an additional customer segment is added, which is those who prefer to use a single platform. It is projected that Extra will provide a one stop travel solution to its users ranging from accommodation, transportation, activities, to packages offerings. Therefore, tourism service providers with many products and services may gradually reduce their dependency of using different sources of promotion channels and can save time and money by only managing their offerings merely in Extra.

It is anticipated that the potential targeted customers from both users and tourism service providers are not limited to only one category within the customer segments block, but it could be a combination of more than one category. 


\section{(6) Key Resources}

The initial assumptions of Extra's key resources were partnerships with tourism service providers, efficient app developer, technology, and skilled staff. At the moment, those four key resources components are still relevant to the business development plan of Extra. The partnership with tourism service providers includes business partnerships with independent local guides, accommodation providers, and travel agents; and an opportunity to have a project partnership with the Ministry of Tourism. Also, an efficient app developer, technology, and skilled staff are the core resources of Extra's conception and long-running operation. Moreover, three new key resources are introduced in light of the research findings of this study. Having learned that one of the tourism stakeholders' participants had employed bloggers and journalists to create engaging content to promote the hotel's services and facilities, it is considered that engaging content including pictures, descriptions, and videos are essential as a key resource to attract users. Also, since travelers' reviews element is considered as one of the value propositions of Extra, other additional strategic resource that has to be maintained are user-generated ratings and reviews. Lastly, a partnership with a third-party booking provider is added as one of key resources in to support information about accommodation and transportation services.

\section{(7) Channels}

Initially, it was assumed that platforms that will be used for Extra were a website and mobile app. Meanwhile, the results show that $94 \%$ of respondents who had visited Indonesia chose a smartphone as the most used device during their trip and only $44 \%$ of them preferred a laptop. As the objective of this project is to identify the minimum viable product of Extra and more than twice of respondents preferred the smartphone over the website - the results confirm a smartphone and refute a website as the platform of Extra. Moreover, $69 \%$ of the respondents selected mobile apps to book their trip itineraries over websites (52\%). Therefore, it is confirmed that the minimum viable product of this project is a travel app exclusively. 


\section{(8) Cost Structures}

The three fundamental cost structures remain unchanged as they cover all costs elements within the development and operational period of Extra. The technological set-up costs include app design and testing costs, while the running costs involve regular server maintenance, content updates, hosting and license renewal expenses. During the launching process, marketing costs most likely will be the largest expense for user acquisitions. As the findings of this study signify that social media can be utilized for the app's marketing purpose, marketing costs will include paid search engine optimization, as well as blogs and social media endorsement. Operational costs cover the monthly expenses of co-working space, customer support, travel and meeting expenses, and other miscellaneous costs. Meanwhile, salaries to staff include monthly wages to technical support, digital marketing manager, partnership manager, content manager, and administrative staff.

\section{(9) Revenue Streams}

The preliminary assumptions of revenue streams that will be applied for the app is a commission from realized deals and an in-app purchase. A commission from realized deals is a subject that is relevant to the tourism stakeholders as they will bear this component if they would like to promote their products and services on the app. However, this subject was considered to be excluded at the qualitative interview in order to not limit and keep the enthusiasm of participants to provide feedback regarding features that they desire in the potential travel app. An exploration of whether this component is feasible will be presented in the benchmark study section.

With relevance to the in-app purchase revenue model, the results from the online questionnaire indicate that the majority of the respondents wanted to be able to use the app for free (76\%) and only $14 \%$ of them desired the in-app purchase model. Therefore, the results diminish the opportunity to obtain revenue from the in-app purchase at the moment. However, the feasibility of the in-app purchase model will be assessed after the implementation of the app by reflecting on the app's offered features, users' feedback and potential future features that will provide more values for its users. Hence, the minimum viable business model of the app is the free scheme with an opportunity to collect revenue from realized deals commissions exclusively. 
As most of the questionnaire's respondents desired to have comprehensive information on local attractions, accommodations, restaurants, and events, as well as design their own itineraries, the findings of this study also hint a potential new revenue stream, which is an affiliate fee from third-party booking services. This new revenue generator is emerged since the app will provide a link to a third-party booking service such as Booking.com to allow users modifying designated accommodations from their tour packages offerings at the initial stage of the app's implementation. In the long-term plan, it is expected that the app will have its own database of various accommodations in Indonesia as part of its objective to be a onestop shopping travel app.

\subsection{Competitors' Analysis}

It is clear that previous studies indicate that the key of travel apps' success determinant is their ability to understand tourists' need. Further, a travel app could be more demanded if it can keep evolving with innovation to solve tourists' problems or improve tourist' experiences. Therefore, this study will examine the development of similar products within the travel industry as part of identifying a gap and positioning in the market.

Due to the large number of travel apps with their various features, travel apps included in this section are selected based on these criteria:

- Number of value propositions that similar with Extra

- Local applicability

- Popularity/number of downloads

The process of selecting the most fit travel apps that will be included in the benchmark study was conducted through an online research by searching with keywords "travel guide app" and "local experience travel app" in the Google search engine. Then, Crunchbase ${ }^{10}$ and Similar $W b^{11}$ website tools were used to attain key information regarding company details, number of downloads, total funding, and annual revenues. Finally, it is considered that Trip Advisor,

\footnotetext{
${ }^{10}$ a platform for finding business information about private and public companies

${ }^{11} a$ website which provides web analytics services for businesses
} 
AirBnb, Triposo and Withlocals are included in this benchmark study. Table 4.3 presents the summary of the said travel apps' value propositions, channels, revenue streams, and limitations factors; along with the potential travel app's competitive advantages and challenges.

\begin{tabular}{|c|c|c|c|c|}
\hline & TripAdvisor & AirBnb & Triposo & Withlocals \\
\hline Headquarters & USA & USA & The Netherlands & The Netherlands \\
\hline Founded Year & 2000 & 2008 & 2010 & 2013 \\
\hline $\begin{array}{l}\text { Number of } \\
\text { downloads (Dec } \\
\text { 2018) }\end{array}$ & 1,36 million & 3,6 million & 41,605 & 9,027 \\
\hline Value propositions & $\begin{array}{l}\text { - Price comparison across many } \\
\text { travel sites } \\
\text { - Reviews from over 500M travelers } \\
\text { - Find places nearby/city guides }\end{array}$ & $\begin{array}{l}\text { - Unique activities from locals } \\
\text { (sharing hobbies, skills, and } \\
\text { expertise) } \\
\text { - Reviews from locals and } \\
\text { travellers } \\
\text { - channel to connect with hosts }\end{array}$ & $\begin{array}{l}\text { - Self designed tour planning } \\
\text { - More than } 300 \text { Indonesia's } \\
\text { travel destinations information } \\
\text { - Offline maps and route } \\
\text { guides }\end{array}$ & $\begin{array}{l}\text { - Personal and customized local } \\
\text { experiences } \\
\text { - Activities \& tours are led by } \\
\text { local experts } \\
\text { - Channel to connect with hosts }\end{array}$ \\
\hline Channels & $\begin{array}{l}\text { - Website } \\
\text { - Mobile app }\end{array}$ & $\begin{array}{l}\text { - Website } \\
\text { - Mobile app }\end{array}$ & $\begin{array}{l}\text { - Website } \\
\text { - Mobile app }\end{array}$ & $\begin{array}{l}\text { - Website } \\
\text { - Mobile app }\end{array}$ \\
\hline Revenue Streams & $\begin{array}{l}\text { - Commission from realized deal } \\
\text { (accommodation: } 12-15 \%) \\
\text { - Advertising placement (pay-per-click } \\
\text { model) } \\
\text { - Subcription plan for advertiser } \\
\text { (calculated based on the property's } \\
\text { location, size, etc.) }\end{array}$ & $\begin{array}{l}\text { Commission from realized deal } \\
\text { Accommodation: } 5-15 \% \\
\text { Experiences: } 20 \%\end{array}$ & $\begin{array}{l}\text { Paid option to access ad-free } \\
\text { version of the app (US } \$ 6.99 \text { ) }\end{array}$ & $\begin{array}{l}\text { Commission from realized deal } \\
(20-30 \%)\end{array}$ \\
\hline $\begin{array}{l}\text { Total funding (Dec } \\
\text { 2018) }\end{array}$ & US $\$ 3.3 \mathrm{M}$ & US $\$ 4.4 \mathrm{~B}$ & US $\$ 8.3 \mathrm{M}$ & US $\$ 7.5 \mathrm{M}$ \\
\hline $\begin{array}{l}\text { Annual revenue } \\
\text { (Dec 2018) }\end{array}$ & US \$1.6B & US $\$ 2.8 \mathrm{~B}$ & US $\$ 1 \mathrm{M}$ & US $\$ 3.8 \mathrm{M}$ \\
\hline Limitations & $\begin{array}{l}\text { - Don't have a channel to contact } \\
\text { directly with hosts } \\
\text { - Offers common activities }\end{array}$ & $\begin{array}{l}\text { - Only offers activities from } 3 \\
\text { major cities in Indonesia } \\
\text { - Can't integrate all of the } \\
\text { booking information into one } \\
\text { master itinerary }\end{array}$ & $\begin{array}{l}\text { - Users have to pay to access } \\
\text { the ad-free version } \\
\text { - Less personalized trip } \\
\text { inspirations to help tourists } \\
\text { make trip decisions }\end{array}$ & $\begin{array}{l}\text { - Only offers activities from } 3 \\
\text { major cities in Indonesia } \\
\text { - Users can't book other services } \\
\text { i.e. accommodation, transport }\end{array}$ \\
\hline $\begin{array}{l}\text { Competitive } \\
\text { advantages of the } \\
\text { potential travel } \\
\text { app }\end{array}$ & $\begin{array}{l}\text { - It is planned to have an } \\
\text { approachable channel to contact the } \\
\text { hosts } \\
\text { - Curate Unique activities based on } \\
\text { local recommendations }\end{array}$ & $\begin{array}{l}\text { - More places, destinations and } \\
\text { activities of Indonesia } \\
\text { - Incorporate all of booking } \\
\text { information into a single itinerary }\end{array}$ & $\begin{array}{l}\text { - Only free-ad model to assure } \\
\text { all of the users get the same } \\
\text { experience } \\
\text { - Trip suggestions from local } \\
\text { experts based on users' } \\
\text { interests }\end{array}$ & $\begin{array}{l}\text { - More places, destinations and } \\
\text { activities of Indonesia } \\
\text { - Users can book a combination } \\
\text { of several services }\end{array}$ \\
\hline
\end{tabular}

Table 4.3 Travel Apps Benchmark Study

Table 4.3 shows that all of Extras are designed both in websites and mobile apps. Airbnb, which recently add an experience feature to complement their accommodation booking service, has the highest number of downloads, total funding, and annual revenue, within ten years of its establishment. Although Airbnb offers unique activities that are equipped with reviews from previous customers and channel to contact directly with hosts, it lacks destination varieties in Indonesia and does not provide a tool to integrate all of the trip itineraries into one master itinerary. Compared to Airbnb, Extra will have additional value propositions by offering more places, destinations, and activities of Indonesia, as well as facilitating trip itineraries management. Meanwhile, TripAdvisor has a variety of value 
propositions, and revenue stream forms compared to other three travel apps. However, activities that TripAdvisor has to offer are mostly general activities that can be obtained through other sources. Further, potential customers do not have an approachable channel to connect with hosts directly. As such, Extra will have the chance to fill these gaps by providing unique activities from trusted locals and a channel to contact with hosts seamlessly. Similar with Airbnb, Withlocals currently only offers activities from three major cities of Indonesia, and the potential travel app will have an additional value proposition on top of Withlocals's service by offering more places, destinations, and activities of Indonesia. In addition, the main element that Extra will provide is a booking service of accommodation and transportation facilities nearby the activities, a service that currently Withlocal cannot address. On the contrary, Triposo appears to have broad features that are valuable to users such as selfdesigned trip planning, travel information, and off-line travel guide. However, the apps' free version may impact on user experience due to some ad placements (Harley, 2015). As such, Extra will be designed without in-app advertisings in order to ensure that all users will have the same user experience (UX). Moreover, as opposed to providing general travel information about destinations and attractions, Extra will offer trip recommendations from local experts based on users' interests. However, challenges such as additional cost and resource requirements are also derived to implement the competitive features of Extra. The detail forecast of cost and resources requirements will be discussed further in the business case chapter.

\subsection{Opportunities and Barriers}

This section presents both opportunities and barriers that have been identified with accordance to the study of previous research and similar product within the travel industry.

\subsubsection{Opportunities}

Below are several opportunities that have been identified, relating to the development of Extra in terms of (a) commercial, (b) product creation, and (c) connection channel and marketing feasibilities. 


\section{a) Commercial Feasibility}

The finding of this study reveals that $90 \%$ of respondents were likely to use the potential travel app if it can provide their most desired features such as comprehensive information about accommodation, facilities, tour and activities based on local insights and other travelers' reviews, offline travel guide, and self-designed trip itineraries. Further, the successful growth of Airbnb and Withlocals is indicating that Extra is commercially viable since it can complement Airbnb and Withlocals by offering more destinations, unique experiences and local recommendations of Indonesia's tourist attractions.

\section{b) Product Creation Feasibility}

The findings of this research provide a clear outcome of the minimum viable product of Extra that includes the channel/platform type, customer channels, and features of the app. It means that the potential travel app is ready to be developed as soon as an agreement with the project partner/s is finalized. Continued adjustments to improve Extra's service will be made as part of the agile strategy development process of the app within the lean start up methodology (Ries, 2011; Blank, 2013).

\section{c) Connection Channel \& Marketing Feasibility}

The findings of this study indicated that tourists utilize social media immensely as part of their trip activities, which is also confirmed by the study from Cristescu (2016). Therefore, this phenomenon leads to a prospect to employ social media as part of Extra's connection channel and marketing strategy. In addition, since the results of this study reveal that there are some respondents who upload trip videos to YouTube (36\%) and write blogs about their trip (17\%), it hints that there is a potential opportunity to promote Extra and/or increase the awareness of Indonesia's tourism destinations by approaching bloggers and YouTubers as influencers as well.

\subsubsection{Barriers}

Although some promising opportunities has been recognized, there are potential barriers that revealed from this study such as: a) user's actual purchase intention, b) tourism service 
provider's actual willingness to get onboard, and c) customers' motivation to write after trip reviews.

\section{a) User's actual purchase intention}

The main barrier of this study is to have a better grasp of potential users' actual intention to purchase Extra. Though $90 \%$ of the respondents intended to use the potential travel app if it can provide their most desired features, only $24 \%$ of them who would like to purchase the app. This figure could be lower or higher depends on how users perceive values that will be offered by the app. This barrier could be addressed by implementing Extra into a real product and conduct further research to its users regarding what extent the app's values could entice its users to pay more for the service.

\section{b) Tourism service provider's actual willingness to get onboard}

During the qualitative interview, most of the tourism stakeholders showed positive response to utilizing the potential travel app to make their business operation easier. However, it will need skill and time resources to manage account and update product information in an online platform. This barrier might prevent tourism service providers to use Extra to promote their products and services. Therefore, Extra will attempt to reduce this barrier by providing a managed content option in which the content managers of the app will create and publish content on behalf of the tourism service providers who decide to select this option. This service will be available at no cost as part of Extra's commitment to support its partners running their business as seamless as possible. In course of time, as Extra's partners will be familiar to operate its system and application, they will have the option to manage their own content to expedite the update process.

\section{c) Customers' motivation to write after trip reviews}

About one third of the questionnaire's respondents desired to see reviews from previous travelers who have completed the offered destinations and activities. 
However, it may be challenging to have customers' willingness to write reviews due to lack of time (Delgado, 2017). It is anticipated to reduce this barrier by designing a prompt and easy review form that simply contains star rating and improvement feedback request and sending a notification email that will lead to the review form at the user's account page. In addition, it is considered to hold a draw with a certain period of time where the customer who has written a review will be eligible to enter the draw and win a voucher gift that can be used globally such as an Amazon voucher.

\subsection{Implications}

This section discusses implications of this research for practice beyond the scope of this study and recommendations for future research.

In a case of successful implementation of Extra, as suggested by the lean start-up model, the 'build-measure-learn' feedback loop (Ries, 2011) will be implemented regularly to allow continued adjustments to improve its service. This includes conducting further research on aspects that need further validation. The following are research question recommendations for future research to gain more grasp on unknown aspects that influence the development of Extra especially in Indonesia context.

- What types of communication tools will be effective in a travel app to enable interaction between tourism service providers and tourists?

- How can current travelers perceive a customer service feature in a travel app to encourage a better traveling experience?

- How can users perceive values that has been offered by the app, and how likely is it that they will pay once they perceive that they gain expected values from the app?

In addition, as the findings of this study indicated that some of the questionnaire respondents considered that the Wonderful Indonesia website has provided a satisfying travel information service whereas the previous study suggested the opposite, further research may be necessary to confirm to what extent the Wonderful Indonesia website has been effective to provide tourism information. 


\section{Chapter 5 : Recommendation (Business Case)}

\subsection{Background}

Indonesia's tourism attractions keep growing with so many packages on offer, including cultural, cuisine and natural attractions. However, based on UNWTO Tourism Highlights (2018), Indonesia is in the 9th position in terms of the number of international tourist arrivals compared to other Asia countries in 2017. The reason for this is that it is assumed that Indonesia lags behind in terms of providing sufficient tourist information on the website and on-site (e.g. information boards, signage, brochures) (Hariguna \& Lai, 2015; Russel, 2016; Lubis, 2017). This leads to many tourists having a low understanding of where Indonesia is located and what types of destinations they can explore in Indonesia. Thus, the objective of this document is to propose a business case to targeted investor audiences in order to support further development and implementation of Extra, a travel app that will promote Indonesia's tourism destinations that focus on local recommendations. This app will provide tourism services and information provided by trusted locals and facilitate tourists to make customized trip itineraries to Indonesia.

\subsection{Goals \& Visions}

Extra aims to give tourists a local experience while visiting Indonesia, as well as to boost more exposure to Indonesia's tourism destinations in the global market. These goals are attained by enabling local tourism service providers to contribute to the app's content with updated tourism information as part of their tour packages and services. Direct communication will also be provided by Extra to allow tourists discussing customized itineraries with their preferred tourism service providers.

As the tourism industry has been Indonesia's fourth largest contributor of foreign exchange revenue (Indonesia Tourism Investment, 2018), the vision of Extra is to be a one stop travel app that offers a broad service that tourists need to explore Indonesia as part of enabling 
better tourist experiences and supporting one of the government's goal - which is to increase the number of international tourist arrivals (Lee, 2018). Extra attempts to accomplish this aspiration by providing tourism information and showcasing local insights to support the promotion of Indonesia's tourism destinations worldwide.

\subsection{Opportunities}

The research project of Extra is carried out based on these potential opportunities; (a) local tourism endorsement, (b) follow the trend, (c) effective communication media, and (d) prospective customer base.

\section{a. Local Tourism Endorsement}

Through Extra, tourists can explore authentic local places and activities recommended by trusted locals. Similarly, tourism service providers from remote areas can gain exposure from this platform to showcase untapped tourist destinations in a global context.

\section{b. Follow the Trend}

As nowadays technology savvy tourists are more sophisticated and determined to retrieve fast and accurate travel information through online access (Yeoman \& McMahon-Beattie, 2006; Mihalcescu, Sion \& Marginean, 2016), Extra will allow them to receive accurate tourism information from trusted locals and customize trip itineraries.

\section{c. Effective Communication Media}

An ICT tool allows tourism service providers to communicate directly and more efficiently with prospective travelers (Ray, et. al, 2011). Hence, Extra aims to establish an interaction between tourism service providers and tourists for trip planning and local recommendations. 


\section{d. Prospective Customer Base}

As aligned with the government's initiative to expand Indonesia's tourism attractions worldwide by promoting "Ten New Balis" (Chan, 2017), Indonesia is expected to welcome 20 million international tourist arrivals by 2020 (Lee, 2018). As such, it is projected that those potential visitors will use Extra to explore Indonesia's tourist destinations and improve traveling experience.

\subsection{Constraints \& Barriers}

While some potential opportunities have been recognized to proceed the development of Extra, there are potential constraints and barriers revealed from this study as well.

\subsubsection{Constraints}

Constraints that may affect the effective development process of Extra are related to the a) complex regulation and b) lack of app developer resources.

\section{a) Complex regulation}

Regulations and bureaucratic procedures are issues that may occur as a challenge to start the app's business. According to the World Bank (World Bank, 2018), Indonesia scored low on the "Ease of doing a business" classification. Compared to Singapore which can take around two days to set up a business, it takes an average of twenty days in Indonesia. This is worsened by various document requirements that need to be submitted for the business registration process (Wasserbauer, 2014). This constraint may prolong the initiation of Extra's development process and opportunity to earn revenue within the projected timeline, as well as potentially put the company in risk due to incomplete permit documents. Though the reigned government will continually improve the regulation process by simplifying unnecessary procedures and utilizing online systems to attract more business startups and investors (Diela, 2017), it is anticipated to consult with a legal advisor to avoid any future compliance risks and administer the company registration as early as possible to avoid the delay of the project development process. 


\section{b) Lack of App Developer Resources}

The development process of Extra - which includes designing, developing and testing the app - requires a set of experienced app developer skills that Indonesia may be lacking. Mandel (2015) study revealed that the app economy of Indonesia - which defines as "the whole ecosystem of jobs, companies, and income connected with the production and distribution of mobile apps" (para. 3 ) - is still in the process to be in the strong position among other South East Asia countries. Therefore, this project will explore an opportunity to have a more matured app developer from neighboring country such as India in order to ensure the cost and time effectiveness of the app development process, as well as the quality of the app's final product.

\subsubsection{Barriers}

Potential barriers that may arise during Extra's implementation are user's actual purchase intention, tourism service provider's actual willingness to get onboard, and customers' motivation to write after trip reviews (see Ch. 4.4.2).

\subsection{Business Model Recommendation}

Through an exploratory mixed methods research design that involved interviews with 11 Indonesia's tourism service providers and 37 tourists that were in Indonesia, as well as 129 respondents from online questionnaires, a better understanding of current tourism phenomena such as challenges and opportunities of the tourism industry in Indonesia is gained. Then, all of the key findings from the research were identified to validate assumptions in the initial draft of the business model canvas in order to develop the minimum viable product of Extra. Most of the assumptions that were presented in the initial business model canvas has been proven by the findings of this study to be included in the development plan of Extra. Referring to the verified assumptions of this study, the recommendation of the most appropriate business model for Extra is outlined in Table 5.1. 


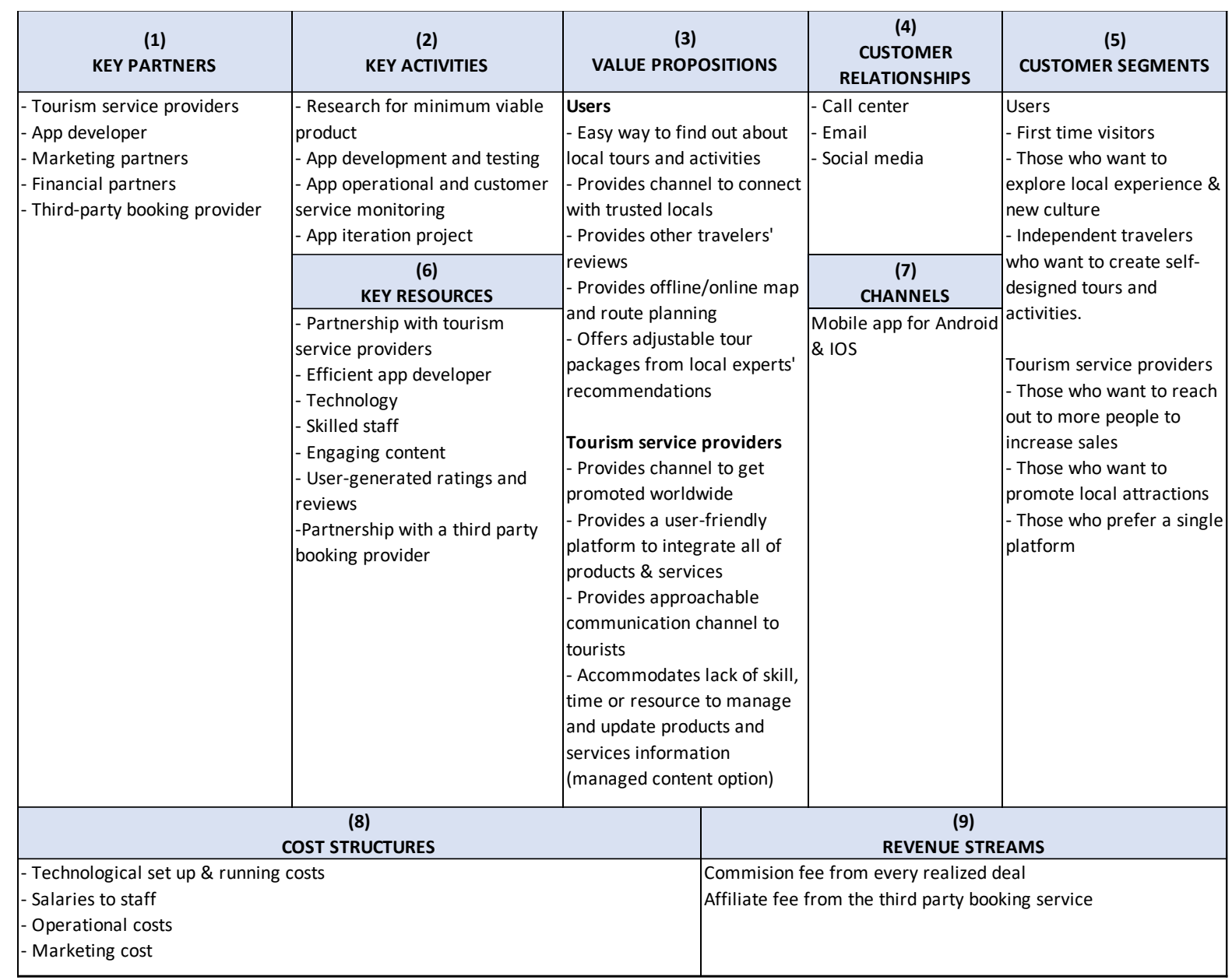

Table 5.1 Business Model Recommendation

At the moment, this study is part of the first key activity of the app's development project, which is conducting research to identify the minimum viable product (MVP) of the app. As such, in order to define the MVP of the app, verified assumptions on customer segments and value propositions are discussed.

\subsubsection{Target Market/Customer Segments}

There are two target market groups of Extra, namely users and tourism service providers as Extra's contributors. As discussed in Chapter 4.2, the target markets of users are first-time visitors, those who want to explore local experiences and new cultures, and independent travelers who want to create self-designed tours and activities. It is forecasted that Indonesia will welcome 20 million tourists in 2019 (Thaib, 2018). Considering that travel apps are accessed by $1,5 \%$ of smartphone users after an online shopping session (Mindsea, 2018), it is expected that the app will capture 25.000 engaged users per month. Meanwhile, taking the 
median number of the conversion rate of the travel online industry from Adler (2018) and Criteo (2017), which is 5\%, it is assumed that the app will yield around 1,250 monthly transactions.

Correspondingly, the target markets of tourism service providers are those who want to reach out to more people to increase sales, those who want to promote local attractions, and those who prefer to use a single platform (see Ch. 4.2).

\subsubsection{Value Propositions}

Having identified the customer segments of Extra, this section discusses the potential value propositions that can attract individuals within the target market to use Extra. The value propositions of the app - which has been verified by the findings of this study - are presented in Table 5.2. 


\begin{tabular}{|c|c|}
\hline Value Propositions & Validations \\
\hline \multicolumn{2}{|r|}{ Users } \\
\hline $\begin{array}{l}\text { Easy way to find out about local tours and } \\
\text { activities }\end{array}$ & $\begin{array}{l}92 \% \text { of the respondents desired to have information } \\
\text { on local attractions, accommodations, restaurants, } \\
\text { and events during their trip }\end{array}$ \\
\hline Provides channel to connect with trusted locals & $\begin{array}{l}\text { Local recommendations were the most suggested } \\
\text { additional feature by the questionnaire respondents }\end{array}$ \\
\hline Provides other travelers' reviews & $\begin{array}{l}33 \% \text { of the respondents preferred to have post-trip } \\
\text { guests' ratings \& reviews in the travel app }\end{array}$ \\
\hline $\begin{array}{l}\text { Provides offline/online map and route } \\
\text { planning }\end{array}$ & $\begin{array}{l}72 \% \text { of the respondents expected that they could } \\
\text { have a travel app that supports offline maps during } \\
\text { their trip }\end{array}$ \\
\hline $\begin{array}{l}\text { Offers adjustable tour packages from local } \\
\text { experts' recommendations }\end{array}$ & $\begin{array}{l}35 \% \text { of the respondents desired to have the ability } \\
\text { to create their own trip itineraries in the travel app }\end{array}$ \\
\hline \multicolumn{2}{|c|}{ Tourism service providers } \\
\hline Provides channel to get promoted worldwide & $\begin{array}{l}\text { Some of the interview participants emphasized the } \\
\text { need of a platform that can extend their products } \\
\text { and services offerings in the global context }\end{array}$ \\
\hline $\begin{array}{l}\text { Provides a user-friendly platform to integrate } \\
\text { all of products \& services }\end{array}$ & $\begin{array}{l}\text { Most of the interview participants desired a } \\
\text { platform that can incorporate all of their products } \\
\text { and services information }\end{array}$ \\
\hline $\begin{array}{l}\text { Provides approachable communication } \\
\text { channel to tourists }\end{array}$ & $\begin{array}{l}\text { Some of the interview participants cited that } \\
\text { alternative channels other than social media are } \\
\text { important to communicate with customers directly }\end{array}$ \\
\hline $\begin{array}{l}\text { Accommodates lack of skill, time or resource } \\
\text { to manage and update products and services } \\
\text { information (managed content option) }\end{array}$ & $\begin{array}{l}\text { Some of the interview participants did not have the } \\
\text { capability to manage the app by themselves due to } \\
\text { the lack of time, skill and experience }\end{array}$ \\
\hline
\end{tabular}

Table 5.2 Value Propositions and Validations

\subsubsection{Extra's Features Summary}

As presented in Chapter 4.2, below are the summary of key elements that relate to the design and function of Extra:

- Channel/Application platform: mobile app for Android and IOS

- Features:

- Local tours and activities offerings (include detail booking form, shopping cart, and payment method) 
- Link to third-party booking services for accommodation (Booking.com) and local transportation reservations

- Offline maps and route planning

- Allow users to modify trip suggestions

- Allow tourism service providers to update their contents and have their own dashboard to manage sales performance

- Customer relationships:

- Call center

- Contact form

- Social Media (Facebook, Instagram, YouTube, Twitter)

- An alternative direct communication channel between tourists and hosts (will be developed after further research regarding the most suitable communication channel platform for the app is carried out)

As a whole package features within Extra, this app could benefit tourists and tourism service providers in the sense of cost and time effectiveness since it enables tourists to explore tours and activities seamlessly with the guidance of local experts and tourism service providers to promote their products and services in a single platform.

\subsection{Product Development Process}

Through a comparison with several prominent travel apps such as TripAdvisor, Airbnb, Triposo, and Withlocals, it is concluded that all of the key elements within the app will potentially add values on top of the said travel apps by offering more activities and destinations in Indonesia, self-designed trip planning, local recommendations, and offline travel guide in a single app (see Ch. 4.3). Through evidence-based assessment of commercial, product creation, connection channel, and marketing feasibilities, Extra is also commercially viable to be further developed into a real product (see Ch. 4.4). The development process of the app includes six phases that are outlined in Figure 5.1. 

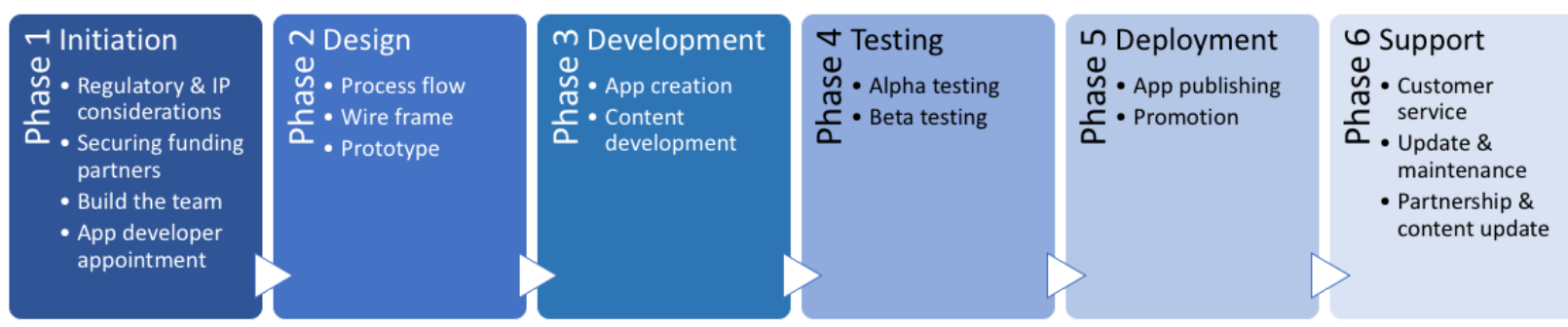

Figure 5.1 Extra Development Process

\subsubsection{Phase 1 - Initiation}

It is very necessary to have thorough planning during this phase to ensure that the following processes flow smoothly. This phase comprises four key activities i.e. regulatory and IP considerations, seeking funding partners, build the team, and app developer appointment. It is expected that all of the activities within this phase are finalized in two months.

\subsubsection{Regulatory Considerations}

Currently, Indonesia does not have a law or policy explicitly regulating the conduct of an online business. In the digital business area, including mobile apps, the principal regulatory would be the Minister of Communication and Information Technology Circular Letter No. 3 of 2016 on Providing Application Services and/or Content Through the Internet (Over-the-Top) (Kominfo, 2016). In order to comply with Indonesia's regulatory body, the first step of doing the mobile app business is to obtain the necessary permits such as the Company Domicile and Registration certificates, the Trade Business License, and the Tax Registration Certificate (Husein, Sirie, \& Rahman, 2018). Further consultation with a legal advisor will be needed to ensure the completeness of the business permits and reduce any potential business risks in the future.

\subsubsection{IP considerations}

It is necessary to secure the intellectual property rights of Extra in order to protect the app against any future infringements that relate to its concepts and brand identities. Therefore, before starting to discuss the design and further development process of Extra, a non- 
disclosure agreement signing process between the project owner and app developer will be conducted to ensure that all of the shared information will be kept confidential. Then, once the development project is finalized, the app developer will need to sign over any copyright to the project owner to avoid the app developer from claiming the copyright of Extra. The next step is to register a trademark for the apps' brand identity (name and image logo). This step is also essential since it can prevent others from using the same name and logo of the app and may take advantages from it. The final step of protecting the intellectual property rights is to seek an opportunity whether the app's methods and processes could be patented since it is recognized that a patent process needs meticulous requirements and the app itself needs to be 'novel' - or different from all previous inventions (Dholakiya, 2017).

\subsubsection{Securing Funding Partners}

Having a funding partner/s is the next core activity in the first phase of developing Extra. Since the main objective of Indonesia's government is to "make Indonesia a global tourism hot spot" (Lee, 2018, para.1), this project will propose a partnership agreement with the Ministry of Tourism to support the promotion of Indonesia's tourism destinations by showcasing unique experiences and activities based on local recommendations. In parallel, this project will also seek funding support from angel investors. Considering the amount of funding that will be required for the initial development of Extra, this project aims to gain funding support from angel investor(s) as opposed to venture capitalists that generally intend to invest in a startup company that needs at least USD 1 million of funding support (Samson, 2015). In particular, Extra's development project will seek an opportunity to collaborate with angel investor(s) that have expertise and networks in a travel app field since their business guidance and networks introduction is paramount in shaping the success of the enterprise's business operation. Further, they would be able to provide key strategic decisions that include advising on effective resource recruitments and tips to raise additional funds (Ward, 2018). Multiple efforts will be carried out to seek funding partners, such as actively participating in the local investor meetup event, seeking investor referrals from existing networks, and connecting with potential angel investors through online network platforms. 
The organization structure of the app's development and operational project is outlined in Table 5.3.

\begin{tabular}{|l|l|c|c|}
\hline \multicolumn{1}{|c|}{ Position } & \multicolumn{1}{|c|}{ Role \& Responsibilities } & $\begin{array}{c}\text { Development } \\
\text { phase }\end{array}$ & $\begin{array}{c}\text { Operational } \\
\text { phase }\end{array}$ \\
\hline CEO & $\begin{array}{l}\text { Manage overall operations and lead the } \\
\text { team }\end{array}$ & 1 & 1 \\
\hline Mobile App Specialist & $\begin{array}{l}\text { Manage and monitor the app branding } \\
\text { and its technical requirements }\end{array}$ & 1 & 1 \\
\hline Digital Marketing Manager & $\begin{array}{l}\text { Develop and execute organization's } \\
\text { marketing and advertising initiatives }\end{array}$ & 1 \\
\hline Partnership Manager & $\begin{array}{l}\text { Foster and maintain partnership with } \\
\text { tourism service providers }\end{array}$ & 1 \\
\hline Content Manager & $\begin{array}{l}\text { Create, publish, and maintain engaging } \\
\text { content }\end{array}$ & 1 & 1 \\
\hline General Affairs Manager & $\begin{array}{l}\text { Manage all general affairs function to } \\
\text { support the key business needs }\end{array}$ & $\mathbf{3}$ & $\mathbf{6}$ \\
\hline
\end{tabular}

Table 5.3 Organization Structure

During the development phase, the app development team will consist of 3 core members, which are the CEO, Mobile App Specialist, and General Affairs Manager. This core group will need a set of specific skills to run each task related to Extra's development project and actively seek advice from legal advisors and subject matter experts. The CEO will ensure that the app's development process is aligned with its intended objectives, features, and functions. Likewise, this individual will make sure that all of the activities within this phase meet the budget, timeline, and job scope. The Mobile App Specialist's main responsibility is to affirm that the enterprise's technology roadmap supports its business strategy. This role includes collaborating with the app developer to develop an engaging travel app, monitoring the technology performance within the app, providing a reliable technical appraisal on potential new services, and projecting future technology plans to add value to the company (Smith, 2003). Meanwhile, the General Affairs Manager will be in charge of supporting day-to-day administrative and organizational activities, including maintaining and supplying office facilities, arranging the meeting and conference logistics, and organizing all of the company's documentation. 
Then, at the first operational phase of Extra, the organization is expanded by adding three core personnel to the team, namely the Digital Marketing Manager, Partnership Manager and Content Manager. The importance of recruiting a Digital Marketing Manager is because this individual can develop and manage the app's marketing campaigns, improve brand awareness to drive user acquisition, as well as identify and evaluate new digital opportunities for marketing campaigns optimization (Talley, n.d.). The Partnership Manager will be in charge of identifying unique tourism experiences across Indonesia, approaching the related tourism service providers to be Extra's business partner, and retaining the business relationship with them. Likewise, this individual will foster and maintain the relationship with third-party booking providers. Meanwhile, the Content Manager's role is to create, update and publish engaging content of tourism service providers' products and services. Further, he/she will also be responsible to provide guidelines for tourism service providers who desire to upload their offerings on the app by themselves. These operational team members will report their work progress regularly to the CEO with the set of Key Performance Indicators (KPIs) and goals from the CEO. In regard to managing customers' queries and feedback, it is considered to use the service of an outsource customer support vendor since it can offer proven swift and reliable customer service to support a startup business with a large amount of operational cost saving (Angeles, 2014).

As the business grows, it is possible to add more personnel to support the business operation in the future. This additional employment will be determined further during Extra's implementation by considering the budget feasibility and ratio of personnel and customers. Further, roles and responsibilities within the organization are subject to change depends on the organization's requirements. In the long run, members with strategic roles within the organization may evolve into an advisory board to enable the opportunity to enlarge the business in a broader scope.

\subsubsection{App Developer Appointment}

Comprehensive online and offline research will be conducted to identify the most fitting app developer for this project. Several criteria for selecting the suitable app developer include 
past projects portfolio, experience, reasonable timeline and cost, organization, and responsiveness. Considering the rising recognition of India's app developer that can produce an app with the same quality as the US developer yet the production cost is ten times less expensive (BI Intelligence, 2017), this development project will collaborate with India's app developer. Once the non-disclosure agreement (NDA) has been finalized with the assigned app developer, the next step is to discuss with the app developer regarding the specifications of Extra including the core functions, the required elements, the user experience approach, and the estimated costs to create Extra from the start to the finish. All of the descriptions of Extra will be outlined in a blueprint that will act as a sole guideline of the application development project for both project owner and app developer.

\subsubsection{Phase 2-Design}

\subsubsection{Process Flow}

At this stage, flow diagrams are identified to get a clear outline of the app flow process. It includes visual presentations of Extra's screen visuality. Currently, a preliminary discussion with a potential app developer has been conducted to design the basic app flow process, which is outlined in Figure 5.2. 


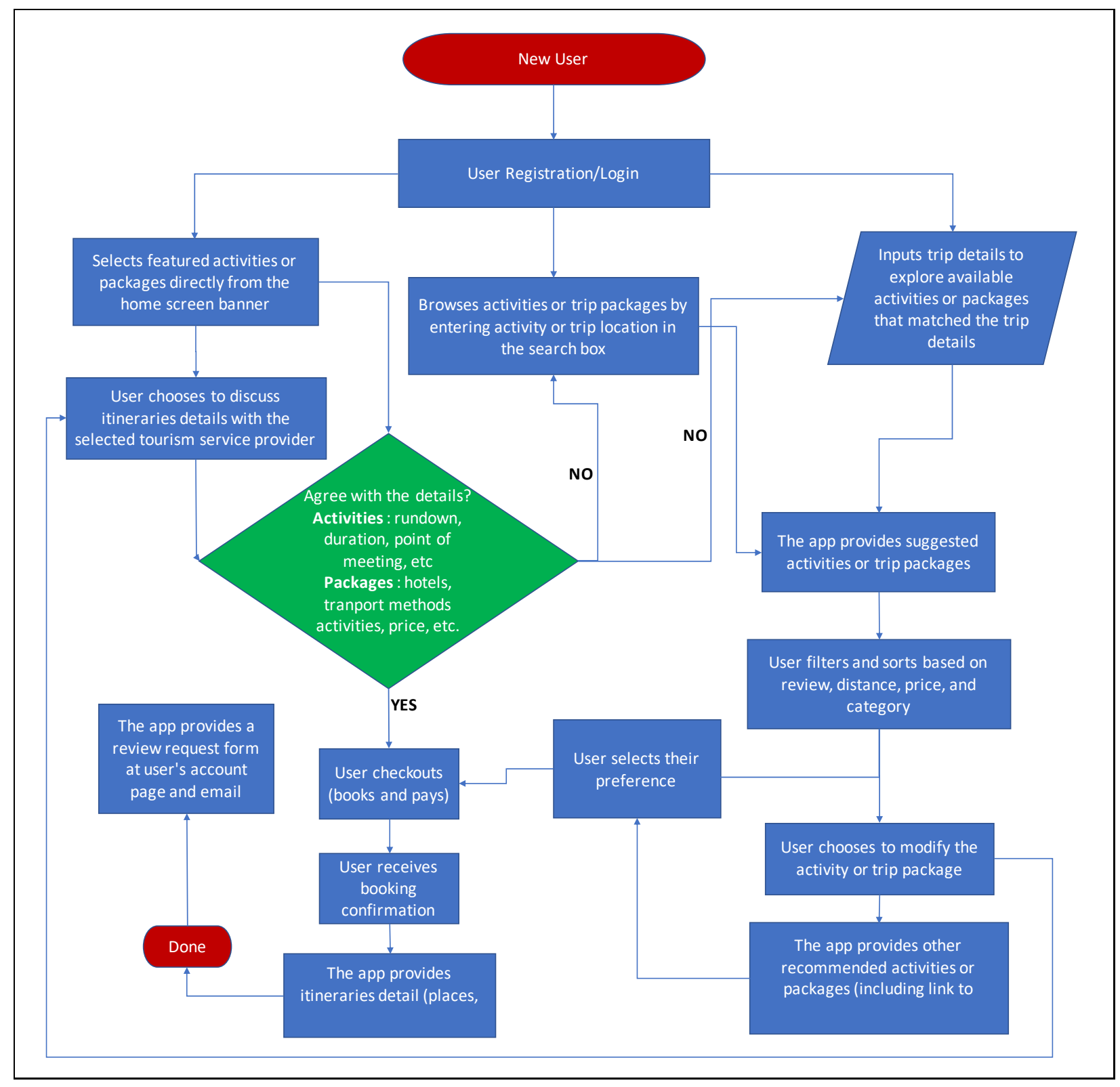

Figure 5.2 Process Flow of Extra

The first interaction of the user with Extra is the registration or login process if the user already has a registered account. Next, Extra's home screen will show featured packages/activities and popular destinations/activities. An engaged user can select their preferred activity or trip package displayed from the home screen then proceed to checkout procedure. Alternatively, the user can enter their desired trip location or activity in the search box or enter trip details such as travel from and to, number of days for the trip package, number of people, and preferred activities to reveal the suggested activities or trip packages from Extra. At this point, the user can sort or filter the packages based on the review, distance, 
price, and category (nature, adventure, local skills, etc.). If the user would like to modify the offered activities or packages, he/she will be redirected to the list of other recommended activities and third-party accommodation and transportation booking services. Otherwise, the user can also discuss any specific trip arrangements with the selected tourism service provider(s) through a phone call or contact form. Once the user decides to book and purchase the offered packages/activities, the app will provide trip itineraries detail that includes places, routes, and maps on the user's booking history. This trip itineraries will be saved on the user's device memory thus it can work both online and offline. After completing the excursion, the user will be given a review form to share their review and experience. This process flow will be further detailed and refined during the implementation of the design process. Afterward, having concluded the process flow plan, the next procedure is to develop the wireframe design.

\subsubsection{Wireframe}

The wireframe design - which is defined as a framework visual guide of an app (Techopedia, n.d.) - will be carried out in order to get a more concrete picture of Extra's function, content, and behavior. This includes creating a storyboard to illustrate the links between each screen, defining the app's navigation, and identifying every element that will be displayed in Extra's screen i.e. pictures, icons, themes, videos, color, background, etc. Considering the importance of creating a compelling app for user acquisition consolidation in the long run, the mobile app specialist will intensely collaborate with the app developer at this stage to produce an engaging and seamless User Experience (UX) and User Interface (UI) design. This can be achieved by ensuring that Extra's design is user-friendly and attractive. It is also expected that a Search Engine Optimization (SEO)-friendly title and description is designed meticulously at this stage to capture people's attention effortlessly in the app store tool and online search engine once the app is live.

\subsubsection{Prototype}

Having finalized the wireframe process, a prototype will be developed to simulate the Extra's performance before the actual app development. In regards to having an efficient 
development process, it is essential to carry out this stage since any changes, bugs and potential additional costs can be identified earlier before Extra enters the real-world circumstances. During this stage, thorough development of the application architecture will be conducted. This means that coding will be executed to activate Extra. Subsequently, security measures will also be assessed to ensure Extra complies with the security standards for data storage, layer protection, and data encryption (Sheldon, 2017). After completing the prototype process, a pretested will be executed to identify potential bugs by running and checking various programs at different scenarios to ensure that the app is robust and flawless. The core activity during this stage is to evaluate process flows and identify faults of Extra's functionality. It is anticipated to modify the wireframes design to anticipate any technical limitations that are revealed during this stage.

\subsubsection{Phase 3-Development}

\subsubsection{App Creation}

Having finalized the prototype testing phase, the actual version of Extra will be created at this development phase. Thus, the app developer will conduct coding and programming process to make Extra goes live. The progress of this development process will be checked and verified intensively by the CEO and Mobile App Specialist to ensures that the application represents the precise design, features, and functions of Extra with the agreed scope of work, timeframe, and budget. It is expected that Extra's creation will be $100 \%$ finalized at this stage although some bugs may still present. After concluding the creation process, the following step is to conduct a testing stage in order to ensure Extra performs flawlessly.

\subsubsection{Content Assemble}

In parallel, the content development process is also carried out during this stage. The Partnership Manager will explore partnership agreements with potential tourism service providers. Several key destinations and activities will be featured in the initial stage of Extra implementation. comprises major destinations such as Bali, Yogyakarta and Jakarta and a 
larger proportion of other attractive activities in other cities. It is projected that the featured three major destinations will be easily discovered in the search engine tools and trigger potential customer to explore new destinations within Extra. Potential destinations and activities will be explored through tourism service providers association and locals' travel communities. Then, the related tourism service providers will be approached to get on board with Extra. At this initial stage, once they agree to promote their products and services through the app, the Content Manager will create and upload the activities' details. Later, prospected tourism service providers will be able to choose a self-managed option for the content update.

Similarly, Extra will collaborate with Booking.com at the initial stage of its commercialization to provide flexibility for those who want to modify their accommodation trip packages offering. Further, as the business is expanded, it is expected that Extra will have its own accommodation booking service in order to provide a one stop travel solution.

\subsubsection{Phase 4-Testing}

\subsubsection{Alpha Testing}

The first process within this phase is to execute an Alpha testing procedure in order to examine the functions and usability of Extra. Along with the project owner, specialized testers with subject matter expertise will be invited to carry out this procedure in a lab environment. This process includes creating test scenarios, performing the test, gathering feedback, and identifying which parts of Extra's performance that are needed to be improved. Once Extra's refinement process is concluded, the next testing stage is the Beta testing.

\subsubsection{Beta Testing}

The Beta testing process - which defines as the testing procedure performed by real users in an actual situation (Software Testing Help, 2018) - will be carried out as a final testing process to ensure Extra's steadiness, robustness, and security before it is deployed to the public. The key differences between this testing procedure and the Alpha testing are the testing environment and the participant's nature. This process will involve end users - that will be 
recruited through an open solicitation - in the real-time environment. Similar with the UAT follow up procedure, all feedbacks will be examined, and necessary adjustments will be made so that Extra will function in a manner appropriate to real-world circumstances and usage.

\subsubsection{Phase 5-Deployment}

\subsubsection{App Publishing}

As soon as Extra is ready to be released to the public, the next step is to register and publish it in the Google Play store and Apple's App Store. Since they have a strict review process, it is necessary to comply with all of their requirements and guidelines and to ensure the submission process runs smoothly and avoid the delay of the expected release date. The publishing of Extra will be followed by the App Store Optimization (ASO) approach to gain more visibility in the app store's search results. This project will utilize an ASO tool to monitor and analyze the quality of the app's title and keywords, as well as to get better keywords suggestion and competitors updates (Ganguly, n.d.).

\subsubsection{Promotion}

As a new product, Extra will need significant marketing efforts to gain brand awareness to its targeted potential customers and partners, which are a) users and b) tourism service providers respectively.

\section{a) Users}

\section{- Web Landing Page}

Prior to Extra's launching, a good quality of a web landing page - that contains information about the app's features and functions, visual presentation (i.e. screenshots, images, icons, videos), frequently asked question (FAQ), as well as the app's background story and objectives - will be created to obtain an early Search Engine Optimization (SEO) advantage. SEO is essential as it enables the app to be easily discovered in the search engine result pages. This can be achieved by optimizing the web landing page's keywords, content, and page loading speed (Patel, 2018). 


\section{- Social Media Integration}

Along with Android and IOS app install buttons, the web landing page will be furnished with visible social media buttons to extend Extra's presence on various social networks such as Facebook, YouTube, Instagram, and Twitter. This approach is considered essential to generate potential users from those particular accounts. A Twitter feed will also be integrated in the landing page to update the latest news or featured activities.

\section{- Paid Advertising}

Search Engine Marketing (SEM) and Facebook ad campaign will be used to incorporate the SEO strategy. It means that a paid marketing campaign - or pay per click advertising in particular (Baadsgaard, 2017) - will be implemented to gain more visibility in search engine result pages.

\section{- Collaboration with Social Media Influencers}

During the launching period, travel and tech bloggers, journalists, and social media influencers will be approached to review Extra and give objective feedbacks. Similarly, throughout its implementation, Extra will keep exploring and reaching out relevant travel blogs, social groups, forums, or websites to share reviews and provide backlinks to the web landing page within their posts.

\section{b) Tourism Service Providers}

\section{- Collaboration with Tourism Service Providers Association}

The Association of the Indonesian Tours and Travel Agencies (ASITA) is the formal body of tourism service providers association. The recruitment of tourism service providers will be effective if this organization endorses this app to its members and highlights that the main value proposition of Extra is its flexibility to customize trip itineraries. Thus, tourism service providers with fixed package offering will not be able to join.

\section{- Collaboration with Locals' Travel Communities}


As part of its value proposition to offer unique experience based on local recommendations, Extra will approach locals' travel communities such as travel photography, open trip, local art and culture, as well as food trip communities at the initial stage of Extra's implementation. The team of Extra will introduce Extra's benefits through hosting an on-site member gathering or webinar to offer members of those communities an opportunity to share their unique, representable, and practicable activities to visitors. These include skills, hobbies, or city guides. Later on, Extra will expand its partners by targeting wider audiences to allow more various of activities offerings.

As Extra has progressed to gain its users, it is also important to make them stay engaged with Extra which may lead to repeat transactions. Therefore, in order to boost users' engagement, it is considered to utilize an app marketing tool to manage email marketing and mobile push notifications. Further retention plans such as users' rewards and exclusive promotions may be implemented as well in the long-run, depend on the next progress of the app's business model.

Meanwhile, in order to motivate tourism service providers to provide their best service to customers, Extra will hold customer review awards. Winners of the awards - that are assessed based on the number of good reviews and ratings during a certain period - will receive a special highlight profile in Extra's home screen and winner tag on their offered products to boost more customers.

These marketing plans are flexible and may subject to change due to further assessment of the marketing strategy from the appointed Digital Marketing Manager. A frequent optimization also will be carried out to explore the most appropriate balance of different marketing methods during Extra implementation.

\subsubsection{Phase 6-Support}

\subsubsection{Customer Service}

As presented previously, during Extra's implementation, it is necessary to ensure the quality of service performance by employing an outsource customer support platform and agents. It 
is deemed important to utilize their service due to their expertise in providing seamless customer experience with their automation, ticket management, and optimization tools (Finances Online, 2018). This team will work upon a help center platform that collects continuous update of information in order to give the most appropriate and effective answers on general inquiries. Both customers and tourism service providers will be able to browse this information in the customer frequently asked question (FAQ) and partner forum section respectively. Further queries will be handled by dedicated support agents through the provided customer service channels (call center, contact form, email, and social media). At the initial stage of the app implementation, as an agent will handle an average of 250 customers per month (Redbord, 2017), and the potential monthly transactions is 1,250 , it is projected that five agents will be employed to respond and resolve current and potential customers' and service providers' queries regarding the app's products and services in a timely manner. Similar with the arrangement of the app's core team, additional agents will be considered further based on the budget feasibility and ratio of agents and customers.

\subsubsection{Update \& Maintenance}

During the implementation of Extra, performance monitoring is a recurring activity to ensure the quality of Extra's service and function. Matanov (2018) describes that the app maintenance is as vital as its development since there are multiple factors that are needed to be addressed such as operating system and security updates, features and user interface enhancements, and performance optimization. The projected cost related to Extra's update and maintenance is discussed in the financial forecasting section. Likewise, iteration efforts are as part of update and maintenance project in which feedback from users are actively gathered from their inquiries or comments through interaction channels (call center, contact form, email, and social media) and post trip reviews. Continual necessary adjustments will be executed following to the feedback evaluation to maintain Extra's service and performance quality. 


\subsubsection{Partnership \& Content Update}

As discussed earlier, the Partnership Manager will actively search and approach eligible tourism service providers to get on board with Extra. In course of time, tourism service providers that have the interest to be the app's partner can submit a partner request form that will be provided in the app and the website landing page. The submitted form will be reviewed by the relevant unit by considering its uniqueness, representability, and practicability factors. Once the proposed activity meets those standards, it will be offered depending on whether the content will be managed by the app's content team. Those who intend to manage content on their own will be provided an admin access in which they can create content that align with Extra's content guidelines and standards. It includes detail and correct information regarding their offered activities i.e. price, description, visual presentation, time and date, meeting location, rundown, what guests should bring/wear, and what they provide. Likewise, it is also important to monitor the performance of Extra's established content to foster and maintain the its trustworthiness and customer satisfaction. As such, activities with many low reviews and ratings - which may be due to the host's low commitment to reservations or inaccurate information - may be removed from Extra.

\subsection{Financial forecasting}

\subsubsection{Cost Structure}

As outlined in the business model canvas, the cost structure of Extra consists of four subjects, namely technological setup \& running costs, salaries to staff, operational costs, and marketing costs. This app development project attempts to utilize human and financial resources as efficiently as possible by selecting an effective app developer, hiring experienced talents with reasonable salaries, and carrying out day-to-day business operating effectively.

\subsubsection{Technological Setup \& Running costs}

The technological setup cost includes Extra development cost from the initiation to the final release stage. As discussed with a potential India's app developer, in order to develop Extra with the intended specifications (Table 5.2), the budget estimation is approximately USD 
7.500 - \$9.500 and it will take around $2-3$ months to finalize the development. The most essential specification within this app development is the type of the app's platform. As opposed of choosing a hybrid platform that can work across multiple platforms and requires less cost and development time than a native platform, it is considered to use a native platform because it can provide a better user experience and supports the future and potential scope of the app (Cleveroad, 2018). Further, when mobile app users experience app crashes, low-quality content, and functional errors, they are more likely to have negative perceptions of the mobile app, thus reducing their trust and satisfaction to use the app (Khalid, Shihab, Nagappan, \& Hassan, 2015). Table 5.4 presents the technical specifications detail of Extra based on the common practice that is relevant for the implementation of Extra's features and functions.

\begin{tabular}{|l|l|}
\hline \multicolumn{1}{|c|}{ Specifications } & \multicolumn{1}{|c|}{ Details } \\
\hline Type & Mobile App \\
\hline Platforms & Android, iOS \\
\hline Design & Custom \\
\hline Pages (approx) & 10 \\
\hline Type of app & Native \\
\hline Versions support & Basic \\
\hline Database & Mongo \\
\hline ERP integrations & Oracle \\
\hline CRM integrations & Zoho \\
\hline Mobile API & NodeJS \\
\hline $\begin{array}{l}\text { Content management } \\
\text { system }\end{array}$ & Ruby \\
\hline Analytics & Google Analytics \\
\hline Mobile payments & Paypal, Alipay, credit card, cash \\
\hline Ecommerce integration & Basic, loyalty coupons \\
\hline Users & Accounts, Email login \\
\hline Features & $\begin{array}{l}\text { 3rd party API, Search, Rating system, Chat, } \\
\text { Gallery, Calendar, Push notifications, Geo } \\
\text { location, Offline capabilities, Maps }\end{array}$ \\
\hline
\end{tabular}

Table 5.4 Technical Specifications of Extra

For this financial planning, a $20 \%$ extra budget will be added on top of the highest budget estimation to cover any needed cost during the development or testing process regarding the app's design, flow or feature adjustments. An additional one month is also anticipated for the app's development timeframe to ensure that Extra will have a flawless and robust 
performance when it is live. Therefore, it is forecasted that Extra's development cost is USD 11.400 and the period needed to build Extra is 4 month.

Another cost that relates to the app development project is the recurring cost for Extra's update and maintenance purpose. Think Mobiles (n.d.) suggests that the yearly running costs of the app's update and maintenance are approximately around $20 \%$ of the development cost, or USD 2.280. This cost includes bug fixing, servers rental, payment gateway fee, app store developer fee, third-party APIs charges and emergency maintenance (Think Mobiles, n.d.).

\subsubsection{Employees' Salaries}

The estimation of employees' salaries within the organization are outlined in Table 5.5 referring to Michael Page's Indonesia Salary Benchmark 2018 (Michael Page, 2018).

\begin{tabular}{|l|r|r|r|}
\hline \multicolumn{1}{|c|}{ Position } & $\begin{array}{c}\text { Monthly Salary } \\
\text { (USD) }\end{array}$ & $\begin{array}{l}\text { Development } \\
\text { phase (6 } \\
\text { months) }\end{array}$ & $\begin{array}{c}\text { Operational } \\
\text { phase (yearly) }\end{array}$ \\
\hline CEO & 1,689 & 10,134 & 20,268 \\
\hline Mobile App Specialist & 1,689 & 10,134 & 20,268 \\
\hline Digital Marketing Manager & 1,216 & 2,432 & 14,592 \\
\hline Partnership Manager & 1,216 & 2,432 & 14,592 \\
\hline Content Manager & 1,216 & 2,432 & 14,592 \\
\hline General Affairs Manager & 700 & 4,200 & 8,400 \\
\hline TOTAL & & 31,764 & $\mathbf{9 2 , 7 1 2}$ \\
\hline
\end{tabular}

Table 5.5 Employee Salaries Estimation

As discussed earlier, this project will require three personnel at the development phase and another additional three people in the operational phase. However, two months prior to the operational phase, the Digital Marketing Manager, Partnership Manager, and Content Manager will be starting to do their roles and responsibilities as well. Thus, the required budget for employees' salaries is USD 31,764 during the six months of the development phase and increases to USD 92,712 for the annual operational phase. 


\subsubsection{Operational Costs}

The estimated for operating Extra business are classified into two phases: development phase and operational phase. These costs are referred to the operational cost estimation in Jakarta, Indonesia (S\&F Consulting Firm, n.d.; Wira, 2018) that include legal advisor assistance to register and process business permits, co-working space, travel and meeting expenses, insurance fee, and miscellaneous expenses such as phone top up and transportation reimbursement. The co-working space will be employed as it provides a convenient and professional working space with less cost as opposed to renting an office space with its attaching additional expenses such as setup cost and monthly utility bills (i.e. electricity, internet, water). The cost for the outsource customer support is referred to Zendesk's monthly pricing for employing five support and guide agents (Zendesk, n.d.) There is also a research and development budget for product testing during the development phase and product iteration during the operational phase to support the app's service and feature improvement.

\begin{tabular}{|l|r|r|r|}
\hline \multicolumn{1}{|c|}{ Operational expenses (USD) } & $\begin{array}{r}\text { Development } \\
\text { Phase (6 } \\
\text { months) }\end{array}$ & $\begin{array}{c}\text { Operational } \\
\text { Phase (Yearly) }\end{array}$ & Remark \\
\hline Company registration, business permit & 1,081 & $\begin{array}{r}\text { one-time } \\
\text { charge }\end{array}$ \\
\hline Coworking space & 840 & 1,680 & \\
\hline Travel expenses & 6,000 & 12,000 & \\
\hline Meeting budget & 1,200 & 2,400 & \\
\hline Insurance & 600 & 1,200 & \\
\hline R\&D expenses & 2,000 & 3,000 & \\
\hline Customer Support & & 2,400 & \\
\hline Miscellaneous (phone top up, parking ticket, & 900 & 1,800 & \\
transport reimbursement) & 12,621 & 24,480 & \\
\hline TOTAL & & & \\
\hline
\end{tabular}

Table 5.6 Operational Expenses Estimation

As presented in Table 5.6, the total operational cost during the sixth months of the development phase is USD 12,621 and reaches USD 24,480 annually for the operational phase. 


\subsubsection{Marketing Cost}

As a new product in the app market, Extra will heavily reliant on a sound marketing strategy to attract potential customers steadily. Therefore, a considerable amount of budget is plotted for this subject. Various sources are explored to identify the projected marketing cost for paid SEO advertising (Kendig, 2017), social media influencers i.e. blog writing, Instagram posts, and Facebook ad campaigns (Lincoln, 2018; Main, 2018; Professional Travel Bloggers Association [PTBA] 2017), tourism service providers event gathering, a mobile marketing tool to manage email marketing and mobile push notifications (Aimtell, n.d.), prizes for the review contest draw winners, and app store optimization tool monthly subscription (Dogtiev, 2018b). In total, it is estimated that the yearly marketing budget at the early stage of Extra promotion is USD 19,908 as seen in Table 5.7.

\begin{tabular}{|l|r|r|}
\hline \multicolumn{1}{|c|}{ Marketing channel } & $\begin{array}{r}\text { Monthly budget } \\
\text { (USD) }\end{array}$ & $\begin{array}{c}\text { Yearly budget } \\
\text { (USD) }\end{array}$ \\
\hline Web SEO advertising & 400 & 4,800 \\
\hline Social media campaign & 400 & 4,800 \\
\hline Event gathering & 600 & 7,200 \\
\hline Mobile marketing platform & 99 & 1,188 \\
\hline Review contest & 100 & 1,200 \\
\hline App store optimization tool (AppRadar) & 60 & 720 \\
\hline TOTAL & 1,659 & 19,908 \\
\hline
\end{tabular}

Table 5.7 Marketing Budget Estimation

In total, the cost that will be required for developing and deploying Extra for the first year is USD 105,894 . This cost includes technological setup \& running costs, employees' salaries, operational expenses, and marketing cost.

\subsubsection{Revenue Stream Projection}

As presented in the business model canvas, Extra's revenue will be generated from the commission fee of the realized transaction and affiliate fee from the third-party booking service. This section discusses more detail on to what extent the app will receive revenue by creating a revenue projection plan. Through multiple approaches of assumptions from previous research that has been discussed earlier, the app will generate around 1,250 monthly transactions from 20 million Indonesia's international tourists (Adler, 2018; Criteo, 
2017; Mindsea, 2018; Thaib, 2018). These transactions could be produced from a single or group booking. Then, the total revenue will be deducted by $1 \%$ of the company's earning tax (Indonesia Investment, n.d.)

\subsubsection{Commission from realized deals}

The commission fee of every realized booking activity is plotted at $20 \%$ referred to the commission fee of Airbnb and Withlocals (Withlocals, n.d.; Airbnb, n.d.). As a newcomer in the travel industry, it is important to ensure Extra's competitiveness compared to other similar industry. Tourism service providers might not be willing to promote their products and services through Extra if it charges a higher commission rate than other competitors. On the contrary, based on Airbnb's and WithLocals's proven experience in running their business, lower commission rate seems not feasible to support the running operation cost of the app. Budget Your Trip (n.d.) estimating that the average price per activity is USD 42 . Thus, the projected net monthly revenue is USD 10,395.

\subsubsection{Affiliate fee}

It has been considered that Extra will collaborate with Booking.com to provide an alternative accommodation booking service. Therefore, the first step to calculate the revenue that is generated from this affiliate fee program is to identify critical elements such as the average accommodation rate per night, the conversion rate of users that book accommodation from the app, and the affiliate fee estimation. The average accommodation price in Indonesia is USD 72 per night (Hikersbay, 2018). Due to numerous options of accommodation booking sites, it is forecasted that from all of the customers that book the activity, only $50 \%$ of them who book the accommodation as well through the link provided by the app to the third-party booking service website. Taking an example from Booking.com that offers a share of $35 \%$ of their commission for 151-500 stayed bookings per month and their fixed commission fee is 15\% ("Booking.com Affiliate Program Review," n.d.), then the affiliate percentage of this financial planning is $5.25 \%$. This would generate a net monthly income of USD 2,339 from the affiliate program.

The following table presents the detail calculation of the monthly revenue projection. 


\begin{tabular}{|l|r|r|}
\hline \multicolumn{1}{|c|}{ Potential tourist arrivals } & \multicolumn{2}{|c|}{$20,000,000$} \\
\hline Revenue Calculation & \multicolumn{2}{|c|}{$1,666,667$} \\
\hline Percential monthly tourist arrivals & \multicolumn{2}{|c|}{$25,50 \%$} \\
\hline Potential users & $\begin{array}{c}\text { Commission } \\
\text { Revenue }\end{array}$ & $\begin{array}{c}\text { Affiliate } \\
\text { Revenue }\end{array}$ \\
\hline Conversion rate (\%) & $5.00 \%$ & $2.50 \%$ \\
\hline Potential purchased users & 1250 & 625 \\
\hline Average price of activity/accommodation (USD) & 42 & 72 \\
\hline Commission/affiliate fee (\%) & $20.00 \%$ & $5.25 \%$ \\
\hline Commission/affiliate fee (USD) & 8.40 & 3.78 \\
\hline Projected monthly gross income (USD) & 10,500 & 2,363 \\
\hline Projected monthly net income after 1\% tax (USD) & 10,395 & 2,339 \\
\hline \multicolumn{2}{|c|}{ TOTAL monthly net income (USD) } & 12,734 \\
\hline Average commission (USD) & 6.79 \\
\hline
\end{tabular}

Table 5.8 Monthly Revenue Projection

In Table 5.8, it is outlined that the monthly net income that will be generated from Extra is USD 12,734 and the average commission is USD 6,79.

\subsubsection{Financial Projection}

There are myriad of factors that impact different calculations in this financial plan. Likewise, there are also numerous possibilities that will influence the overall business performance. Therefore, this report attempts to present three different business cases based on the revenue growth level, namely moderate (10\%), high-growth (15\%), and worst-case scenario (5\%). The financial business projection is outlined with several limitations such as unknown justifiable percentages of the revenue growth, undetermined amortization and depreciation factors, and other unidentified components that have not been assessed by this study. Therefore, this financial plan will be adjusted over time during Extra's implementation. In this financial planning, it is forecasted that the annual inflation rate for the next five year is $3.85 \%$ ("Indonesia - Inflation rate 2022 | Statistic," n.d.) and the annual increase price of the activity and hotel is $5 \%$ in average. 


\subsubsection{Moderate Scenario}

Table 5.10 illustrates the moderate scenario of the financial plan. The Year 1 consists of 6month development period and the 6-month implementation period. It is assumed that the app will receive a positive response from end users and the yearly transaction growth is $10 \%$. This figure is considered realistic because the number of international visitors will keep growing and many of them might be interested to visit other destinations than mainstream destinations such as Bali, Jakarta, and Yogyakarta. Further, it is assumed that the involvement of social media influencers as part of the campaign strategy is successful to attract new acquisitions.

\begin{tabular}{|c|c|c|c|c|c|}
\hline MODERATE & Year 1 & Year 2 & Year 3 & Year 4 & Year 5 \\
\hline \multicolumn{6}{|l|}{ REVENUE } \\
\hline YoY Growth (\%) & & $10 \%$ & $10 \%$ & $10 \%$ & $10 \%$ \\
\hline Transactions (unit) & 11,250 & 24,750 & 27,225 & 29,948 & 32,942 \\
\hline Commission increase (\%) & & $5 \%$ & $5 \%$ & $5 \%$ & $5 \%$ \\
\hline Average commission (USD) & 6.79 & 7.13 & 7.49 & 7.86 & 8.25 \\
\hline TOTAL REVENUE (USD) & 76,388 & 176,455 & 203,806 & 235,396 & 271,882 \\
\hline
\end{tabular}

\begin{tabular}{|c|c|c|c|c|c|}
\hline COST & & & & & \\
\hline Inflation rate (\%) & & $3.85 \%$ & $3.85 \%$ & $3.85 \%$ & $3.85 \%$ \\
\hline App development (USD) & 11,400 & & & & \\
\hline App update $\&$ maintenance (USD) & 1,140 & 2,280 & 2,368 & 2,459 & 2,554 \\
\hline Employee salary (USD) & 78,120 & 92,712 & 96,281 & 99,988 & 103,838 \\
\hline Operational expenses (USD) & 24,861 & 24,480 & 25,422 & 26,401 & 27,418 \\
\hline Marketing expenses (USD) & 13,272 & 19,908 & 20,674 & 21,470 & 22,297 \\
\hline TOTAL COST (USD) & 128,793 & 139,380 & 144,746 & 150,319 & 156,106 \\
\hline NET PROFIT (LOSS) (USD) & $(52,406)$ & 37,075 & 59,060 & 85,077 & 115,776 \\
\hline BREAKEVEN (USD) & & $(15,330)$ & 43,729 & 128,806 & 244,582 \\
\hline
\end{tabular}

Table 5.9 Moderate Financial Plan

In Table 5.9, it shows that the total revenue is the product of transactions and the average commission. As for the cost calculation, the app development cost refers to the technological setup \& running costs section, while the app update and maintenance cost is derived from the proportional calculation of the half-year cost. The employee salary figure is obtained from the sum of the development phase and the half-year of operational phase in the employees' salaries section (see Table 5.6). Likewise, the amount of operational expenses is gained from the sum of the development phase and the half-year of operation phase that are presented in the operational costs section (see Table 5.7). Meanwhile, the marketing expenses figure is 
calculated from the monthly marketing expenses showed in Table 5.8 multiplied by 8 months ( 2 months at the development phase and 6 months at the operational phase).

Table 5.10 also shows that the first year has a negative profit at USD 52,406 since it only has a half year of commercial activity. The total cost that will be required to develop and operate the app during the first year is USD 128,793 . Through this scenario, it is expected that the company will reach a break-even period - which defined as point in time when projected revenue precisely equals the projected total costs; where loss ends and profit begins to accrue (Business Dictionary, n.d.) - after 4 years of operation at USD 128,806 although it starts to obtain positive profit in the third year of operation (USD 43,729 ).

\subsubsection{High Growth Scenario}

The most profitable business plan is when it is expected that the growth of transaction is $15 \%$ per year due to successful app iteration projects and marketing strategies. It is assumed that the total cost is as same as the moderate business case. Akin to the moderate financial plan, it is expected that the company will reach a break-even period after 4 years of operation with a slightly higher amount at USD 189,356 (see Table 5.10). As the business grows, it may be considered to hire more resources to update more content and support customer service as soon as the business has reached the breakeven period. However, this financial plan has excluded this factor in the cost calculation estimation.

\begin{tabular}{|c|c|c|c|c|c|}
\hline HIGH GROWTH & Year 1 & Year 2 & Year 3 & Year 4 & Year 5 \\
\hline \multicolumn{6}{|l|}{ REVENUE } \\
\hline YoY Growth (\%) & & $15 \%$ & $15 \%$ & $15 \%$ & $15 \%$ \\
\hline Transactions (unit) & 11,250 & 25,875 & 29,756 & 34,220 & 39,353 \\
\hline Commission increase (\%) & & $5 \%$ & $5 \%$ & $5 \%$ & $5 \%$ \\
\hline Average commission (USD) & 6.79 & 7.13 & 7.49 & 7.86 & 8.25 \\
\hline TOTAL REVENUE (USD) & 76,388 & 184,476 & 222,755 & 268,976 & 324,789 \\
\hline \multicolumn{6}{|l|}{ COST } \\
\hline TOTAL COST (USD) & 128,793 & 139,380 & 144,746 & 150,319 & 156,106 \\
\hline NET PROFIT (LOSS) (USD) & $(52,406)$ & 45,096 & 78,008 & 118,657 & 168,683 \\
\hline BREAKEVEN (USD) & & $(7,310)$ & 70,699 & 189,356 & 358,039 \\
\hline
\end{tabular}

Table 5.10 High Growth Financial Plan 


\subsubsection{Worst-case Scenario}

For the worst-case scenario, it is assumed that the yearly increase of realized transactions is only $5 \%$ or approximately $0.4 \%$ per month. Hence, in order to not borne anymore cost while the profit performance is still negative, it is assumed to perform the business as usual by not increasing the marketing budget nor hiring additional personnel. In this case, it is anticipated that the iteration project is also being done but only be able to attract the same level of transaction growth due to other competitors' attractive offers in the market. With this scheme, it is projected that the company will reach a break-even after 5 years of operation at USD 141,628 (see Table 5.11). Given the fact from App Promo research that $67 \%$ of apps operated for at least three years were not yet breakeven (McKendrick, 2013) and that the current app business is concentrating on the long-term profitability than its novelty factor (Dogtiev, 2018a), the worst case scenario is still financially viable since at least it manages to reach the breakeven point yet with a longer time.

\begin{tabular}{|c|c|c|c|c|c|}
\hline WORST CASE & Year 1 & Year 2 & Year 3 & Year 4 & Year 5 \\
\hline \multicolumn{6}{|l|}{ REVENUE } \\
\hline YoY Growth (\%) & & $5 \%$ & $5 \%$ & $5 \%$ & $5 \%$ \\
\hline Transactions (unit) & 11,250 & 23,625 & 24,806 & 26,047 & 27,349 \\
\hline Commission increase (\%) & & $5 \%$ & $5 \%$ & $5 \%$ & $5 \%$ \\
\hline Average commission (USD) & 6.79 & 7.13 & 7.49 & 7.86 & 8.25 \\
\hline TOTAL REVENUE (USD) & 76,388 & 168,434 & 185,699 & 204,733 & 225,718 \\
\hline \multicolumn{6}{|l|}{ COST } \\
\hline TOTAL COST (USD) & 128,793 & 139,380 & 144,746 & 150,319 & 156,106 \\
\hline NET PROFIT (LOSS) (USD) & $(52,406)$ & 29,054 & 40,953 & 54,414 & 69,612 \\
\hline BREAKEVEN (USD) & & $(23,351)$ & 17,602 & 72,016 & 141,628 \\
\hline
\end{tabular}

Table 5.11 Worst Case Financial Plan 


\subsection{Timeline of All Activities}

The timeline of all activities related to the development of Extra is presented in Table 5.12.

\begin{tabular}{|c|c|c|c|c|c|c|c|c|c|c|c|c|c|}
\hline \multirow[b]{2}{*}{ Phase } & \multirow[b]{2}{*}{ Description } & \multirow[b]{2}{*}{$\begin{array}{c}\text { Jun - } \\
\text { Nov'18 }\end{array}$} & \multirow[b]{2}{*}{ Des-18 } & \multirow[b]{2}{*}{ Jan-19 } & \multicolumn{2}{|c|}{ Milestone 1} & \multirow[b]{2}{*}{ Apr-19 } & \multirow[b]{2}{*}{ May-19 } & \multirow[b]{2}{*}{ Jun-19 } & \multirow[b]{2}{*}{ Jul-19 } & \multicolumn{2}{|c|}{ Milestone 2} & \multirow[b]{2}{*}{$\begin{array}{c}\text { Oct'18 - } \\
\text { Feb'20 }\end{array}$} \\
\hline & & & & & Feb-19 & Mar-19 & & & & & Aug-19 & Sep-19 & \\
\hline \multirow{2}{*}{ 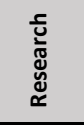 } & Data collection and analysis & & & & & & & & & & & & \\
\hline & $\begin{array}{l}\text { Research portfolio } \\
\text { finalization }\end{array}$ & & & & & & & & & & & & \\
\hline \multirow{4}{*}{ 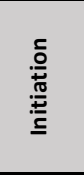 } & $\begin{array}{l}\text { Regulatory \& IP } \\
\text { considerations }\end{array}$ & & & & & & & & & & & & \\
\hline & Securing funding partners & & & & & & & & & & & & \\
\hline & Build the team & & & & & & & & & & & & \\
\hline & App developer appointment & & & & & & & & & & & & \\
\hline \multirow{3}{*}{$\begin{array}{l}\frac{c}{.00} \\
\overline{\tilde{\nu}} \\
\underline{\Delta}\end{array}$} & Process flow & & & & & & & & & & & & \\
\hline & Wire frame & & & & & & & & & & & & \\
\hline & Prototype & & & & & & & & & & & & \\
\hline \multirow{2}{*}{ 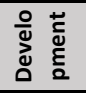 } & App creation & & & & & & & & & & & & \\
\hline & Content development & & & & & & & & & & & & \\
\hline \multirow{2}{*}{ 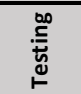 } & Alpha & & & & & & & & & & & & \\
\hline & Beta & & & & & & & & & & & & \\
\hline \multirow{2}{*}{ 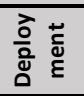 } & App publishing & & & & & & & & & & & & \\
\hline & Promotion & & & & & & & & & & & & \\
\hline \multirow{3}{*}{ 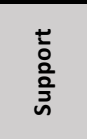 } & Customer service & & & & & & & & & & & & \\
\hline & Update \& maintenance & & & & & & & & & & & & \\
\hline & $\begin{array}{l}\text { Partnership \& content } \\
\text { update }\end{array}$ & & & & & & & & & & & & \\
\hline
\end{tabular}

Table 5.12 Timeline of All Activities

Table 5.12 shows that having concluded with data collection and analysis, the finalization of the research portfolio is carried out from December 2018 until end of February 2019. The first milestone is attained when the research portfolio is completed. Then, the project is ready to progress to Extra development phases. The initiation phase of the app development will be commenced from March to mid of May 2019, in which it will be trailed with the design phase promptly. As soon as the design phase is finalized, the development phase will begin from June until mid of July 2019. Following up the development phase, the testing and adjustment process will be set from mid of July until August 2019. The pre-launched promotion activity will also start on July 2019. The second milestone will be reached when Extra is ready to be released to the public. Subsequently, its publishing process will take around two weeks until mid of September 2019. Finally, it is forecasted that Extra will start to run publicly starting at the middle of September 2019, in which the support phase will also start to be performed. 


\subsection{Summary}

The objective of the business case is to present recommendation of Extra's commercialization plan that may benefit to increase the awareness of the tourism industry in Indonesia. Prior to this business case chapter, this study has outlined findings of the exploratory mixed-methods research design to answer the research problem and verify assumptions in the business model plan to explore the feasibility of developing Extra. Having identified key features that should be installed in Extra - which are local recommendations of local tours and activities, online/offline route planning, self-designed itinerary, and ratings/reviews from other travelers - as the minimum viable product, the development plan is presented in six phases, which are initiation, design, development, testing, distribution, and customer support phase. Approximately, it will take around 6 months to create Extra from the initiation phase until it is ready to be released to end users, or at the distribution phase. The total cost that is required to develop and run Extra in the first year is USD 128,793. In contrast, revenue sources of Extra are yielded from commissions from realized transactions and affiliate fees from third-party booking services. In the first year of operation, it is predicted that Extra will receive net profit at USD 76,388 for the first six months of implementation. After calculating monthly revenues and costs, three business plans are presented with $5 \%, 10 \%$, and $15 \%$ growth projection. The moderate business plan with $10 \%$ growth level shows that Extra will reach the breakeven period after 4 years of operation with the total cumulative amount is USD 128,806 . 


\section{Chapter 6 : Conclusions}

\subsection{Project Background}

The tourism industry has been Indonesia's fourth largest contributor of foreign exchange revenue (Indonesia Tourism Investment, 2018) with many packages on offer to tourists, including cultural, culinary and natural attractions. However, UNWTO's (2018) research revealed that Indonesia is in 9th position in terms of the number of international tourist arrival compared to other Asia countries in 2017. Numerous studies suggesting that Indonesia's tourism destinations are underrated due to the limited information of Indonesia tourism worldwide (Cholik, 2017; Petriana, 2017; Wijaya, 2017). As Indonesia is an archipelago country with diverse topographies, it is very necessary to provide a considerable amount of tourism information since not every place is simply reachable for first-time visitors. This leads to many tourists having a low understanding of where Indonesia is located and what types of destinations they can explore in Indonesia. On the other hand, previous studies have outlined the effectiveness of ICT tool to support the dissemination of tourism products, services, and information (Buhalis \& Law, 2008; Hyde, 2008, Caraivan, 2017).

Thus, the objective of this study was to explore the opportunity to support the information availability of the tourism destinations in Indonesia through a commercialisable mobile travel app called Extra. In particular, Extra aims to give tourists a local experience while visiting Indonesia, as well as to boost more exposure to Indonesia's tourism destinations in the global market. Following research into the experiences of tourism stakeholders, tourists and the online questionnaire's respondents, a business case projection was formed to propose the development and commercialization of Extra.

\subsection{Key Outtakes and Implications}

Through using a mixed method research design, the previous chapters have outlined the main findings of this study, suggesting features that are desired to appeal potential users to use the app are local recommendations of local tours and activities, online/offline route planning, 
self-designed itinerary, and ratings/reviews from other travelers. From the tourism service providers' perspectives, Extra will be beneficial for them if it can provide more approachable contact to their customers, accommodate the lack of skill, time or resource to update tourism information or social media regularly, and encourage more efficient business operation by providing a single platform to manage all of tourism products and services. The findings of this research also signified that almost all of the questionnaire respondents are engaged with social media. This evidence contributes to the utilization of social media for Extra's customer relationship channel and marketing purpose.

The recommendations chapter has outlined how the major findings of this study contribute to the development of Extra. It includes the recommendation of the business model design, market and product validation evaluation, as well as resource requirements of Extra development project. In the business model recommendation, barriers of the project are also identified to have a better understanding of potential conditions that may prevent the successful implementation of Extra and how these will be addressed, such as the actual user's intention to purchase the app, tourism service provider's actual willingness to become Extra's business partner, and motivation of customers to share after trip review. The market validation of Extra comprises the identification of the potential target market and how Extra could be positioned and distributed in the market. It is considered that Extra will be aimed at first-time visitors, those who want to explore local experiences and new cultures, and Independent travelers who want to create self-designed tours and activities. As for tourism service providers, the target markets of Extra are those who want to reach out to more people to increase sales and promote local attractions, as well as those who prefer to use a single platform. The product validation of Extra involves the details of regulatory, development, testing, and deployment process to create Extra with its intended features and functions. Finally, in order to realize Extra into a real product, the resource requirements that will be needed at Extra's development stage are funding partners, app developer, and Mobile App Specialist. At the operational stage, resources that will be needed are the Digital Marketing Manager, Partnership Manager, Content Manager, and General Affairs Manager. Meanwhile, the time period that is required to develop Extra is six months and the total cost that will be needed to develop and operate the app for the first year is USD 105,894 . This cost includes 
technological setup \& running costs, employees' salaries, operational expenses, and marketing costs.

Reflecting on the research findings and recommendations, taking into an acknowledgement of the necessary future research that will be discussed in the next section, the development of Extra is commercially viable. Further, it is estimated that Extra will reach the break-even period in the fourth year of its implementation if the annual growth of the realized transaction is $10 \%$ steadily. Therefore, the decision has been made that the development project of Extra is set to go. After finalizing this research report, the author will be involved as the CEO of the project, and the next immediate step that will be performed is to approach potential investors or project partners to initiate the development process of Extra. This includes submitting a proposal of partnership agreement to the Ministry of Tourism, participating in the local investor meetup event, seeking investor referrals from existing networks, and connecting with potential angel investors through online network platforms. Correspondingly, the author will also seek a legal advisor who will support the administration process of necessary permits to start the travel app business in Indonesia.

Later on, in a case of successful implementation of Extra, the 'build-measure-learn' feedback loop (Ries, 2011) will be applied consistently to allow continued adjustments in order to improve the app's service. This includes conducting further research on aspects that need further validation.

\subsection{Limitations and Future Research}

Due to the short nature of this study, the total of interview participants and questionnaire respondents reduced a broader exploration of this research topic. In addition, limitations on the amount of research conducted have constrained the ability to examine certain subjects, such as the type of preferred communication channel to enable effective and more approachable interaction between tourist and tourism service providers, as well as the importance of a customer service feature in a travel app to encourage a better traveling experience. Further, without the implementation of Extra, it is difficult to identify the actual value propositions that are needed by both tourists and tourism stakeholders to make them 
use the app or purchase it if the revenue business model is transformed from a free to a paid app or in-app purchase.

Therefore, future research is required after the implementation of Extra in order to identify to what extent the app's values could entice its users to pay more for the service, and what features will be likely to be added or removed to improve Extra's perceived values to its users.

\subsection{Summary}

The research of this study, which aims to investigate the prospect to support the information availability of the tourism destinations in Indonesia through a mobile travel app called Extra, has been concluded with several key outtakes and implications to the viability of proceeding the development process of Extra. Though there were limitations that reduced a broader exploration of this study and lead to the recommendation of future research, the findings of this study signify that Extra is commercially viable. Therefore, it is considered that the development project of Extra will be carried out after the finalization of this research. As the CEO of the project, the author will initiate Extra's development project by exploring potential investors and project partners such as the Ministry of Tourism and angel investors. At the same time, a discussion with a legal advisor regarding necessary permits that will be required to establish the travel app business in Indonesia will be performed. 


\section{References}

Adler, B. (2018). Mobile Apps: What's a Good Conversion Rate? | Localytics. Retrieved December 24, 2018, from http://info.localytics.com/blog/mobile-apps-whats-a-goodconversion-rate

Aimtell. (n.d.). Aimtell: Web Push Notifications Pricing And Plans. Retrieved January 4, 2019, from https://aimtell.com/pricing

Airbnb. (n.d.). Why does Airbnb charge a service fee for experiences? Retrieved December 24, 2018, from https://www.airbnb.co.nz/help/article/1604/why-does-airbnb-chargea-service-fee-for-experiences

Ali, A., Frew, A. J. (2014). ICT for sustainable tourism: a challenging relationship? Inf Technol Tourism, 14, 261-264. https://doi.org/10.1007/s40558-014-0020-x

Angeles, S. (2014). 10 Customer Service Solutions for Small Businesses. Retrieved January 2, 2019, from https://www.businessnewsdaily.com/7575-customer-servicesolutions.html

Asia Sentinel. (2017). Indonesia Can't Get its Tourism Act Together - Asia Sentinel. Retrieved January 25, 2019, from https://www.asiasentinel.com/society/wonderful-indonesiatourism/

Aramendia-Muneta, M. E., \& López, A. O. (2013). ICT impact on tourism industry. International Journal of Management Cases. 15. 84-98.

Baadsgaard, J. (2017). What is SEM? Search Engine Marketing Explained | Disruptive Advertising. Retrieved January 5, 2019, from https://www.disruptiveadvertising.com/adwords/search-engine-marketing/

Baym, N. K. (2009). Personal Connections in the Digital Age, Polity Press. ProQuest Ebook Central, http://ebookcentral.proquest.com/lib/vuw/detail.action?doclD=1392377. Created from vuw on 2018-06-21 15:54:56.

Bennett, M. (1993). Information technology and travel agency-a customer service perspective.

Tourism Management, 14 (4) (1993), pp. 259-266

Benyon, D., Quigley, A., O’Keefe, B., \& Riva, G. (2014). Presence and digital tourism. Al \& SOCIETY, 29(4), 521-529. https://doi.org/10.1007/s00146-013-0493-8 
Berne, C., Garcia-Gonzalez Margarita, M., \& Mugica, J. (2012). How ICT shifts the power balance of tourism distribution channels. Tourism Management. https://doi.org/10.1016/j.tourman.2011.02.004

BI Intelligence. (2017). India is 10x cheaper than US for app development - Business Insider. Retrieved December 29, 2018, from https://www.businessinsider.com/india-is-10xcheaper-than-us-for-app-development-2017-1/?r=AU\&IR=T

Blank, S. (2013). Why the Lean Start-Up Changes Everything. Retrieved November 3, 2018, from https://hbr.org/2013/05/why-the-lean-start-up-changes-everything

Boehmer, J. (2013). FlightView survey: Frequent flyers want more out of airline apps.

Business Travel News, 30(13), 29. Retrieved from https://search-proquestcom.helicon.vuw.ac.nz/docview/1448806422?accountid=14782

Bohlin, M., \& Brandt, D. (2014). Creating tourist experiences by interpreting places using digital guides. Journal of Heritage Tourism, 9(1), 1-17. https://doi.org/10.1080/1743873X.2013.799173

Booking.com Affiliate Program Review. (n.d.). Retrieved December 25, 2018, from https://onemorecupof-coffee.com/booking-com-affiliate-program-review/

Brace, I. (2008). Questionnaire design : how to plan, structure and write survey material for effective market research. Kogan Page. Retrieved from https://books.google.co.nz/books?id=0r8xOI5rBZoC\&printsec=frontcover\&dq=questio nnaire\&hl=en\&sa=X\&ved=0ahUKEwjsrrOg6feAhUFWysKHUtpAMMQ6AEIOTAD\#v=onepage $\& q=q u e s t i o n n a i r e \& f=f a l s e$

Brinkmann, S. (2013). Qualitative Interviewing. Oxford University Press. https://doi.org/10.1093/acprof:osobl/9780199861392.001.0001

Browne, K. (2005). Snowball sampling: using social networks to research non-heterosexual women. International journal of social research methodology, 8(1), 47-60.

Bryman, A. (2016). Social research methods. Oxford university press.

Buhalis, D. (1998). Strategic use of information technologies in the tourism industry. Tourism Management, 19(5), 409-421. https://doi.org/10.1016/S0261-5177(98)000387

Buhalis, D. (2003). eTourism: Information technology for strategic tourism management. Pearson Education.

Buhalis, D., \& Law, R. (2008). Progress in information technology and tourism management: 
20 years on and 10 years after the Internet-The state of eTourism research. Tourism Management, 29(4), 609-623. https://doi.org/10.1016/J.TOURMAN.2008.01.005 Business Dictionary. (n.d.). breakeven point. BusinessDictionary.com. Retrieved January 6, 2019, from http://www.businessdictionary.com/definition/breakeven-point.html Caraivan, L. (2017). DIGITAL TOURISM: A REVIEW OF TRENDS IN PROMOTING TOURISM ACTIVITIES. Quaestus, (11), 159-162. Retrieved from https://search-proquestcom.helicon.vuw.ac.nz/docview/1950620655?accountid=14782

Chan, F. (2017). Jokowi plans to replicate Bali's success in 10 other Indonesian spots, Asia News \&amp; Top Stories - The Straits Times. Retrieved June 26, 2018, from https://www.straitstimes.com/asia/jokowi-plans-to-replicate-balis-success-in-10other-indonesian-spots

Chandralal, L., Rindfleish, J., \& Valenzuela, F. (2014). An Application of Travel Blog Narratives to Explore Memorable Tourism Experiences. Asia Pacific Journal of Tourism Research, 0, 1094-1665. https://doi.org/10.1080/10941665.2014.925944

Charmaz, K. (2006). Constructing grounded theory: a practical guide through qualitative analysis. Sage Publications. Retrieved from https://books.google.co.nz/books?id=2ThdBAAAQBAJ\&dq=qualitative+analysis\&lr=\&so urce $=g b s \_n a v l i n k s \_s$

Cholik, S. M. A. (2017). THE DEVELOPMENT OF TOURISM INDUSTRY IN INDONESIA : CURRENT PROBLEMS AND CHALLENGES. European Journal of Research and Reflection in Management Sciences, 5(1). Retrieved from www.idpublications.org

Cleveroad. (2018). Native vs. Hybrid App: Considering Pros and Cons of Each Option. Retrieved December 29, 2018, from https://www.cleveroad.com/blog/native-orhybrid-app-development-what-to-choose

Cohen, N., \& Arieli, T. (2011). Field research in conflict environments: Methodological challenges and snowball sampling. https://doi.org/10.1177/0022343311405698

Cotter, S. (2016). Quantitative vs. Qualitative Research: Which Should Come First? | Think Company. Retrieved November 8, 2018, from https://www.thinkcompany.com/2016/07/quantitative-vs-qualitative-research-whichshould-come-first/

Crawford, G. (2009). Qualitative research. In S. H. Callahan, The SAGE dictionary of leisure studies. London, UK: Sage UK. Retrieved from 
http://helicon.vuw.ac.nz/login?url=https://search.credoreference.com/content/entry/ sageukdicles/qualitative_research/0?institutionld=5378

Creswell, J. W., \& Plano Clark, V. L. (2011). Designing and conducting mixed methods research (2nd ed.). Thousand Oaks, CA: Sage.

Cristescu, C. G. (2016). The Significance of Tourist Apps on a tourist experience. Retrieved from https://projekter.aau.dk/projekter/files/239506846/Master_Thesis.pdf

Criteo. (2017). Retail and Travel Apps See 4x More Conversions than Mobile Web | Criteo. Retrieved December 25, 2018, from https://www.criteo.com/insights/retail-travelapps-higher-conversions-mobile/

Curtin, G. (2017). 6 ways augmented reality can help governments see more clearly. Retrieved from https://www.weforum.org/agenda/2017/02/augmented-reality-smartgovernment/

Delgado, M. (2017). 5 Ways E-Commerce Websites Can Collect More Customer Reviews I Clutch.co. Retrieved January 11, 2019, from https://clutch.co/websitebuilders/resources/how-to-collect-more-online-reviews-ecommerce deMarrais, K. (2004). Qualitative interview studies: Learning through experience. In K. deMarrais \& S.D. Lapan (Eds.), Foundations for research (pp. 51-68). Mahwah, NJ: Erlbaum.

Derrick Huang, C., Goo, J., Nam, K., \& Yoo, W. (2017). Smart tourism technologies in travel planning: The role of exploration and exploitation. https://doi.org/10.1016/j.im.2016.11.010

Dholakiya, P. (2017). How to Patent Your Mobile App - A Truly Brilliant Idea Deserves to be Protected. Retrieved December 18, 2018, from https://www.moveoapps.com/blog/how-to-patent-your-mobile-app/

Diela, T. (2017). Indonesia Jumps to 72nd on World Bank's Global Ease of Doing Business Report | Jakarta Globe. Retrieved January 7, 2019, from https://jakartaglobe.id/business/indonesia-jumps-72nd-world-banks-global-easebusiness-report/

Digiorgio, V. (2016). Impact of promotional tools on reservation channels management: a descriptive model of Italian accommodation facilities. Information Technology \& Tourism, 16(4), 347-373. https://doi.org/10.1007/s40558-016-0069-9

Dogtiev, A. (2018a). App Revenues (2017) - Business of Apps. Retrieved January 6, 2019, 
from http://www.businessofapps.com/data/app-revenues/

Dogtiev, A. (2018b). Top App Store Optimization Tools (2018) - Business of Apps. Retrieved December 26, 2018, from http://www.businessofapps.com/guide/app-storeoptimization-tools/

Fatanti, M. N., \& Suyadnya, W. (2015). Beyond User Gaze: How Instagram Creates Tourism Destination Brand? Procedia -Social and Behavioral Sciences, 211, 1089-1095. https://doi.org/10.1016/j.sbspro.2015.11.145

Finances Online. (2018). Easy to Use Help Desk Software: Is Zendesk the Top Choice? Financesonline.com. Retrieved January 4, 2019, from https://financesonline.com/easyuse-help-desk-software-zendesk-top-choice/

Frerichs, R. R. (2008). Simple random sampling. Rapid Survey. https://doi.org/10.1007/9783-642-04898-2_518

Ganguly, R. (n.d.). App Store Optimization - A Crucial Piece of the Mobile App Marketing Puzzle. Retrieved January 5, 2019, from https://neilpatel.com/blog/app-storeoptimization/

Goldman, J. (2018). AR and VR Will Fail Without These 3 Changes | Inc.com. Retrieved November 23, 2018, from https://www.inc.com/jeremy-goldman/ar-vr-will-failwithout-these-3-changes.html

Guest, G., Bunce, A., \& Johnson, L. (2006). How Many Interviews Are Enough? Field Methods, 18(1), 59-82. https://doi.org/10.1177/1525822X05279903

Gunter, B., Nicholas, D., Huntington, P., \& Williams, P. (2002). Online versus offline research: Implications for evaluating digital media. Aslib Proceedings (Vol. 54). Retrieved from https://search-proquestcom.helicon.vuw.ac.nz/docview/217749694/fulltextPDF/C7F856F446CF49F0PQ/1?acco untid $=14782$

Gursoy, D., \& Umbreit, W. T. (2004). Tourist information search behavior: cross-cultural comparison of European union member states ARTICLE IN PRESS. Hospitality Management, 23, 55-70. https://doi.org/10.1016/j.ijhm.2003.07.004 Haan, J. De. (2018). The Indonesian Tourism Industry: A Bright Future and Opportunities for Australia - Future Directions International. Retrieved June 25, 2018, from http://www.futuredirections.org.au/publication/indonesian-tourism-industry-brightfuture-opportunities-australia/ 
Hariguna, T., \& Lai, M.-T. (2015). The Holistic Information Communication and Technology in Order to Increase Number of Tourist in Indonesia. Journal of Knowledge Management, Economics and Information Technology, V(3), 1-10. Retrieved from www.scientificpapers.org

Harley, A. (2015). Ad Placement for Mobile. Retrieved December 9, 2018, from https://www.nngroup.com/articles/ad-placement-mobile/

Hasen, J. (2012). Mobilized marketing: how to drive sales, engagement, and loyalty through mobile devices. Retrieved from https://ebookcentral.proquest.com Hikersbay. (2018). Indonesia - prices, cost of travel and accommodation 2018. Retrieved December 25, 2018, from http://hikersbay.com/prices/indonesia?lang=en Husein, Z. Z., Sirie, M. I., \& Rahman, A. A. (2018). Digital business in Indonesia: overview | Practical Law. Retrieved December 20, 2018, from https://uk.practicallaw.thomsonreuters.com/5-6211310?transitionType=Default\&contextData=(sc.Default $) \&$ firstPage $=$ true $\&$ comp $=$ pluk\&b $\mathrm{hcp}=1$

Hyde, K. F. (2008). Information processing and touring planning theory. Annals of Tourism Research, 35(3), 712-731. https://doi.org/10.1016/j.annals.2008.05.001 Indonesia - Inflation rate 2022 | Statistic. (n.d.). Retrieved December 23, 2018, from https://www.statista.com/statistics/320156/inflation-rate-in-indonesia/ Indonesia Investment. (n.d.). Tax System in Indonesia - Corporate \&amp; Individual Income Tax | Indonesia Investments. Retrieved December 25, 2018, from https://www.indonesia-investments.com/finance/tax-system/item277? Indonesia Tourism Investment. (2018). Retrieved June 25, 2018, from http://indonesiatourism-investment.com/?page=tourism-overview Influence Society. (2018). Travelers in the Age of Assistance - Influence Society Insights. Retrieved December 4, 2018, from https://insights.influence-society.com/hotelmarketing-news/travelers-in-the-age-of-assistance/

Kang, M., \& Schuett, M. A. (2013). Determinants of Sharing Travel Experiences in Social Media. Journal of Travel \& Tourism Marketing, 30(1-2), 93-107. https://doi.org/10.1080/10548408.2013.751237

Keller, C. T. (2016). 5 Things to do after a trip | Go Ahead Tours travel blog. Retrieved June 23, 2018, from https://travelblog.goaheadtours.com/things-to-do-after-a-trip/ 
Kelley, K., Clark, B., Brown, V., \& Sitzia, J. (2003). Good practice in the conduct and reporting of survey research. International Journal for Quality in Health Care, 15(3), 261-266. https://doi.org/10.1093/intqhc/mzg031

Kemper, E. A., Stringfield, S., \& Teddlie, C. (2003). Mixed method sampling strategies in social science research. In Tashakkori \& Teddlie (Eds.). Handbook of Mixed Methods in Social and Behavioral Research (Chapter 10). Thousand Oaks, CA: Sage Publications. Kendig, P. (2017). How Much to Budget for SEO. Retrieved December 26, 2018, from https://www.webstrategiesinc.com/blog/how-much-to-budget-for-seo

Khalid, H., Shihab, E., Nagappan, M., \& Hassan, A. E. (2015). What do mobile app users complain about? IEEE Software. https://doi.org/10.1109/MS.2014.50

Kominfo. (2016). Kementerian Komunikasi dan Informatika. Retrieved December 20, 2018, from https://www.kominfo.go.id/content/detail/7194/siaran-persno28pihkominfo32016-tentang-surat-edaran-nomor-3-tahun-2016-terkait-penyediaanlayanan-aplikasi-danatau-konten-melalui-internet-over-the-top/0/siaran_pers Lavrakas, P. . (2008). Self-Administered Questionnaire. In Encyclopedia of Survey Research Methods. Thousand Oaks CA: Sage Publications, Inc. https://doi.org/10.4135/9781412963947.n522

Lee, X. E. (2018). Indonesia Tourism Minister Arief Yahya talks goals. Retrieved January 12, 2019, from https://www.cnbc.com/2018/12/20/indonesia-tourism-minister-ariefyahya-talks-goals.html

Lincoln, J. E. (2018). How Much Does Social Media Influencer Marketing Cost? - Ignite Visibility. Retrieved December 26, 2018, from https://ignitevisibility.com/much-socialmedia-influencer-marketing-cost/

Loo, J. (2017). How the travel industry is shifting to assistance - Think with Google. Retrieved October 24, 2018, from https://www.thinkwithgoogle.com/marketing-resources/newconsumer-travel-assistance/

Lubis, Z. (2017). The Comparison Between Indonesian and Malaysian Tourism Performance Policies and Sources. The Social Sciences, Medwell Journals, 12(9), 1646-1657. Retrieved from http://docsdrive.com/pdfs/medwelljournals/sscience/2017/16461657.pdf

Lucey, B. (2018). [RESEARCH] 7 Key Trends for the Travel Industry in 2018 | Criteo. Retrieved December 4, 2018, from https://www.criteo.com/insights/travel-market-research/ 
Ma, J., \& Scott, N. (2017). Customer delight from hospitality and tourism experience. In The Routledge Handbook of Consumer Behaviour in Hospitality and Tourism. https://doi.org/10.4324/9781315659657

Main, K. (2018). Facebook Advertising Cost by Industry 2018. Retrieved December 26, 2018, from https://fitsmallbusiness.com/how-much-does-facebook-advertising-cost/ Mandel, D. M. (2015). Indonesia: Road to the App Economy. Retrieved from https://www.progressivepolicy.org/wp-content/uploads/2015/09/2015.09Mandel_Indonesia-Road-to-the-App-Economy.pdf Matanov, I. (2018). Here Is What You Should Include in Your Mobile App Maintenance Plan. Retrieved January 4, 2019, from https://expertise.jetruby.com/here-is-what-youshould-include-in-your-mobile-app-maintenance-plan-e97ebec37585

McKendrick, J. (2013). Most app developers aren't even breaking even, but still keep going | ZDNet. Retrieved January 6, 2019, from https://www.zdnet.com/article/most-appdevelopers-arent-even-breaking-even-but-still-keep-going/

McNulty, S. (2012). The Google+ guide : circles, photos, hangouts, and more. Peachpit Press. Retrieved from https://www.safaribooksonline.com/library/view/the-googleguide/9780132927512/?ar

Merriam, S. B., \& Tisdell, E. J. (2016). Qualitative Research : A Guide to Design and Implementation. San Francisco, CA: Jossey-Bass.

Michael Page. (2018). Salary Benchmark 2018 Worldwide leaders in specialist recruitment. Retrieved from www.michaelpage.co.id

Mihalcescu, C., Sion, B., \& Marginean, A. (2016). THE DEVELOPMENT, SUCCESS AND IMPACT OF ELECTRONIC TOURISM IN THE DIGITAL AGE. Journal of Information Systems \& Operations Management, , 416-424. Retrieved from https://search.proquest.com/docview/1861345923 ?accountid=14782

Mindsea. (2018). 25 Mobile App Usage Statistics To Know In 2019. Retrieved December 24, 2018, from https://mindsea.com/app-stats/

Minghetti, V., \& Buhalis, D. (2010). Digital divide in tourism. Journal of Travel Research, 49(3), 267-281.

Morse, J. M. (2003). Principles of mixed methods and multimethod research design. In A. Tashakkori \& C. Teddlie (Eds.), Handbook of mixed methods in social and behavioral research, (pp. 189-208). Thousand Oaks, CA: Sage. 
Neuhofer, B., Buhalis, D., \& Ladkin, A. (2015). Smart technologies for personalized experiences: a case study in the hospitality domain. Electronic Markets, 25(3), 243-254. https://doi.org/10.1007/s12525-015-0182-1

Nielsen, J. (2013). Conversion Rate: Definition as used in UX and web analytics. Retrieved

December 4, 2018, from https://www.nngroup.com/articles/conversion-rates/

O'Leary, Z. (2017). The essential guide to doing your research project. Sage.

Osterwalder, A., \& Pigneur, Y. (2010). Business model generation : a handbook for visionaries, game changers, and challengers. John Wiley \& Sons.

Palinkas, L. A., Horwitz, S. M., Green, C. A., Wisdom, J. P., Duan, N., \& Hoagwood, K. (2015). Purposeful Sampling for Qualitative Data Collection and Analysis in Mixed Method Implementation Research. Administration and Policy in Mental Health and Mental Health Services Research, 42(5), 533-544. https://doi.org/10.1007/s10488-013-0528-y

Patel, N. (2018). The Top 14 Ways to Improve Your SEO Ranking. Retrieved January 5, 2019, from https://www.quicksprout.com/2018/02/05/the-top-14-ways-to-improve-yourseo-ranking/

Patten, M. L. (2016). Questionnaire Research: A Practical Guide. Taylor \& Francis. Retrieved from https://books.google.co.nz/books?id=SCkxDQAAQBAJ

Petriana, B. (2017). The perceived destination image of Indonesia: an assessment on travel blogs written by the industry's top markets. Retrieved from https://viewer.waireto.victoria.ac.nz/wairetostreams/get?dps_dvs=1529695527293 639\&dps_pid=FL989828

Pitoska, E. (2013). E-TOURISM: THE USE OF INTERNET AND INFORMATION AND COMMUNICATION TECHNOLOGIES IN TOURISM: THE CASE OF HOTEL UNITS IN PERIPHERAL AREAS. Tourism in South East Europe ..., 2, 335-344. Retrieved from https://search.proquest.com/docview/1806060081 ?accountid=14782

PTBA. (2017). What Travel Bloggers REALLY Charge | Professional Travel Bloggers Association. Retrieved December 26, 2018, from https://travelbloggersassociation.com/what-travel-bloggers-charge/

Ray, N., et al. (2011). A Study on Application of Information Technology on Tourism Development. In Management and Service Science (MASS), International Conference on (pp. 1-7). IEEE. doi:10.1109/ICMSS.2011.599870710.1109/ICMSS.2011.5998707

Redbord, M. (2017). How Many Customer Support Reps Do You Need? | Sales Hacker. 
Retrieved January 12, 2019, from https://www.saleshacker.com/how-many-customersupport-reps-do-you-need/

Ries, E. (2011). The lean startup: How today's entrepreneurs use continuous innovation to create radically successful businesses. Crown Books.

Rosana, F. C. (2018). Indonesia Eyeing First Spot in 2019 World Halal Tourism Index | Food \&amp; Travel | Tempo.Co :: Indonesian News Portal. Retrieved June 24, 2018, from https://en.tempo.co/read/news/2018/04/12/199917529/Indonesia-Eyeing-First-Spotin-2019-World-Halal-Tourism-Index

Russel, B. (2016). Why American tourists don't come to Indonesia - News - The Jakarta Post. Retrieved January 25, 2019, from https://www.thejakartapost.com/travel/2016/09/28/why-american-tourists-dontcome-to-indonesia.html

S\&F Consulting Firm. (n.d.). Company registration fees in Indonesia-license fee. Retrieved December 31, 2018, from https://www.sfconsultingbd.com/asia/indonesia-foreigncompany-registration-formation/company-registration-fees-in-indonesia/

Samson, R. (2015). Angel investors and venture capitalists: A comparison | Version Daily. Retrieved December 31, 2018, from http://www.versiondaily.com/angel-investors-andventure-capitalists-a-comparison/

Sharpley, R., \& Telfer, D. J. (2015). Tourism and development in the developing world. Routledge.

Sheldon, R. (2017). A mobile app security checklist for developers. Retrieved December 31, 2018, from https://searchmobilecomputing.techtarget.com/tip/A-mobile-app-securitychecklist-for-developers

Sinaga, D. A. (2017, May 02). Jokowi Promotes 'Ten New Balis' to Investors in Hong Kong. Jakarta Globe. Retrieved from http://jakartaglobe.id/news/jokowi-promotes-tennew-balis-to-investors-in-hong-kong/

SME Business Owners/Directors. (2009). The benefits of an advisory board-mentoring for growth. Retrieved from http://www.companydirectors.com.au/ /media/Resources/Director Resource Centre/Directorship in your organistation/00660_SME_FY_The_Benefits_of_an_Advisory Board_web.ashx Smith, R. D. (2003). The Chief Technology Officer: Strategic Responsibilities and 
Relationships. Research-Technology Management, 46(4), 28-36.

https://doi.org/10.1080/08956308.2003.11671574

Software Testing Help. (2018). What is Alpha Testing and Beta Testing: A Complete Guide.

Retrieved January 3, 2019, from https://www.softwaretestinghelp.com/what-is-alphatesting-beta-testing/

Stamboulis, Y., \& Skayannis, P. (2003). Innovation strategies and technology for experiencebased tourism. Tourism management, 24(1), 35-43.

Sylejmani, K., Dorn, J., \& Musliu, N. (2017). Planning the trip itinerary for tourist groups. Information Technology \& Tourism, 17(3), 275-314. https://doi.org/10.1007/s40558017-0080-9

Talley, J. (n.d.). What Does a Digital Marketing Manager Do? Retrieved December 27, 2018, from https://www.mediabistro.com/climb-the-ladder/skills-expertise/what-does-adigital-marketing-manager-do/

Techopedia. (n.d.). What is a Website Wireframe? - Definition from Techopedia. Retrieved January 1, 2019, from https://www.techopedia.com/definition/5216/websitewireframe

Thaib, H. (2018). Tourism Industry Indonesia: Gov't Seeks \$20 Billion of Investment | Indonesia Investments. Retrieved December 25, 2018, from https://www.indonesiainvestments.com/culture/culture-columns/tourism-industry-indonesia-gov-t-seeks-20billion-of-investment/item8518

Think Mobiles. (n.d.). How Much Does it Cost to Make an App in 2018 - App Cost Calculator. Retrieved December 29, 2018, from https://thinkmobiles.com/blog/how-much-costmake-app/

Tosun, C. (2000). Limits to community participation in the tourism development process in developing countries, Tourism Management, vol. 21.613-633

Trading Economics. (2018). Indonesia Tourist Arrivals. Retrieved August 16, 2018, from https://tradingeconomics.com/indonesia/tourist-arrivals

Travel Guide. (2017). Digital platform, air accessibility among priority tourism programs in 2017. Retrieved January 24, 2019, from https://www.thejakartapost.com/travel/2017/04/07/digital-platform-air-accessibilityamong-priority-tourism-programs-in-2017.html

Tussyadiah, I. P., Jung, T. H., \& tom Dieck, M. C. (2018). Embodiment of Wearable 
Augmented Reality Technology in Tourism Experiences. Journal of Travel Research. https://doi.org/10.1177/0047287517709090

UNWTO Tourism Highlights. (2018). https://doi.org/10.18111/9789284419876

Urry, J. (2001). Globalising the tourist gaze. Tourism development revisited: Concepts, issues and paradigms, $150-160$.

van Nes, F., Abma, T., Jonsson, H., \& Deeg, D. (2010). Language differences in qualitative research: is meaning lost in translation? European Journal of Ageing, 7(4), 313-316. https://doi.org/10.1007/s10433-010-0168-y

Wang, D., \& Fesenmaier, D. R. (2013). Transforming the Travel Experience: The Use of Smartphones for Travel. https://doi.org/10.1007/978-3-642-36309-2_6

Wang, D., Xiang, Z., \& Wang, D. (2016). Assessing Hotel-Related Smartphone Apps Using Online Reviews. Journal of Hospitality Marketing \& Management, 25, 291-313. https://doi.org/10.1080/19368623.2015.1012282

Ward, S. (2018). What Are Angel Investors Looking for in a Business? Retrieved December 30, 2018, from https://www.thebalancesmb.com/the-7-things-angel-investors-arelooking-for-2948104

Wasserbauer. (2014). Permanent Business License in Indonesia - Your Business Partner in Indonesia and Vietnam. Retrieved January 12, 2019, from https://www.cekindo.com/blog/how-to-create-a-permanent-business-license-inindonesia

Watkins, D., \& Gioia, D. (2015). Mixed Methods Research. Oxford University Press. https://doi.org/10.1093/acprof:oso/9780199747450.001.0001

Wei, S., Ren, G., \& O'Neill, E. (2014). Haptic and audio displays for augmented reality tourism applications. In 2014 IEEE Haptics Symposium (HAPTICS) (pp. 485-488). IEEE. https://doi.org/10.1109/HAPTICS.2014.6775503

Wijaya, A. (2017). Is Indonesia among the most underrated tourism destinations in the world? - Quora. Retrieved June 25, 2018, from https://www.quora.com/Is-Indonesiaamong-the-most-underrated-tourism-destinations-in-the-world

Winarti, O. (2017). Halal Tourism in Indonesia: Does it attract only Muslim Tourists? Jurnal Studi Komunikasi (Indonesian Journal of Communications Studies), 1(3), 232-239. https://doi.org/10.25139/jsk.v1i3.139

Wira, N. N. (2018). Jakpost guide to coworking spaces - Guide To - The Jakarta Post. 
Retrieved December 31, 2018, from

https://www.thejakartapost.com/travel/2018/07/08/jakpost-guide-to-coworkingspaces.html

Wirtz, B. W., Schilke, O., \& Ullrich, S. (2010). Strategic Development of Business Models: Implications of the Web 2.0 for Creating Value on the Internet. Long Range Planning, 43(2-3), 272-290. https://doi.org/10.1016/J.LRP.2010.01.005

Withlocals. (n.d.). How It Works? Retrieved December 1, 2018, from https://www.withlocals.com/info/how-it-works/

Wonderful Indonesia. (2018). Experience 5 Wonders. Retrieved June 24, 2018, from http://www.indonesia.travel/gb/en/experience

Wonderful Indonesia Campaign - Visual + Movement. (2015). Retrieved November 20, 2018, from https://baswaramursyid.wordpress.com/2015/09/30/wonderful-indonesiacampaign/

World Bank. (2018). Doing Business in Indonesia - World Bank Group. Retrieved January 7, 2019, from http://www.doingbusiness.org/en/data/exploreeconomies/indonesia\#starting-abusiness\%23jakarta

World Economic Forum. (2017). The Travel \& Tourism Competitiveness Report 2017. Retrieved from http://www3.weforum.org/docs/WEF_TTCR_2017_web_0401.pdf Wright, C. A. (2015). Digital tourism. Journal of Science and Technology of the Arts, 7(2), 8587. doi:http://dx.doi.org.helicon.vuw.ac.nz/10.7559/citarj.v7i2.163

Xiang, Z., Magnini, V. P., \& Fesenmaier, D. R. (2015). Information technology and consumer behavior in travel and tourism: Insights from travel planning using the internet. Journal of Retailing and Consumer Services, 22, 244-249. https://doi.org/10.1016/J.JRETCONSER.2014.08.005

Xiang, Z., \& Wang, D. (2012). The New Landscape of Travel: A Comprehensive Analysis of Smartphone Apps. https://doi.org/10.1007/978-3-7091-1142-0_27

Yeoman, I., \& McMahon-Beattie, U. (2006). Tomorrow's tourist and the information society. Journal of Vacation Marketing. https://doi.org/10.1177/1356766706064623

Yunus, U., \& Tanuar, E. (2018). Usability testing of indonesia tourism promotion website. J. Phys. Journal of Physics: Conf. Series, 978. https://doi.org/10.1088/17426596/978/1/012007 
Zendesk. (n.d.). Zendesk Pricing | Plans starting from just \$5 a month. Retrieved January 13, 2019, from https://www.zendesk.com/product/pricing/ 


\section{Appendices}

Appendix A: Information sheet and consent form for interview Appendix B: Interview guidelines

Appendix C: Questionnaire 


\section{Appendix A: Information sheet and consent form for interview}

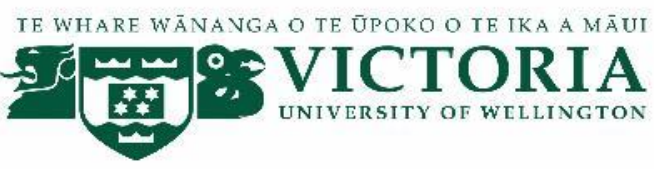

\section{Research for A Travel Application to Explore Indonesia Like Never Before}

\section{INFORMATION SHEET FOR PARTICIPANTS}

You are invited to take part in this research. Please read this information before deciding whether or not to take part. If you decide to participate, thank you. If you decide not to participate, thank you for considering this request.

\section{Who am I?}

My name is Yuwanti Rili Respatyanti and I am a Masters student in Innovation \& Commercialisation at Victoria University of Wellington. This research project is work towards my thesis.

\section{What is the aim of the project?}

The objective of doing this research is to explore an opportunity to create a travel app to increase Indonesia's tourism destinations awareness.

I will ask you questions about the main challenges of tourism industry in Indonesia and your business, and how a travel application/digital technology can help to face the challenges.

This research has been approved by the Victoria University of Wellington Human Ethics Committee [Application Reference \#0000026197].

\section{How can you help?}

You have been invited to participate because of your expertise in tourism industry in Indonesia. If you agree to take part, I will interview you [tbc]. The interview will take 20-30 minutes. I will audio record the interview with your permission and write it up later. You can choose to not answer any question or stop the interview at any time, without giving a reason. You can withdraw from the study by contacting me at any time within four weeks of the interview. If you withdraw, the information you provided will be destroyed or returned to you.

\section{What will happen to the information you give?}


This research is confidential. This means that the researcher named below will be aware of your identity, but the research data will be combined and your identity will not be revealed in any reports, presentations, or public documentation.

Only my supervisors and I will read the notes or transcript of the interview. The interview transcripts, summaries and any recordings will be kept securely and destroyed on 31 December 2019.

\section{What will the project produce?}

The information from my research will be used in my Masters report, academic publications and conferences.

\section{If you accept this invitation, what are your rights as a research participant?}

You do not have to accept this invitation if you don't want to. If you do decide to participate, you have the right to:

- $\quad$ choose not to answer any question;

- $\quad$ ask for the recorder to be turned off at any time during the interview;

- $\quad$ withdraw from the study within four weeks of the interview;

- $\quad$ ask any questions about the study at any time;

- $\quad$ read over and comment on a written summary of your interview

- be able to read any reports of this research by emailing the researcher to request a copy.

\section{If you have any questions or problems, who can you contact?}

If you have any questions, either now or in the future, please feel free to contact either:

Name: Yuwanti Rili Respatyanti

University email address:

respatyuwa@myvuw.ac.nz

\author{
Name: Ina Reichenberger \\ Role: Supervisor \\ School: Management \\ Email : ina.reichenberger@vuw.ac.nz
}

\section{Human Ethics Committee information}

If you have any concerns about the ethical conduct of the research you may contact the Victoria University HEC Convenor: Dr Judith Loveridge. Email hec@vuw.ac.nz or telephone +64-4-463 6028. 


\section{TE WHARE WĀNANGA O TE C̈POKO O TE IKA A MĀUI 59 VICTORIA \\ Research for A Travel Application to Explore Indonesia Like Never Before \\ CONSENT TO INTERVIEW}

This consent form will be held for 2 years.

Researcher: Yuwanti Rili Respatyanti, School of Chemical and Physical Science, Victoria University of Wellington.

I have read the Information Sheet and the project has been explained to me. My questions have been answered to my satisfaction. I understand that I can ask further questions at any time. I agree to take part in an audio recorded interview.

ınderstand that:

I may withdraw from this study at any point within four weeks of the interview and any information that I have provided will be returned to me or destroyed.

The identifiable information I have provided will be destroyed on 31 December 2019.

Any information I provide will be kept confidential to the researcher and the supervisors. I understand that the results will be used for a Masters report [AND/OR] an academic publications and conferences.

My name will not be used in reports, nor will any information that would identify me.

I would like a summary of my interview: Yes No

I would like to receive a copy of the final report and have added my email address below.

Signature of participant:

Name of participant:

Date:

Contact details: 


\section{Appendix B: Interview guidelines}

\section{Interview for tourism stakeholders}

Q1. May I know some information about you and your organization?

- Name

- Organization

- The position in the organization

Q2. What do you think the main challenges of the tourism industry in Indonesia?

Q3. What do you think the main challenges of the tourism business within your organization?

Q4. How can a travel apps or digital technology help you to face the said challenges?

Q5. How do you use apps or digital technology for your business operation?

- What apps?

- Why you choose those apps?

- If you don't use it, why not?

- Are there any challenges/problems?

- Plans for future?

Q6. What would you like to see in app to improve your business operation?

Q7. Is there anything else that you would like to add?

\section{Interview for tourists}

Q1. May I know some information about your travel here?

- Nationality

- Length of stay

- Travel plan

- Preferred transport/accommodation

Q2. How do you use apps or digital technology for your trip planning?

- What apps?

- Why you choose those apps?

Q3. How do you use apps or digital technology during your trip?

- What apps?

- Why you choose those apps?

Q5. What would you like to see in app to improve your travelling experience?

- Features?

- Type of apps?

Q5. Is there anything else that you would like to add? 


\section{Appendix C: Questionnaire}

\section{Start of Block: Introduction}

Q1

$$
\begin{aligned}
& \text { Research for A Travel Application to } \\
& \text { Explore Indonesia Like Never Before } \\
& \text { INFORMATION FOR PARTICIPANTS }
\end{aligned}
$$

\section{INFORMATION FOR PARTICIPANTS}

\section{How can you help?}

The objective of doing this research is to explore an opportunity to create a mobile phone app to improve the traveling experience to Indonesia. You have been invited to participate because you have visited or are planning to visit Indonesia. The survey will ask you questions about your experience of using travel apps while planning and/or doing your trip, and what expectations do you have in a travel application. This survey - which takes around 5 minutes to complete - is only open until Monday, 19 November 2018. After you complete the survey, you will be offered to enter the prize draw to win one of two US $\$ 50$ Amazon vouchers or one of 12 US $\$ 20$ Amazon vouchers.

\section{What will happen to the information you give?}

This research is anonymous. This means that nobody, including the researchers, will be aware of your identity. By answering it, you are giving consent for us to use your responses in this research. Your answers will remain completely anonymous and unidentifiable. Once you submit the survey, it will be impossible to retract your answer. Personal details will be collected only for those who wish to enter the prize draw. All personal details will be received separately from the survey data. This ensures that your answers to the survey questions are anonymous.

\section{Who am I?}

My name is Yuwanti Rili Respatyanti and I am a master's student in Innovation \& Commercialisation at Victoria University of Wellington. This research project is work towards my thesis.

The information from my research will be used in my master's report, academic publications and conferences.

If you have any questions or problems, who can you contact?

If you have any questions, either now or in the future, please feel free to contact either:

Name: Yuwanti Rili Respatyanti

University email address:

respatyuwa@myvuw.ac.nz
Name: Ina Reichenberger

Role: Supervisor

School: Management

Email : ina.reichenberger@vuw.ac.nz 


\section{Human Ethics Committee information}

This research has been approved by the Victoria University of Wellington Human Ethics Committee [Application Reference \#0000026197].

If you have any concerns about the ethical conduct of the research, you may contact the Victoria University HEC Convenor: Dr. Judith Loveridge. Email hec@vuw.ac.nz or telephone +64-4-463 6028.

\section{End of Block: Introduction}

\section{Start of Block: Respondent selection}

Q2 Have you ever visited Indonesia in the past five years?

Yes

No

\section{End of Block: Respondent selection}

\section{Start of Block: Respondent has visited Indonesia}

Q3 How many times have you visited Indonesia in the past five years?

Once

Twice

3 times

More than 3 times

Q4 Which of these channels did you use to book your last trip to visit Indonesia's tourism attractions? Please select all that apply.

Booking websites (e.g. Expedia, Skyscanner)

Booking mobile apps (e.g. Airbnb, Agoda)

Travel agent

Hotel/flight direct channels (website/call center)

Other (please specify) 
Q5 During your last trip to visit Indonesia's tourism attractions, what devices did you use to obtain online information about places to visit and things to do? Please select all that apply.

A smartphone/internet on a mobile phone

A laptop

A tablet PC

A desktop at the hotel/internet cafe

I did not use any of these devices since I did not access any online information

Other (please specify)

Q6 Which of these channels did you use during your last trip to visit Indonesia's tourism attractions to obtain information about places to visit and things to do? Please select all that apply.

The official website of Indonesia tourism - Wonderful Indonesia

Travel community websites (TripAdvisor, Lonely Planet, etc)

Blog posts/reviews

Google search

Printed booklets/brochures provided by tour operators

Printed booklets/brochures at hotel's reception desk

Printed booklets/brochures at the tourism information center

Asking locals

Asking other travelers

Other (please specify) 
Q7 Thinking about your last trip to visit Indonesia's tourism attractions overall, how satisfied were you with the availability of information to help you plan your trip?

\begin{tabular}{|c|c|c|c|c|c|}
\hline & $\begin{array}{l}\text { Extremely } \\
\text { satisfied }\end{array}$ & Satisfied & Neutral & Dissatisfied & $\begin{array}{l}\text { Extremely } \\
\text { dissatisfied }\end{array}$ \\
\hline $\begin{array}{l}\text { The official } \\
\text { website of } \\
\text { Indonesia tourism } \\
\text { - Wonderful } \\
\text { Indonesia }\end{array}$ & ○ & 0 & $\bigcirc$ & $\bigcirc$ & $\bigcirc$ \\
\hline $\begin{array}{l}\text { Travel community } \\
\text { websites } \\
\text { (TripAdvisor, } \\
\text { Lonely Planet, etc) }\end{array}$ & $\bigcirc$ & 0 & $\bigcirc$ & 0 & 0 \\
\hline Blog posts/reviews & ○ & $\bigcirc$ & $\bigcirc$ & 0 & 0 \\
\hline Google search & ○ & 0 & ○ & 0 & 0 \\
\hline $\begin{array}{c}\text { Printed } \\
\text { booklets/brochures } \\
\text { provided by tour } \\
\text { operators }\end{array}$ & ○ & $\bigcirc$ & ○ & $\bigcirc$ & $\bigcirc$ \\
\hline $\begin{array}{c}\text { Printed } \\
\text { booklets/brochures } \\
\text { at hotel's reception } \\
\text { desk }\end{array}$ & O & 0 & ○ & ○ & ○ \\
\hline $\begin{array}{l}\text { Printed } \\
\text { booklets/brochures } \\
\text { at the tourism } \\
\text { information center }\end{array}$ & ○ & 0 & ○ & $\bigcirc$ & $\bigcirc$ \\
\hline Asking locals & ○ & ○ & ○ & 0 & 0 \\
\hline $\begin{array}{l}\text { Asking other } \\
\text { travelers }\end{array}$ & ○ & $\bigcirc$ & $\bigcirc$ & ○ & 0 \\
\hline $\begin{array}{l}\text { Other (please } \\
\text { specify) }\end{array}$ & 0 & ○ & 0 & 0 & 0 \\
\hline
\end{tabular}


Q8 Are you planning to go to Indonesia anytime soon?

Yes, I am planning to go there and have booked all of my itineraries

Yes, I am planning to go there but still do some research about Indonesia

Probably, if I find interesting places or attractions in Indonesia

No, I am not interested to go to Indonesia because (please specify)

If Are you planning to go to Indonesia anytime soon? = Yes, I am planning to go there and have booked all of my itineraries

Q9 Which of these channels did you use to book your trip to Indonesia? Please select all that apply.

Booking websites (e.g. Expedia, Skyscanner)

Booking mobile apps (e.g. Airbnb, Agoda)

Travel agent

Hotel/flight direct channels (website/call center)

Other (please specify)

\section{Display This Question: \\ If Are you planning to go to Indonesia anytime soon? = Yes, I am planning to go there but still do some research about Indonesia \\ Or Are you planning to go to Indonesia anytime soon? = Yes, I am planning to go there and have booked all of my itineraries}

Q10 Which of these channels you usually use to find information about Indonesia? Please select all that apply.

The official website of Indonesia tourism - Wonderful Indonesia

Travel community websites (TripAdvisor, Lonely Planet, etc)

Blog posts/reviews

Google search

Other (please specify) 
Q11 During your last international holiday trip, what devices did you use to obtain online information about places to visit and things to do? Please select all that apply.

A smartphone/internet on a mobile phone

A laptop

A tablet PC

A desktop at the hotel/internet cafe

I did not use any of these devices since I did not access any online information

Other (please specify)

Q12 Which of these channels did you use during your last international holiday trip to obtain information about places to visit and things to do? Please select all that apply.

The official tourism local website

Travel community websites (TripAdvisor, Lonely Planet, etc)

Blog posts/reviews

Google search

Printed booklets/brochures provided by tour operators

Printed booklets/brochures at hotel's reception desk

Printed booklets/brochures at the tourism information center

Asking locals

Asking other travelers

Other (please specify) 
Q13 Thinking about your last international holiday trip overall, how satisfied were you with the availability of information to help you plan your trip?

\begin{tabular}{|c|c|c|c|c|c|}
\hline & $\begin{array}{l}\text { Extremely } \\
\text { Satisfied }\end{array}$ & Satisfied & Neutral & Dissatisfied & $\begin{array}{l}\text { Extremely } \\
\text { dissatisfied }\end{array}$ \\
\hline $\begin{array}{l}\text { The official tourism } \\
\text { local website }\end{array}$ & ○ & $\bigcirc$ & ○ & ○ & ○ \\
\hline $\begin{array}{l}\text { Travel community } \\
\text { websites }\end{array}$ & & & & & \\
\hline $\begin{array}{c}\text { (TripAdvisor, } \\
\text { Lonely Planet, etc) }\end{array}$ & ○ & 0 & ○ & ○ & ○ \\
\hline Blog posts/reviews & $\bigcirc$ & $\bigcirc$ & ○ & ○ & ○ \\
\hline Google search & ○ & ○ & ○ & ○ & ○ \\
\hline $\begin{array}{c}\text { Printed } \\
\text { booklets/brochures } \\
\text { provided by tour } \\
\text { operators }(x 6)\end{array}$ & ○ & $\bigcirc$ & 0 & ○ & ○ \\
\hline $\begin{array}{c}\text { Printed } \\
\text { booklets/brochures } \\
\text { at hotel's reception } \\
\text { desk }\end{array}$ & ○ & ○ & 0 & ○ & 0 \\
\hline $\begin{array}{c}\text { Printed } \\
\text { booklets/brochures } \\
\text { at the tourism } \\
\text { information center }\end{array}$ & ○ & $\bigcirc$ & 0 & ○ & O \\
\hline Asking locals & ○ & $\bigcirc$ & ○ & ○ & ○ \\
\hline $\begin{array}{l}\text { Asking other } \\
\text { travelers }\end{array}$ & ○ & 0 & 0 & ○ & ○ \\
\hline $\begin{array}{l}\text { Other (please } \\
\text { specify) }\end{array}$ & ○ & $\bigcirc$ & 0 & $\bigcirc$ & 0 \\
\hline
\end{tabular}


Q14 When you are deciding which travel application to use, what features are most important to you? Please select a maximum of 5 choices.

Information on local attractions, accommodations, restaurants, events

Online/offline location map

Route planning

Self-designed tour package

Guests can discuss their inquiries with tour operators through online messenger

Guests can book a personal guide during the trip

Loyalty reward program

24/7 customer service support

Multilingual support

Post-trip guests rating \& review

Guests can reserve product or service with instant confirmation

Guests can book rental services such as car, motorbike, bicycle, pocket WiFi, etc

Interactive 3D experience of a real-world environment (Virtual Reality)

Show information on a captured object (Augmented Reality)

Other (please specify) 
Q15 And what features are least important to you? Please select a maximum of 5 choices.

Information on local attractions, accommodations, restaurants, events

Online/offline location map

Route Planning

Self-designed tour package

Guests can discuss their inquiries with tour operators through online messenger

Guests can book a personal guide during the trip

Loyalty reward program

24/7 customer service support

Multilingual support

Post-trip guests rating \& review

Guests can reserve product or service with instant confirmation

Guests can book rental services such as car, motorbike, bicycle, pocket WiFi, etc

Interactive 3D experience of a real-world environment (Virtual Reality)

Show information on a captured object (Augmented Reality)

Other (please specify)

Q16 If a travel application that covers your most important features and all you need to know about Indonesia were available today, how likely would you be to use it?

Extremely likely

Very likely

Moderately likely

Slightly likely

Not likely at all 
Q17 And what kind of offer would you prefer to use this app?

Free (may contains advertising)

Paid (no advertising, user can get all of the features)

Free with in-app purchase for premium service

Free with subscription option for premium service

\section{Display This Question: \\ If And what kind of offer would you prefer to use this app? = Paid (no advertising, user can get all of the features)}

Q18 What price would you be willing to pay for this app?

Less than US $\$ 1$

From US $\$ 1$ to US $\$ 3$

From US $\$ 3$ to US $\$ 5$

More than US $\$ 5$, if I can receive these benefits (please specify) service

Q19 What price would you be willing to pay for in-app purchase?

Less than US $\$ 1$

From US $\$ 1$ to US $\$ 3$

From US $\$ 3$ to US $\$ 5$

More than US $\$ 5$, if I can receive these benefits (please specify) 
Q20 What price would you be willing to pay for the subscription?

Less than US $\$ 1$ per month

From US $\$ 1$ to US $\$ 3$ per month

From US $\$ 3$ to US $\$ 5$ per month

More than US $\$ 5$ per month, if I can receive these benefits (please specify)

Q21 During or after your trip overall, did you do any of the following? Please select all that apply.

Upload trip photos to the internet, i.e. Instagram or Facebook

Upload trip videos to the internet, i.e. YouTube

Update your Facebook status about your trip

Tweet about your trip

Write blog about your trip

None of these

Q22 Based on your past experience, what else would you like to see in an app that can improve your traveling experience?

Q23 What is your gender?

Male

Female

Prefer not to answer

Other 
Q24 What is your age?

Less than 18 years old

18 - 24 years old

25 - 34 years old

35 - 44 years old

45 years old and over

Q25 In which country do you currently reside?

Afghanistan (1) ... Zimbabwe (1357)

Q26 Do you wish to participate in the draw? You can win one of two US $\$ 50$ Amazon vouchers or one of 12 US \$20 Amazon vouchers. Please note that your name and contact information will remain completely anonymous and will not be linked with any of your survey answers.

Yes

No 